GENERATING SOCIAL CAPITAL IN FIRST-GENERATION STUDENTS

THROUGH A FIRST-YEAR SEMINAR AT A MIDWEST UNIVERSITY

\begin{tabular}{c} 
A Dissertation \\
presented to \\
the Faculty of the Graduate School \\
at the University of Missouri-Columbia \\
In Partial Fulfillment \\
of the Requirements for the Degree \\
Doctorate of Education \\
\hline CHRISTINE SUDBROCK \\
bames Sottile, Dissertation Supervisor
\end{tabular}

MAY 2019 
The undersigned, appointed by the dean of the Graduate School, have examined the dissertation entitled

\section{GENERATING SOCIAL CAPITAL IN FIRST-GENERATION STUDENTS}

\section{THROUGH A FIRST-YEAR SIMINAR AT A MIDWEST UNIVERSITY}

Presented by Christine Sudbrock, a candidate for the degree of doctor of education, and hereby certify that, in their opinion, it is worthy of acceptance.

Professor Dr. James Sottile

Associate Professor Dr. Kim Finch

Associate Director of the Center for Academic Success and Transition Dr. Tracey Glaessgen

Assistant Professor Dr. Ximena Uribe-Zarain 


\section{Dedication}

This dissertation is dedicated to the many people who were vital along the way. First and foremost, none of this would have been possible without the constant love and support of my husband, Brian. Thank you for holding down the fort and being my biggest cheerleader while enabling me to pursue this dream. This dissertation is also dedicated to our two precious children, Riley and Marz, who each completed a few semesters right along with me in the classroom. This dissertation would not have been possible without the rest of my family (biological, in-law, work, and cohort). Words cannot express how grateful I am to each of you for your words of encouragement and helping hands at every turn. Thank you especially to my parents who instilled a love of learning in me at an early age and starting me on this path. Finally, this dissertation is dedicated to Dr. Anson Elliott for constantly dreaming with me and imagining a future for me I would not have dared to reach for otherwise. 


\section{ACKNOWLEDGEMENTS}

First and foremost, I would like to acknowledge Dr. James Sottile for his work as my dissertation advisor. Dr. Sottile was immensely supportive throughout the process. His insight, advice, and encouragement was invaluable. I would also like to acknowledge Dr. Ximena Uribe for her wonderful book suggestions and for lending her expertise in all things Excel and statistics, as well as Dr. Tracey Glaessgen for her constant encouragement and expertise in first-year students. Thank you to Dr. Kim Finch for serving on my committee and her dedication to help ensure a quality final manuscript. Finally, I would like to acknowledge Dr. Cindy MacGregor for her guidance for the last four years, and Dr. Tim Wall for getting me through the first summer and believing in my ability to complete high caliber work. 


\section{TABLE OF CONTENTS}

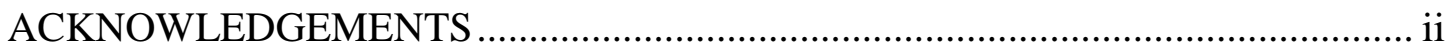

LIST OF TABLES .................................................................................. vii

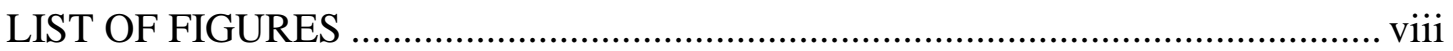

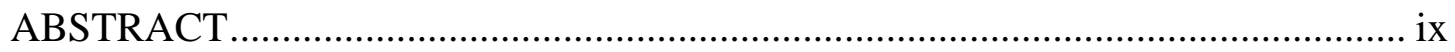

Chapter

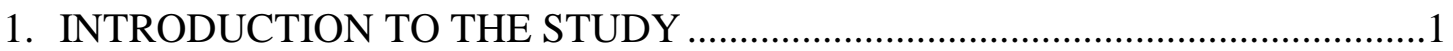

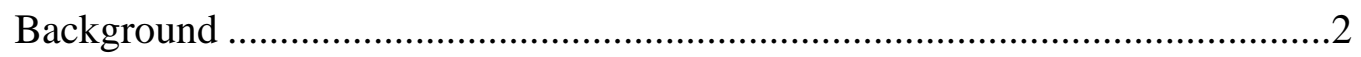

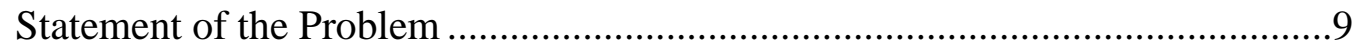

Problem of Practice ............................................................................. 10

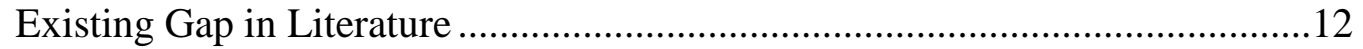

Purpose of the Study ............................................................................ 18

Conceptual/Theoretical Framework .......................................................19

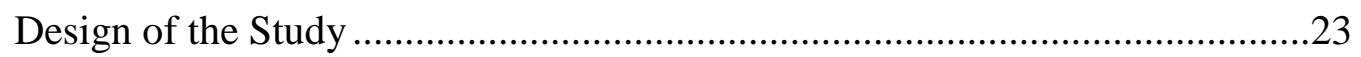

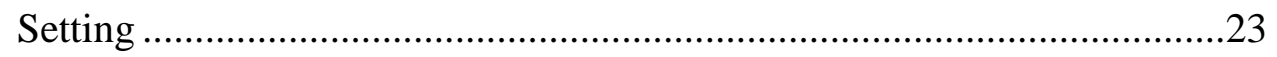

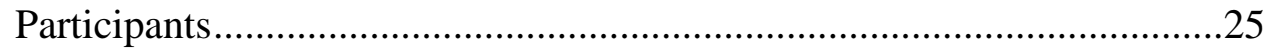

Data Collection Tools..................................................................................28

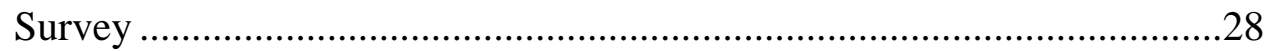

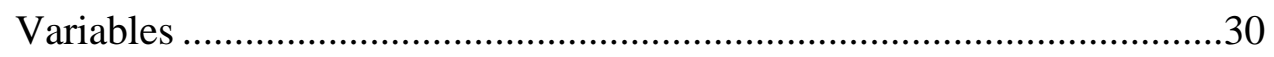

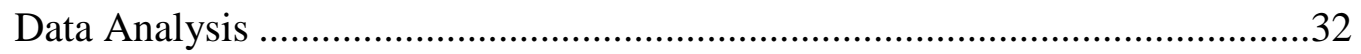

Limitations, Assumptions and Design Controls ............................................37

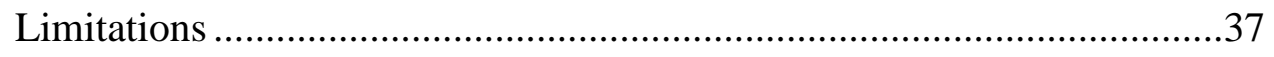

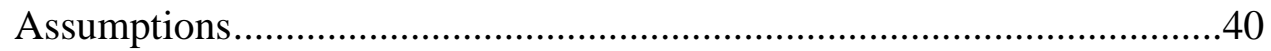




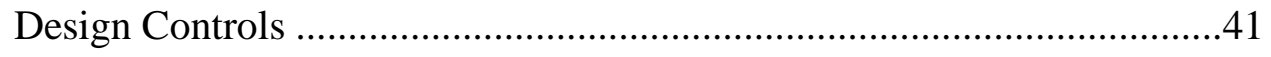

Definition of Key Terms ...............................................................................

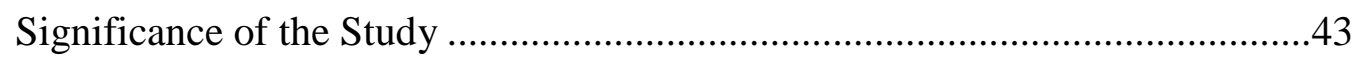

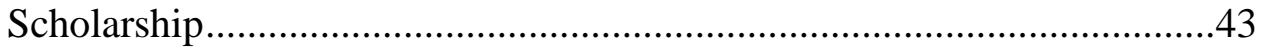

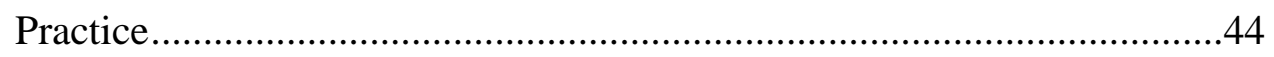

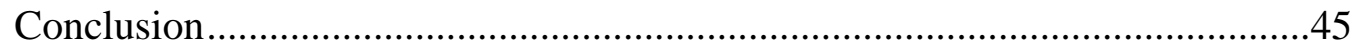

2. PRACTITIONER SETTING FOR THE STUDY ..............................................4

History of Organization.................................................................................. 48

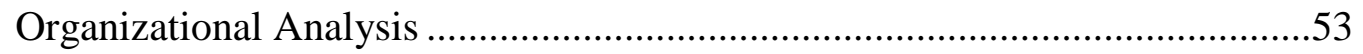

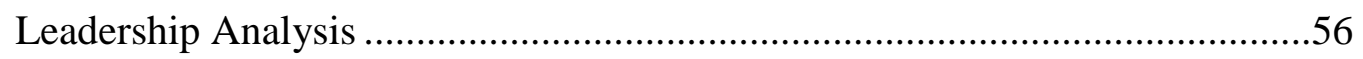

Implications for Research in the Practitioner Setting.......................................59

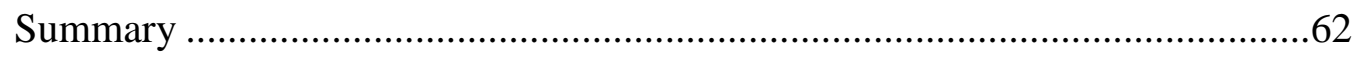

3. SCHOLARLY REVIEW FOR THE STUDY …………………………….......63

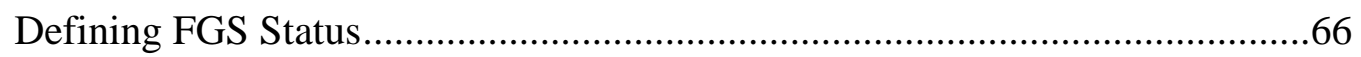

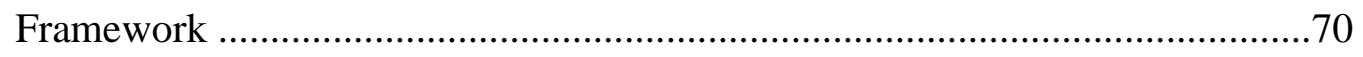

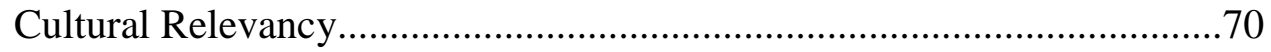

Cultural Relevancy and FGS .............................................................

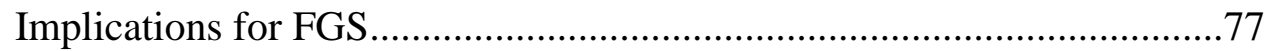

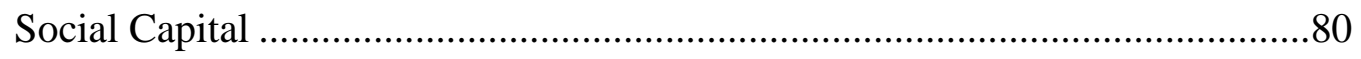

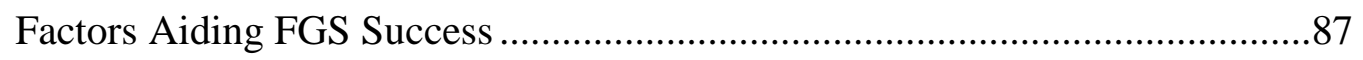

Factors Hindering FGS Success ………………………................................93

Factors with an Unclear Relationship ..............................................................96

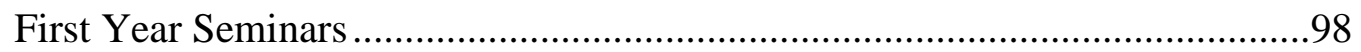




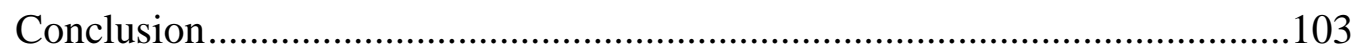

4. CONTRIBUTION FOR PRACTICE..........................................................106

Presentation Slides ........................................................................... 107

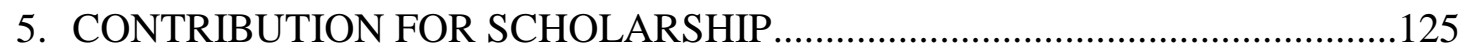

Abstract ........................................................................................... 126

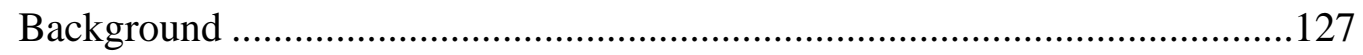

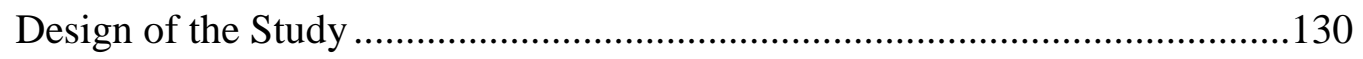

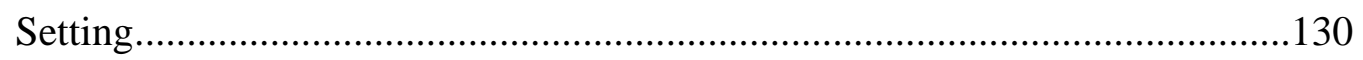

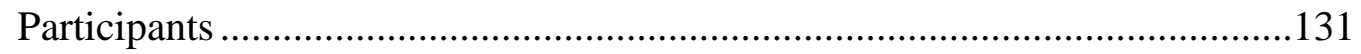

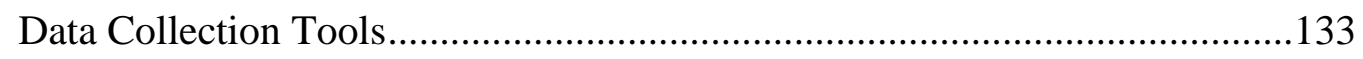

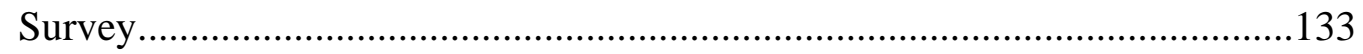

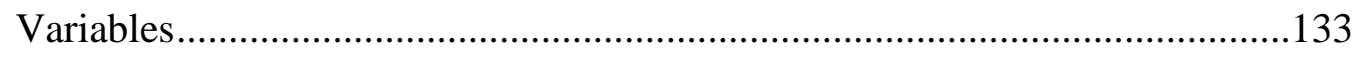

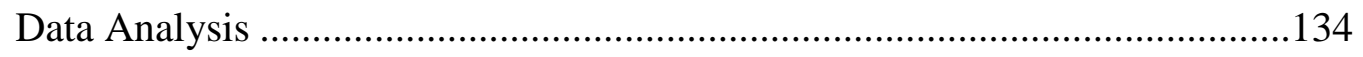

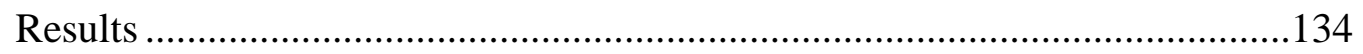

Social Capital and Parental Education .....................................................134

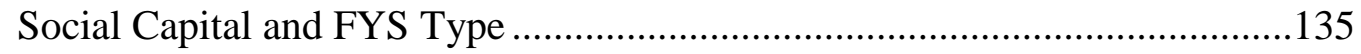

Changes in Social Capital and Parental Education ......................................135

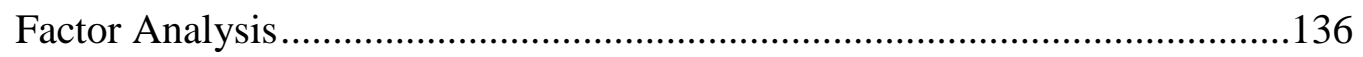

Differences in Types of Social Capital .....................................................138

Changes in Types of Social Capital ........................................................139

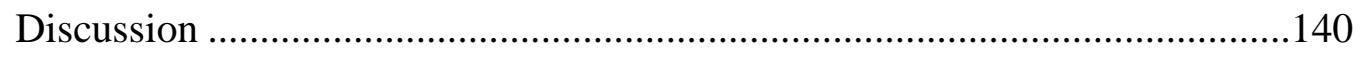

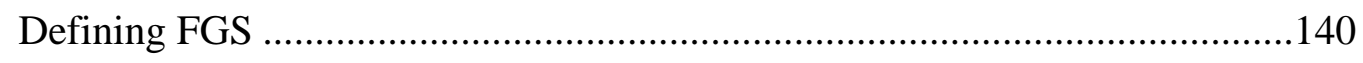

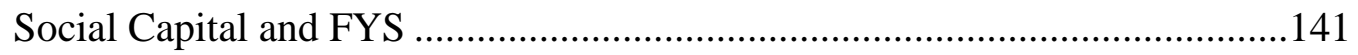




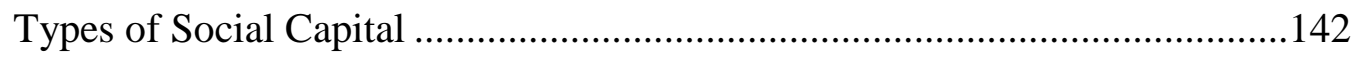

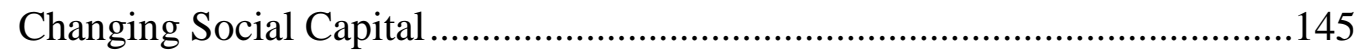

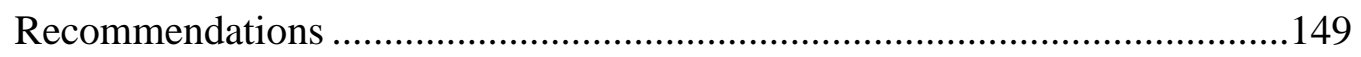

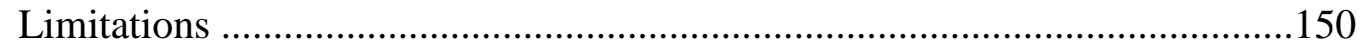

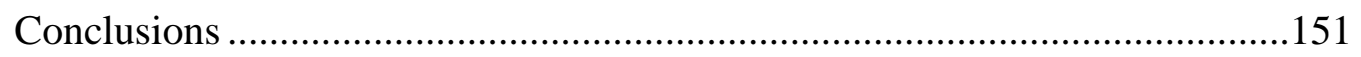

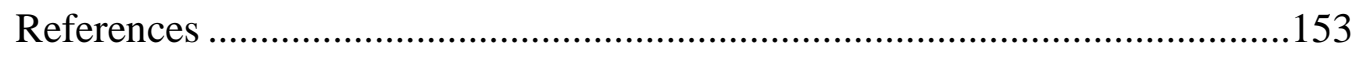

6. SCHOLARLY PRACTIONER REFLECTION .........................................159

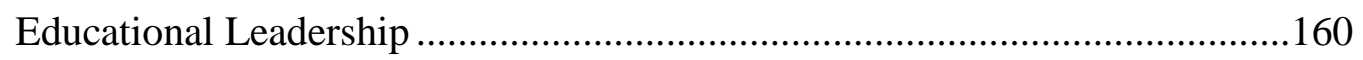

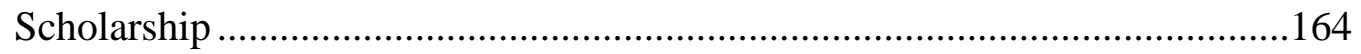

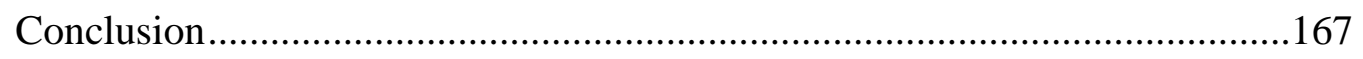

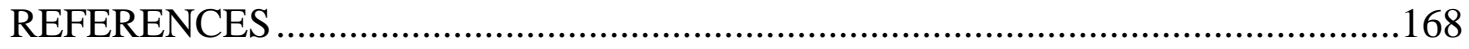

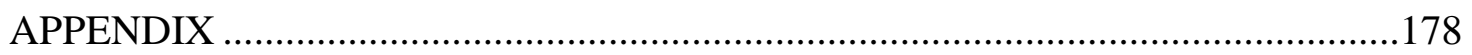

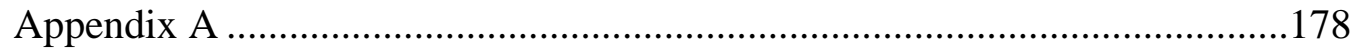

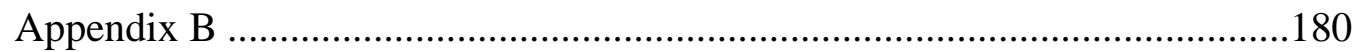

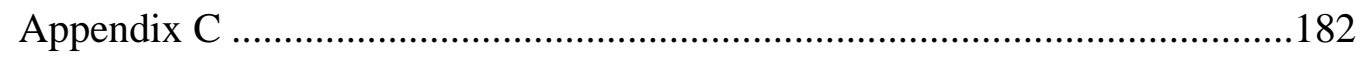

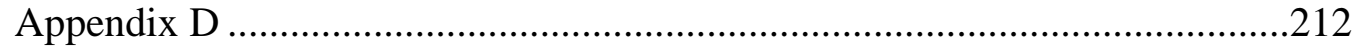

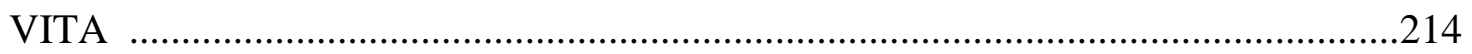




\section{LIST OF TABLES}

Table

Page

1. Number of Entering New-in-College, Full-Time Freshman at a Public, Four-Year University in the Midwest from Fall 2015-Fall 2018.

2. ACT Scores for Full-Time, First-Time, New in College FGS and Continuing-

Education Students at a Public Four-Year Institution .25

3. Selected Demographics of Full-Time, First-Time, New in College Students at the University and Participants Completing the Survey

4. Computed Means and Standard Deviations for Initial and End of the Semester Weighted Social Capital

5. Varimax Rotated Component Matrix for Initial Social Capital Scale. 186

6. Varimax Rotated Component Matrix for Social Capital at the End of the

Semester .187

7. Calculated Means and Standard Deviations for Initial Social Capital Types by FGSStatus .190

8. Calculated Means and Standard Deviations for End of the Semester Types by FGS-

Status

9. Changes in Types of Social Capital 


\section{LIST OF FIGURES}

Figure Page

1. Retention Rates for Full-Time, First-Time, New-in-College Students by Parental

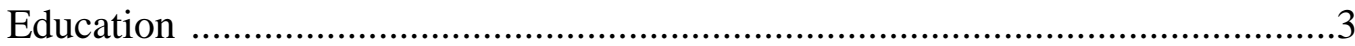

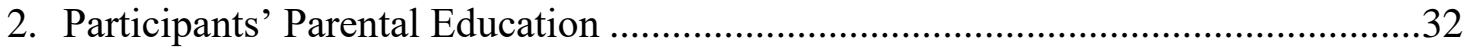

3. Number of Students Living On- and Off-Campus by FGS Status .........................33

4. Student Work Situation Status of Students Participating in the Study by FGS

Status

5. Number of Hours Worked by Student Participating in the Study by FGS Status....35

6. Screeplot for PCA for Initial Social Capital.....................................................211

7. Screeplot for PCA for Social Capital at the End of the Semester .......................212 
GENERATING SOCIAL CAPITAL IN FIRST-GENERATION STUDENTS

THROUGH A FIRST-YEAR SEMINAR AT A MIDWEST UNIVERSITY

Christine Sudbrock

Dr. James Sottile, Dissertation Supervisor

\begin{abstract}
Graduating college is an important milestone, but, for first-generation students (FGS), this can be more of a challenge than continuing-generation students. First-year seminars (FYS) aim to integrate students academically and socially to university life. The literature has not measured how social capital may differ based on parental education or in different types of FYS. No evidence was found for considering FGS-none (students where neither parent has had any education beyond high school) and FGS-some (students where at least one parent has had some education beyond high school, but did not complete a four-year degree) distinct populations. Social capital at the end of the semester for FGS-none was significantly smaller than continuing-generation students. There were significant increases in total social capital for FGS-none and continuing-generation students but not FGS-some. Factor analysis revealed five dimensions of social capital in the survey instrument: advisor, faculty, institutional, family, and peer. All FGS groups increased advisor social capital; FGS-some and continuing-generation students increased faculty social capital; FGS-some increased peer social capital; and continuing-generation students increased institutional social capital.
\end{abstract}




\section{Chapter 1:}

Introduction to the Study 


\section{Introduction to the Study}

In this chapter, the study will be introduced including background information and the statement of the problem. The literature regarding first-generation student (FGS) status will be briefly discussed and one current gap in the literature will be identified: how FGS status is defined and implications for social capital and first-year seminars (FYS). The chapter will also provide information on the conceptual framework undergirding the study. Further, the design of the study, data collection tools, data analysis, limitations, assumptions and design controls will be covered. The chapter concludes with definitions of key terms.

\section{Background}

A college graduate will make an estimated additional $\$ 800,000$ in their lifetime compared to their high school educated counterparts (Daly \& Bengali, 2014). Not only do college graduates enjoy higher wages, but the Pew Research Center (2014) found college graduates were less likely to be unemployed or living in poverty. Additionally, $72 \%$ of Millennials, defined as those born between the years of 1981 and 1996, reported their education has paid off already (Pew Research Center, 2014). Further, only 3.8\% of college educated Millennials in the survey were unemployed compared to $12.2 \%$ of their less educated counterparts (Pew Research Center, 2014; Pew Research Center, 2019).

It should come as no surprise that more students are choosing to further their education. In 1995, 33\% of Generation X, defined as those born between the years 1965 and 1980, stopped their education after getting a high school diploma, while $25 \%$ went on to get a bachelor's degree (Pew Research Center, 2014; Pew Research Center, 2019). In 
2013, those numbers had reversed for Millennials with only $26 \%$ stopping after high school and 34\% pursuing a bachelor's degree or higher (Pew Research Center, 2014).

While these numbers are encouraging, student debt is also on the rise. The average student graduated college with $\$ 28,950$ in debt in 2014 , twice the rate of inflation since 2004 (Institute for College Access \& Success, 2015). Economists are concerned with the effect this debt will have on the overall economy, speculating students will delay important milestones such as purchasing a house or even starting a family (Girouard, 2018). The potential effects of mounting student debt were even highlighted during the 2016 presidential election (Klein, 2016). Students who fail to complete their degrees are unable to reap the financial rewards, and they are also likely saddled with debt, making them less likely to pay their loans back (Hechinger Report, 2015; Schwartz et al., 2018). At particular risk are FGS. While a number of definitions exist, most universities define FGS as students where neither parent has graduated with a four-year degree while continuing-generation students are those with at least one parent obtaining a four-year degree (Billson \& Terry, 1982; Choy, Horn, Nunez, \& Chen, 2000; Ishitani, 2006; Terenzini, 1996). Previous research has found FGS are less likely to have access to college (Choy et al., 2000; Wohn et al., 2013) and obtain a bachelor's degree (Billson \& Terry, 1982; McCarron \& Inkelas, 2006; Thayer, 2000). Wohn, Ellison, Khan, FewinsBliss and Gray (2013) defined access as "applying for, being accepted at, and attending college" (p. 424). In their study, FGS reported lower confidence in their knowledge regarding the college application process. These same students reported lower expectations for college success compared to their continuing-generation counterparts Wohn et al., 2013). 
In a longitudinal study examining persistence defined as "successfully adjusting to and finishing college" (Wohn et al., 2013, p. 424), McCarron and Inkelas (2006) found that while $40.2 \%$ of FGS 10th-graders in 1990 had aspirations for a bachelor's degree, only $29.5 \%$ had acquired the degree eight years after high school. In contrast, $28.4 \%$ of continuing-generation students planned on completing a bachelor's and $55.9 \%$ continuing-generation students in the sample had completed the degree eight years after graduating high school (McCarron \& Inkelas, 2006).

In addition to lower persistence rates, FGS are more likely to be of lower socioeconomic status (SES) (Bui, 2002; Coffman, 2011; Covarrubias \& Fryberg, 2015; Kezar, Walpole, \& Perna, 2015; McCarron \& Inkelas, 2006; Thayer, 2000). Obtaining an education has the potential to greatly increase FGS' futures (Schwartz et al., 2018). Unfortunately, with low SES FGS are the least likely to complete a bachelor's degree (McCarron \& Inkelas, 2006; Thayer, 2000). In McCarron and Inkelas's (2006) sample, $76.6 \%$ of low SES FGS obtained less than a bachelor's degree eight years after high school while only $48 \%$ of high SES FGS had less than a bachelor's degree.

FGS are also more likely to have lower SAT scores (Bui, 2002), which affects access to college (Choy et al., 2000). Additionally, FGS tend to have lower grades in college (Billson \& Terry, 1982), which affects persistence. Overall, FGS have been found to be less prepared for college (Bui, 2002; Coffman, 2011; Terenzini, 1996; Thayer, 2000). Indeed, a wealth of literature is devoted to examining factors contributing to FGS's success or failure in college.

While helping to provide insight into the experiences of FGS, studies regarding FGS have not all used the same definition of FGS status. Universities tend to use an 
operational definition as "a college student whose parents did not graduate from college with at least a bachelor's degree" (Shumaker \& Wood, 2016, pgs. 9-10). The literature examining FGS uses at least three definitions. A number of studies characterize FGS as those whose parents did not "attend" college (Billson \& Terry, 1982; Choy et al., 2000; Ishitani, 2006; Terenzini, 1996). It is unclear if this definition includes community colleges, universities, and/or trade schools. Pascarella, Pierson, Wolniak, and Terenzini (2003) defined FGS as those whose parents had no additional education since high school. This means if parents had attended any form of higher education the students were not considered FGS. It appears this definition does include community colleges, universities, and/or trade schools. Studies conducted by Collier and Morgan (2008), Moschetti and Hudley (2008), Petty (2014), Shumaker and Wood (2016), Thayer (2000) and Wohn et al. (2013) defined FGS status as no parent completing a four-year degree. In some studies, a differentiation is made between FGS whose parents have had no education beyond high school (FGS-none) and FGS whose parents have had some additional education beyond high school but have not earned a four-year degree (FGSsome), the theory being that FGS-none and FGS-some may, in fact, be distinct populations. Ward, Siegle, and Davenport (2012) contend FGS-none is a more appropriate definition for FGS. The authors assert parental education experiences gained prior to completing a degree are not irrelevant. Rather the value of parental educational experiences comes from significant and meaningful experiences which can occur at any time during an individual's educational career (Ward et al., 2012). For this study, FGSnone and FGS-some will be used to signify results where both groups were studied. FGS will be used when FGS status was not separated by FGS-some and FGS-none. Only one 
study has examined the difference in outcomes, such as persistence and time to graduation, comparing FGS-none, FGS-some, and continuing-generation students (Ishitani, 2006).

Additionally, studies comparing FGS-none, FGS-some, and continuinggeneration students utilized the same data set limiting the generalizability of the results and potential implications for how FGS status is defined (Choy et al., 2000; Ishitani, 2006; McCarron \& Inkelas, 2006). Therefore, it remains unclear if the current operational definition for FGS status (i.e. a parent has completed a four-year degree) used by universities is appropriate. Confirming the proper definition of FGS status will help ensure institutions are collecting appropriate information regarding parental education. Using a definition grounded in research will aid in determining funding and resource allocation to assist the most at-risk students to graduation. Finally, such a definition has the potential to provide uniformity in future research.

Unfortunately, while student characteristics such as parental education, high school preparation, SES, or other pre-college attributes impact persistence to graduation, they are not necessarily easily changed. Therefore, in response to lower access and persistence rates for FGS, many institutions of higher education have adopted intervention strategies such as bridge programs, orientation programs, and FYS. Each of these interventions comes in a variety of formats with specific goals and strategies to aid students. Generally, bridge programs are designed to develop important academic and social skills for students prior to their first semester (Cabrera, Miner, \& Milem, 2013). Bridge programs typically take place on campus (Thayer, 2000). A number of bridge 
programs have been found to be successful at increasing retention (Cabrera et al., 2013; Thayer, 2000; Tomasko, Ridgeway, Waller, \& Olesik, 2016).

However, perhaps students who participate in summer bridge programs are highly motivated to complete a degree and are better able to seek out resources for aid. Additionally, bridge programs increase costs, in terms of both time and money. FGS are likely to be low-income and work more hours (Bui, 2002; Kezar et al., 2015; McCarron \& Inkelas, 2006; Thayer; 2000). FGS may also have additional time constraints due to family commitments and addressing academic deficiencies (Bui, 2002; Collier \& Morgan, 2008; Hottell, Martinez-Aleman, \& Rowan-Kenyon, 2014). Bridge programs may remain inaccessible to FGS due to existing pressures on time and money.

Summer orientation programs for first-time college students introduce students to the campus and student life in a shorter time frame prior to the start of classes. These programs may include registering for classes and learning about student resources (Fowler \& Boylan, 2010). FYS are distinct from summer orientations and come in a variety of formats including extended orientations, academic seminars, discipline-linked seminars, basic study skills, and a combination of all the former (Permzadian \& Credé, 2016). FYS vary in length, lasting a few weeks to a full semester, as well as, being offered for credit or no credit, pass/fail or graded, and targeting only academically underprepared students to targeting all incoming freshmen (Permzadian \& Credé, 2016).

Orientations and FYS have been shown to have positive impacts on first-year students (Cambridge-Williams, Winsler, Kitsantas, \& Bernard, 2013; Pascarella, Terenzini, \& Wolfe, 1986; Permzadian \& Credé, 2016). Unfortunately, the variety of formats taken by FYS make it difficult to compare results. In an effort to find consensus 
in the literature regarding FYS effectiveness Permzadian and Credé (2016) conducted a meta-analysis and found FYS with an extended orientation focus taught by trained faculty and staff, targeting all incoming freshmen without being tied to a living learning community, were most effective at retaining students into the second year. Conversely, hybrid courses focused on academics and orientation at smaller, more diverse two-year institutions with majority commuter populations were most effective at increasing cumulative first-year GPA (Permzadian \& Credé, 2016).

The transition from high school to college is inherently a stressful experience, one that is particularly more difficult for FGS (Pascarella, Pierson, Wolniak, \& Terenzini, 2004; Permzadian \& Credé, 2016). Students must adjust to a new academic culture as well as form new social contacts (Brouwer, Jansen, Flache, \& Hofman, 2016; Permzadian \& Credé, 2016). Permzadian and Credé (2016) contend students must possess coping skills, such as social support or social capital, in order to successfully transition to college. Social capital in the context of higher education is:

the ease with which students find a faculty or staff member who can help them navigate the university, have instructors think they are capable of producing quality work, talk with faculty outside of class, find people on campus who share their background and experiences, deal with the size and complexity of the university, have an active social life, and find students in their classes with whom to study. (Soria \& Stebleton, 2013, p.143)

Social capital can come from a variety of sources including family capital, peer capital and faculty capital (Brouwer et al., 2016). FGS are at a disadvantage because their parents are unable to pass on information and beliefs that aid in college success 
(Ward et al., 2012). Continuing-generation parents pass along information on college, jargon, cultural understanding, experience and emotional directions from their lived experience at college to their children (Ward et al., 2012).

Brouwer et al. (2016) suggest such family capital plays a less important role for students as they continue in their college career, depending on the student's learning context and developmental stage. Instead, due to their close proximity, faculty and peers begin to provide more relevant social capital (Brouwer et al., 2016). FYS facilitate interactions with faculty and peers, orient students to college culture (Permzadian \& Credé, 2016), and focus on both social and academic integration in the first semester, which is critical for shaping academic and social perspectives (Pascarella et al., 2003; Petty, 2014; Thayer, 2000; Ward et al., 2012). FYS provide social capital to FGS by allowing students to learn in a safe environment while developing professional relationships (Fowler \& Boylan, 2010).

Missing from the literature are studies gauging the effectiveness of a required FYS for FGS and the potential for increasing key aspects of social support to build social capital. Incorporating programing into required curriculum not only reduces the financial burden on FGS but may also increase effectiveness since participation is not voluntary (Beattie \& Thiele, 2016) and students spend a significant amount of time in classrooms (Fowler \& Boylan, 2010; Morales, 2014). A required FYS program may provide needed social support to these at-risk students (Ward et al., 2012).

\section{Statement of the Problem}

In this section, the statement of the problem will be explored. First, the issue at hand, FGS and social capital, will be explored as a problem of practice. This will provide 
context for considering FGS and social capital for practitioners in higher education.

Next, FGS and social capital will be examined as a gap in the available literature, specifically as it relates to defining FGS and the effectiveness of FYS to generate social capital for FGS. The section will conclude with the proposed research questions guiding the study.

\section{Problem of Practice}

A large percentage of enrollment in universities are FGS; an estimated $34 \%$ of undergraduates in 2011-2012 were FGS-none and another 28\% were FGS-some (U.S. Department of Education, 2014). Table 1 shows the number full-time, first-time, newincollege numbers of FGS and continuing-generation students for fall 2015 through fall 2018 at the public, four-year university in the Midwest under study. Relatively stable enrollment numbers of FGS is encouraging, however, FGS are less likely to complete a degree (Billson \& Terry, 1982; McCarron \& Inkelas, 2006; Thayer, 2000). Further, these students are more likely to be low SES (Bui, 2002; Coffman, 2011; Covarrubias \& Fryberg, 2015; Kezar et al., 2014; McCarron \& Inkelas, 2006; Thayer, 2000), meaning their departure from college potentially leaves them saddled with debt in addition to lower paying job opportunities than their more educated counterparts (Hechinger Report, 2015; Schwartz et al., 2018).

Lower retention rates for FGS also means less revenue for the university. Permzadian and Credé (2016) found a small effect size on increased retention in their meta-analysis of FYS. Even so, they estimated if a FYS achieved the average effectiveness found in their study at a public four-year university with freshmen enrollment of approximately 3,000 students, the university would retain an additional 150 
students. The revenue from these retained students would result in approximately $\$ 417,750$ in additional revenue (Permzadian \& Credé, 2016).

Table 1

Number of Entering New-in-College, Full-Time Freshman at a Public, Four-Year University in the Midwest from Fall 2015 to Fall 2018.

\begin{tabular}{rcccc}
\hline & Fall & Fall & Fall & Fall \\
2015 & 2016 & 2017 & 2018 \\
\hline FGS & 1,096 & 1,092 & 1,061 & 951 \\
$\begin{array}{r}\text { Continuing- } \\
\text { Generation }\end{array}$ & 1,854 & 1,820 & 1,854 & 1,838 \\
Unknown & 186 & 178 & 213 & 164 \\
Total & 3,136 & 3,090 & 3,128 & 2,953 \\
\hline
\end{tabular}

Note. Adapted from “ODSPROD-Retention Dashboard” by Missouri State University, ARGOS (2019). [Data set] retrieved from https://www.missouristate.edu/oir/Argos.htm When students depart from a university, the revenue stream directly from the student is not only lost, but state funding is at risk as well. Some state funding is being tied to retention rates (Missouri Department of Higher Education, 2017; Porter \& Swing, 2006). In the state of Missouri for instance, performance funding has been determined by graduation rates, student retention rates, licensure/certification rates of graduates, and job placement rates (Missouri Department of Higher Education, 2017). Institutions can earn partial or full funding depending on the number of indicators they successfully achieve. Universities must find ways to retain and graduate more FGS in order to maintain performance funding.

Retaining FGS is also a moral consideration. The monetary gains from education are potentially more valuable to FGS. These students are more likely to come from low 
SES backgrounds (Bui, 2002; Coffman, 2011; Covarrubias \& Fryberg, 2015; Kezar et al, 2014; McCarron \& Inkelas, 2006; Thayer, 2000). Having access to better paying career fields could be instrumental in breaking the cycle of poverty. Incurring debt and not gaining a degree is more likely to perpetuate the cycle of poverty (Schwartz et al., 2018).

\section{Existing Gap in Literature}

The current definition for FGS does not appear to be grounded in research, but rather ease. In its current form, FGS status can be determined by a single yes or no question on a student's admission application. Choy et al. (2000) examined parental education status and its impact on college attendance. In their sample of students graduating from high school in 1992, 27\% of students' parents had no college experience, $42 \%$ had some college experience but no degree, and 32\% had a bachelor's degree (Choy et al., 2000). Using the operational definition of FGS, $69 \%$ of the sample would be considered FGS. In their study, FGS-some shared characteristics with FGS-none, and continuing-generation students (Choy et al., 2000).

The percentage of FGS-some in each step of the college application process was consistently higher than FGS-none and lower than continuing-generation students (Choy et al., 2000). FGS-some and FGS-none parents were similar in parental involvement in their discussion of ACT preparation and postsecondary plans. FGS-some scored in the middle of FGS-none and continuing-generation students in discussing educational opportunities and attending college visits (Choy et al., 2000). FGS-some were more similar to continuing-generation students when it came to parents seeking financial aid and attending a program on financial aid. While these differences were not tested for 
significance, it appears FGS-some may be a distinct population from FGS-none and continuing-generation students.

Similarly, Bui (2002) examined FGS-none, FGS-some, and continuing-generation students and their first-year experiences. FGS-some appeared to come from a higher SES than FGS-none. FGS-some were also more likely to be white, speak only English at home, and scored higher on the verbal and quantitative sections of the SAT (Bui, 2002). In regard to first-year experiences, FGS-some shared characteristics with both of the other parental education groups. In terms of motivating factors for attending college, FGS-some and FGS-none were similar in dimensions related to family. Continuinggeneration students and FGS-some were similarly unmotivated to attend college for respect, the need for skills, and social status compared to FGS-none (Bui, 2002). The two groups also shared similarities in their first-year experiences in terms of feeling prepared and knowledgeable about their program of study. FGS-some and FGS-none had similar first-year experiences in decision making, financial aid, and making friends (Bui, 2002). Again, while not tested for significance, it appears FGS-some may be a distinct population from FGS-none and continuing-generation students.

Ishitani (2006) analyzed data from a national longitudinal study of 4,427 students to examine differences in retention and graduation by parental educational attainment. FGS-none and FGS-some were 8.5 times and 4.5 times, respectively, more likely to leave by year two compared to continuing-generation students. FGS-none were 1.3 times more likely to leave higher education prior to graduation, and FGS-some were 99\% more likely to leave than continuing-generation students. FGS-some were more likely than FGS- 
none to graduate in five years or less providing further evidence FGS-some may be a separate population from FGS-none.

Ishitani (2006) is the only study to date examining the definition of FGS status and its relationship to retention and graduation. The data were last collected in 2000 and followed 1992 high school graduates. Since then, universities have developed a number of strategies to address the needs of FGS. It is unclear if these strategies are equally effective for FGS-none and FGS-some. Further, Ishitani (2006) noted national data sets, such as the study used, are inadequate and lack necessary detail and context available through localized samples. The population of FGS proposed for this study, for example, have traditionally been as prepared as continuing-generation students in terms of ACT and SAT scores. Additionally, the FGS in this study are not as diverse as researchers have found in other samples of FGS. Finally, some studies imply other members of a student's immediate family, such as siblings, may provide institutional knowledge, offsetting the parents' lack of knowledge (McCarron \& Inkelas, 2006; Wohn et al., 2013).

Numerous studies have examined the unique challenges FGS experience when applying and persisting in college. Some of these challenges include lack of high school preparation (Bui, 2002; Choy, et al., 2000; Coffman, 2011; Terenzini, 1996; Thayer, 2000), finances (Bui, 2002; Thayer, 2000), lack of college knowledge (Bui, 2002; Byrd \& MacDonald, 2005; Coffman, 2011; McCarron \& Inkelas, 2006; Thayer, 2000; Wohn et al., 2013), lack of family support (Billson \& Terry, 1982; Byrd \& MacDonald, 2005) and lack of social capital (Hottel et al., 2014; Schwartz et al., 2018; Ward et al., 2012). 
Additional research has discovered factors that aid FGS in their educational pursuits including self-advocacy (Byrd \& MacDonald, 2005), taking advanced math courses in high school (Choy et al., 2000), securing Pell grants or work study (Ishitani, 2006), wanting a better life (Blackwell \& Pinder, 2014; Byrd \& MacDonald, 2005; Coffman, 2011), engaging in university activities (Kezar et al., 2015), and participating in bridge programs (Cabrera et al., 2013; Thayer, 2000; Tomasko et al., 2016). However, FGS status was not consistently defined throughout these studies.

Some factors, either helping or hurting FGS, are outside of a university's control, such as high school mathematics preparation. Fortunately, engagement and participating in interventions such as bridge programs, orientations, and FYS are within a university's sphere of influence. Unfortunately, research has also shown FGS are more likely to be low SES and working class (Bui, 2002; Coffman, 2011; Covarrubias \& Fryberg, 2015; Kezar et al., 2015; McCarron \& Inkelas, 2006; Thayer, 2000). These students are also more likely to work off campus jobs, work more hours, and plan school work around work (Billson \& Terry, 1982; Collier \& Morgan, 2008; Terenzini, 1996; Ward et al., 2012). Measures of engagement and bridge program success are potentially being confounded by SES and financial aid. Kezar et al. (2015) may have said it best: engagement is "a luxury that affluent students are most able to afford" (p. 237).

Largely missing from the literature are studies aimed at assessing FYS and FGS. FYS are typically a class for entering university students (Permzadian \& Credé, 2016). The course may be required or voluntary. The content covered in a FYS can vary, as can the number of weeks of instruction, grading systems, target audience, and credit received (Permzadian \& Credé, 2016). These programs do not require students to reduce time 
spent studying or working in order to participate since the course is required by all students, unlike Bridge programs or extracurriculars (Beattie \& Thiele, 2016). Research has suggested such programs show promise for FGS success (Cambridge-Williams et al., 2013; Collier \& Morgan, 2008; Terenzini, 1996; Thayer, 2000; Ward et al., 2012). The literature examining first-year experiences, including FYS and orientation courses tend to have mixed results. Pascarella et al. (1986) and Connolly, Flynn, Jemmott, and Oestreicher (2017), found no statistically significant difference in persistence and retention, while Cambridge-Williams et al. (2013) found a statistically significant and positive relationship between FYS and retention. Pacarella et al. (1986) concluded there was a significant indirect effect on persistence through increasing social integration and commitment to the university.

In their meta-analysis of 284 independent samples examining the effectiveness of FYS, Permzadian and Credé (2016) concluded the average effect of a FYS on GPA was negligible while the effect on retention was small. The overall effectiveness of a FYS depended on format, the composition of the instructors and their training, and the target audience (Permzadian \& Credé, 2016). The authors noted even small changes in GPA and retention can lead to relatively large numbers of fewer students on academic probation as well as large increases in revenue from those retained students over four years.

One potential explanation for FYS increasing retention might be that FYS aid students in building social capital. There are a number of definitions for social capital (Beattie \& Thiele, 2016; Brouwer et al., 2016; Schwartz et al., 2018; Soria \& Stebleton, 2013; Ward et al., 2012). One definition of social capital specific to college students is: 
the ease with which students find a faculty or staff member who can help them navigate the university, have instructors think they are capable of producing quality work, talk with faculty outside of class, find people on campus who share their background and experiences, deal with the size and complexity of the university, have an active social life, and find students in their classes with whom to study. (Soria \& Stebleton, 2013, p.143)

Students obtain social capital in college through their parents, other students, friends, extended family, or even individuals at the university (Beattie \& Thiele, 2016; Brouwer et al., 2016; Collier \& Morgan, 2008; Malecki \& Demaray, 2006; Moshetti \& Hudley, 2008; Schwartz, et al., 2018; Ward et al., 2012; Wohn et al., 2013). Moshetti and Hudley (2008) referred to individuals at the university who provide social capital as institutional agents. Institutional agents facilitate opportunities and resources at the university. For example, a student's advisor may connect a student with a representative in the financial aid office to resolve an issue. It is possible that social capital helps connect students to the university in meaningful ways, by encouraging them to persist in their education.

Ward et al. (2012) stress the importance of a student's first year in developing critical social capital as ideas and perceptions of college are first being shaped. The authors postulated FYS may help create invaluable social capital for FGS (Ward et al., 2012). To date, there have been no studies examining the ability of FYS to generate social capital in FGS students or a potential tie to persistence. 


\section{Purpose of the Study}

The literature remains unclear how FGS status should be defined. While many universities have adopted a common operational definition, little research exists to support this decision. Research suggests that FGS-some appear to share characteristics with both FGS-none and continuing-generation students regarding college attendance and first-year experiences but have not been tested for significance (Bui, 2002; Choy et al., 2000). Additionally, it appears both FGS-none and FGS-some are at an increased risk for dropping out of college (Ishitani, 2006).

The purpose of this study is to examine the definition of FGS within the context of a public, four-year institution of higher education in the Midwest. The study will also attempt to establish a link between types of FYS and the generation of social capital by the end of the first semester by FGS status, as well as, potential differences in the type of social capital. Specifically, the study will aim to answer the following research questions:

1. Is initial social capital significantly different for full-time, first-time, new-incollege FGS-none, FGS-some, and continuing-generation students?

2. Is social capital significantly different for full-time, first-time, new-in-college FGS-none, FGS-some, and continuing-generation students when comparing FYS type at the end of the student's first semester?

3. Is the change in social capital significantly different for full-time, first-time, new-in-college FGS-none, FGS-some, and continuing-generation students? 
4. Is the change in social capital significantly different for full-time, first-time, new-in-college FGS-none, FGS-some, and continuing-generation students by social capital type: peer, advisor, faculty, institutional, and family?

Based on past research and student characteristics, it is unclear if there will be a significant difference between FGS-none and FGS-some in terms of initial social capital when entering college. Further, a FGS specific FYS is expected to create more social capital for FGS than a general FYS. Additionally, students enrolled in a FGS college FYS are predicted to have the highest social capital at the end of the first semester. Finally, it is predicted FGS-none and FGS-some will initially have lower levels of social capital than continuing-generation students, specifically in terms of family social capital, but will have greater increases in total social capital with gains being highest for FGS. It is unclear, what if any, differences may exist in FGS ability to change different sources of social capital.

\section{Conceptual/Theoretical Framework}

In order to answer the research questions, Kezar et al.'s (2015) framework regarding low-income students will be used. Originally, Kezar et al. (2015) utilized four theoretical models; Maslow's Hierarchy of Needs, human capital theory, cultural relevancy, and post structuralism. This research will focus on cultural relevancy combined with Malecki and Demaray's (2006) theory of social support to examine how a required FYS may influence social capital in FGS without placing an increased burden on time or money (Beattie \& Thiele, 2016).

Kezar et al. (2015) used an economic model where students weighed the pros and cons of different choices and made decisions based on their preferences. While 
potentially relevant, Malecki and Demaray's (2006) theory of social support is more germane to FGS. According to the theory, students gain valuable social support through emotional support, informational support, appraisal support, and instrumental support (Malecki \& Demaray, 2006; Wohn et al., 2013). Emotional support is displayed through caring behaviors; informational support is displayed by providing information or advice; appraisal support is displayed by providing feedback, and instrumental support is displayed by providing necessary resources (Malecki \& Demaray, 2006). Support can come from parents, peers, extended family, and the institution (Brouwer et al., 2016; Collier \& Morgan, 2008; Malecki \& Demaray, 2006; Moshetti \& Hudley, 2006; Schwartz et al., 2018; Wohn et al., 2013). Nevertheless, it is not sufficient for such support to simply be available to students. Students must also believe in their ability to use these resources (Dumais, 2002; Malecki \& Demaray, 2006; Terenzeni, 1996).

One way to encourage resource use may be by ensuring resources are presented in culturally relevant ways. According to Kezar et al. (2015):

cultural relevancy suggest that for a program, service, or activity to be engaged by people from diverse groups, it should be modified in ways that make it understandable or accessible based on the experience or perspective of that cultural group or subgroup. (p. 242)

Cultural relevancy is potentially important for FGS who spend more time working and less time engaging at the university (Billson \& Terry, 1982; Pascarella et al., 2003; Ward et al., 2012; Warnock \& Hurst, 2016; Williams \& Ferrari, 2015). Offering programs which do not require FGS to take on additional time commitments, such as 
activities outside of the classroom, may increase engagement and thereby increase social support.

Further, knowing where to go for help and believing help is accessible may go a long way in helping students remain in college. According to McCarron and Inkleas (2006), cultural and social capital in a college setting include knowledge of the campus environment and values, jargon, processes, and access to resources such as personnel and finances. Increasing social support may help students connect to vital resources on campus by increasing their confidence in their ability to effectively use the resource.

Still, because of the unique culture FGS come from, increasing social capital in academia can be difficult. Traditional methods, such as engagement, may not be effective due to time constraints because of family and work commitments (Collier \& Morgan, 2008; Hottell et al., 2014; Ward et al., 2012) and because of the additional time spent addressing academic deficiencies (Hottell et al., 2014; Terenzini, 1996). Moreover, FGS may find themselves at odds with traditional academic culture and may not value out of classroom experiences (Ward et al., 2012). Further, activities that require evenings and weekends may be impractical especially for FGS; because of this, FGS may take longer to learn their 'college role', which may be further compounded by work and family commitments (Collier \& Morgan, 2008; Hottell et al., 2014; Ward et al, 2012).

Cultural relevancy requires universities to consider key aspects of services such as time, cost, and content to ensure accessibility (Kezar et al., 2015). According to Kezar et al. (2015) a post-structuralism stance in education shifts the burden of student engagement from the student to the university by examining policies and structures which serve as unintentional barriers. From this viewpoint, it is essentially the university's 
responsibility to provide students opportunities to engage in meaningful and accessible ways. Redon (2005) suggested in order to do this, the university should not expect students to mold to the system. The general attitude at the institution should shift from expecting students to "suck it up" and "not be coddled" to an attitude of validation. Universities should validate students, their experiences, and feelings by seeking to form caring relationships with them which may allow students and institutional agents to work collaboratively to meet the unique needs of FGS by reducing barriers to their engagement (Redon, 2005). Caring relationships are also a form of social capital and support (Malecki \& Demaray, 2006).

Ward et al. (2012) insist persistence is ultimately a function of how well colleges aid FGS's assimilation by examining key variables important to the group. Addressing students' lack of social capital can occur quicker by focusing on integrating students both socially and academically, leaving students better able to successfully navigate challenges as they arise (Ward et al., 2012). Ward et al. (2012) stress the importance of informing students of resources before they are needed. Finally, the ultimate goal of universities should not be persistence, but rather engagement, which in turn leads to persistence (Ward et al., 2012).

In order to measure social capital Kezar et al.’s (2015) nine areas of focus for low SES students and Malecki and Demaray's (2006) theory of social support were used to develop a survey instrument for the study. The survey focuses on key aspects of social capital identified in the literature and a student's belief in their ability to access the support. The survey items were used to create a measure of social capital in a higher 
education setting, as well as, to assess potential types of social capital including advisor, faculty, peer, institutional, and family.

\section{Design of the Study}

\section{Setting}

The study was conducted at a public, four-year institution of higher education in the Midwest. In Fall 2018, 32\% of full-time, first-time, new-in-college students were classified by the university as FGS, as defined by neither parent graduating with a fouryear degree. Figure 1 shows freshman-to-sophomore retention rates of full-time FGS compared to the retention rates of continuing-generation students, from fall 2014 to fall 2018 at the university. As depicted, the freshman-to-sophomore retention rates for FGS, full-time, first-time, new-in-college students from fall 2014 to fall 2018 are consistently lower than continuing-generation students, ranging from $8.6 \%$ to as high as $13.69 \%$.

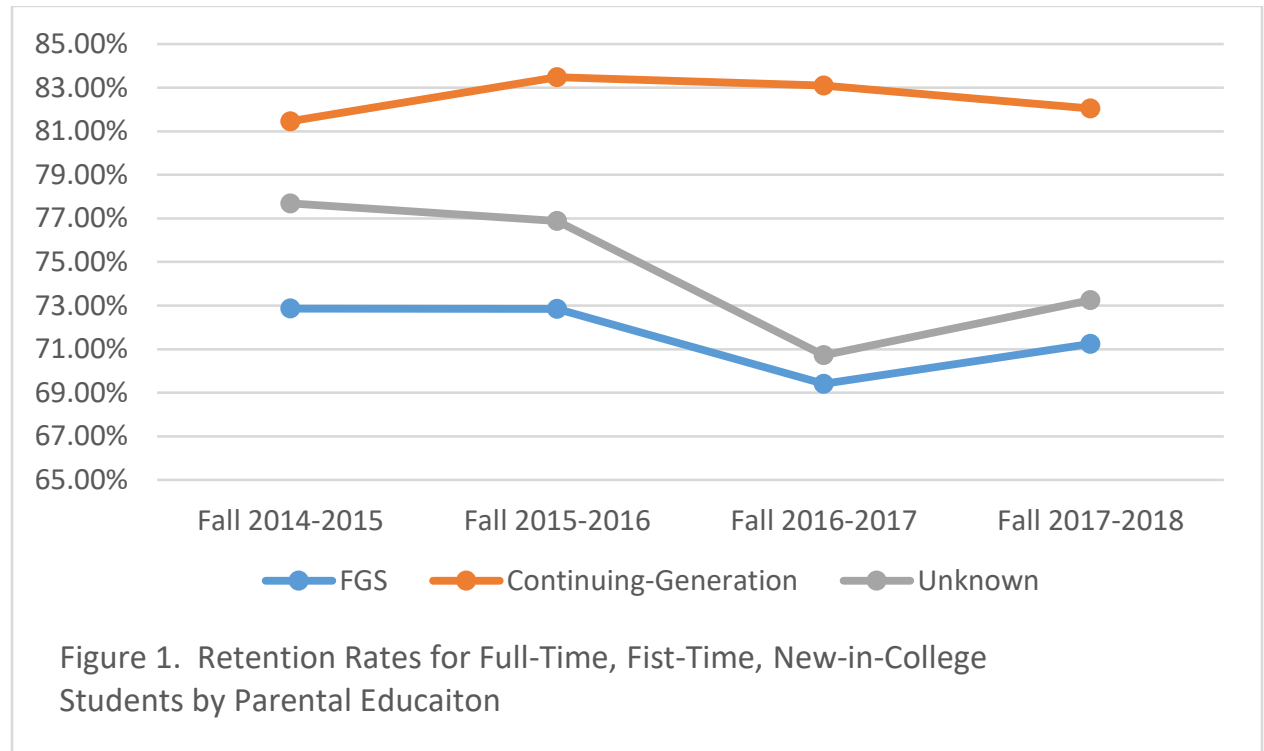

Note. Adapted from “ODSPROD-Retention Dashboard” by Missouri State University, ARGOS (2019). [Data set] retrieved from https://www.missouristate.edu/oir/Argos.htm 
At the institution under study, all incoming freshmen are required to take a FYS unless they are enrolled in the honors college or enter the university with 24 hours after high school. The content of the FYS most closely resembles what Permzadian and Credé (2016) describe as a hybrid course. Part of the course is an extended orientation course focusing on introducing students to campus resources, policies and procedures, as well as study skills, time management, and learning strategies. The other part of the course is an academic seminar; focusing on the development of academic skills such as writing (Permzadian \& Credé, 2016). For the purpose of this study, the course will be referred to as "Intro". For three years, the institution has offered sections specifically designed for FGS. The faculty teaching the course receive special training orienting them to the unique strengths and challenges of FGS.

Intro provides students with an opportunity to learn about university services, study strategies, advising, and other resources to increase the likelihood of a successful transition to college. The course content is aimed at building academic skills (40\%), covering the public affairs mission of the university (40\%), and covering campus connections (20\%). Intro courses may focus on (a) a college, (b) a college and FGS status, or (c) general content. Additionally, an Intro section may be FGS designated for undecided majors.

It is important to note, historically, FGS at the institution under study have differed from traditional FGS. Specifically, FGS at this institution are generally as well prepared as continuing-generation students in terms of admission scores, such as the ACT whereas most FGS are less prepared than continuing-generation students (Bui, 2002; Coffman, 2011; Terenzini, 1996; Thayer, 2000). Table 2 shows information on ACT 
scores for full-time, first-time, new-in-college FGS and continuing-generation students at the institution in fall 2018. While not tested for significance, the means between the two populations are very similar.

Table 2.

ACT Scores for Full-Time, First-Time, New-in-College, FGS and Continuing-Generation Students at a Public Four-Year Institution

\begin{tabular}{lcc}
\hline & \multicolumn{2}{c}{ Average ACT Composite Score } \\
\cline { 2 - 3 } College & FGS & Continuing- \\
& & Generation \\
\hline Agriculture & 23.39 & 23.53 \\
Arts \& Letters & 23.72 & 25.56 \\
Business & 23.28 & 23.9 \\
Education & 22.88 & 23.31 \\
Health \& Human Services & 23.25 & 24.16 \\
Humanities \& Public Affairs & 23.08 & 24.77 \\
Natural \& Applied Sciences & 24.18 & 26.37 \\
Undergraduate College/Provost & 22.78 & 23.12 \\
\hline
\end{tabular}

Note. Adapted from “ODSPROD-Student Enrollment” by Missouri State University, ARGOS (2019). [Data set] retrieved from https://www.missouristate.edu/oir/Argos.htm

\section{Participants}

The overall population consisted of full-time, first-time, new-in-college students. There were 2,953 freshmen in fall 2018 matching this description. Of these, 951 were FGS. Parental education was captured for students in each group via the survey 
instrument since the university's definition of FGS lacked the necessary detail to separate FGS-none and FGS-some. From this population, the researcher was interested in three distinct groups:

- Group 1: All full-time, first-time, new-in-college students enrolled in general content sections by FGS-none, FGS-some, and continuing-generation student status.

- Group 2: All full-time, first-time, new-in-college students enrolled in college sections by FGS-none, FGS-some, and continuing-generation student status.

- Group 3: All full-time, first-time, new-in-college students enrolled in FGS college designated sections by FGS-none and FGS-some status.

According to Creswell (2014), a single stage sample is appropriate when the researcher has access to the entire population and can sample directly, as was the case for this study. Student email addresses were provided for all full-time, first-time, new in college students at the university by the Office of Institutional Research. In total 2,953 students were invited to participate in the study. To ensure accuracy of the list, students were asked to indicate when they graduated high school. Additionally, honors students, as indicated on the survey, were not included in the final sample as they were assumed to be a distinct population due to their advanced academic ability. Of the 2,953 invited to participate, 343 completed the initial survey, an $11.6 \%$ response rate. Of those, 148 completed the follow up survey, a $5 \%$ response rate from the initial population. Table 3 shows demographic characteristics of students completing the survey compared to the general university population in fall 2018. In the final sample there was a higher 
percentage of female participants, FGS students, and less diversity than would be expected based on the population at the university.

Table 3

Selected Demographics of Full-Time, First-Time, New-in-College Students at the University and Participants Completing the Survey

\begin{tabular}{|c|c|c|c|c|}
\hline & \multirow{2}{*}{\multicolumn{2}{|c|}{$\begin{array}{l}\text { University } \\
(n=2953)\end{array}$}} & \multirow{2}{*}{\multicolumn{2}{|c|}{$\begin{array}{l}\text { Sample } \\
(n=343)\end{array}$}} \\
\hline & & & & \\
\hline & Total & Percent & Total & Percent \\
\hline Male & 1,136 & $38 \%$ & 55 & $16 \%$ \\
\hline Female & 1,817 & $62 \%$ & 286 & $84 \%$ \\
\hline Hispanic or Latino & 127 & $4 \%$ & 15 & $4 \%$ \\
\hline Not Hispanic or Latino & 3,001 & $96 \%$ & 323 & $94 \%$ \\
\hline \multicolumn{5}{|l|}{ American Native or Alaska } \\
\hline Native & 7 & $0 \%$ & 4 & $1 \%$ \\
\hline Asian & 53 & $2 \%$ & 7 & $2 \%$ \\
\hline Black or African American & 143 & $5 \%$ & 10 & $3 \%$ \\
\hline \multicolumn{5}{|l|}{ Native Hawaiian or other } \\
\hline Pacific Islander & $\mathrm{n} / \mathrm{a}$ & $\mathrm{n} / \mathrm{a}$ & 3 & $1 \%$ \\
\hline White or Caucasian & 2,629 & $84 \%$ & 314 & $92 \%$ \\
\hline FGS & 951 & $32 \%$ & 139 & $41 \%$ \\
\hline Continuing-Generation & 1,838 & $62 \%$ & 200 & $58 \%$ \\
\hline
\end{tabular}


Participants were contacted two times to complete the initial survey and three times for the follow-up survey as suggested by Creswell (2014). Students received an email with an invitation to participate and a letter of consent to review. The letter of consent is included in Appendix A. Follow up invitations were sent within 4 to 10 days after the initial invitations and subsequent follow up emails

\section{Data Collection Tools}

This section describes the data collection tools used for the study. The survey is discussed in depth including format, administration, and timing. Information about key variables are also discussed.

\section{Survey}

Two surveys were administered making this a longitudinal study (Creswell, 2014; Fink, 2017). The survey was administered toward the beginning and end of the fall semester. An electronic survey was administered by email using Qualtrics. Online surveys are appropriate when there are a large number of people to be surveyed, the researcher has access to valid email addresses, and the survey is not likely to be marked as spam (Fink, 2017). For this survey, students were contacted via their university email accounts as provided by the Office of Institutional Research. One assumption with online surveys is participants have access to reliable Internet. The campus has a multitude of open access computer labs for students to use as well as free Wi-Fi. The survey formatting was examined across potential browsers as well as mobile devices to ensure compatibility (Fink, 2017).

Another advantage of surveys is the ability for rapid turnaround (Creswell, 2014). Further, surveys are appropriate when researchers need information about people's 
knowledge, feelings, values, or behavior (Fink, 2017). Participants answered a sevenpoint Likert scale ranging from "strongly disagree" to "strongly agree" for 28 survey items geared toward measuring college social capital. Participants also provided information on parental education, ethnicity, and other demographics.

Surveys are useful to inform policy decisions and to guide programs (Fink, 2017). If the college specific FGS Intro sections are successful at creating social capital for FGS students, first-year programs will likely want to expand FGS college specific Intro sections. Moreover, it will be useful to know some of the factors contributing to social capital such as interactions with peers, faculty, advisors, and/or the institution.

To ensure a quality survey, a number of steps were taken. First, jargon and lengthy questions were avoided. Every effort was made to ensure questions were nonbiased. Further, as a quantitative study, survey items were a Likert scale. Multiple choice items are useful for both the researcher and participant (Fink, 2017). Likert scales are easy to score and provide a level of uniformity and reliability for the data. Questions were grouped according to the type of social capital being assessed and easy-to-answer questions, including demographics, were placed at the end of the survey (Fink, 2017). Finally, in order to ensure the survey was understandably written, a Flesch-reading ease and Flesh-Kincaid grade level was calculated. The Flesch-reading ease was calculated using Microsoft Word to generate a readability statistic of 68.8 , falling with the acceptable range of 60-70 (Mircosoft Office, 2019). Additionally, the Flesch-Kincaid grade level was calculated as 6.1 , falling within the suggested range of sixth to eighth grade (Fink, 2017). 
When administering surveys, researchers are confronted with the issue of validity, which questions the accuracy of the data (Fink, 2017). Researchers are often concerned with three types of validity, including content, predictive, and construct validity (Creswell, 2014). Prior to administering the survey, it was examined by experts in the field of first-year programs. This process helped improve the format, questions, and resulting scales (Creswell, 2014) as well as helped improve validity by verifying the questions are grounded in theory and experience (Fink, 2017).

Additionally, researchers are often concerned with reliability, that is, how consistent the information is (Fink, 2017). The survey should demonstrate internal consistency (Creswell, 2014). One method to ensure internal consistency is by using Cronbach's alpha (Field, 2013; Fink, 2017). The Cronbach's alpha coefficient was .94 for initial social capital and .91 for social capital at the end of the semester, indicating a high level of internal consistency (Field, 2013).

Finally, a potential threat regarding survey data is non-response bias (Creswell, 2014). Non-response bias is present when individuals who choose not to participate in the study differ significantly than those who do participate in the study. While the survey may not take a great deal of time, it has already been demonstrated FGS have less time than other students (Collier \& Morgan, 2008; Kezar et al., 2015). Therefore, nonresponse bias is a significant concern for this study. All results must be interpreted with this in mind.

\section{Variables}

Previous studies have identified a number of important variables to consider. Namely, in addition to the main variables of interest, it is important to collect information 
on demographics (Cambridge-Williams et al., 2013; Ishitani, 2006; Pascarella et al., 2004), pre-college attributes (Billson \& Terry, 1982; Ishitani, 2006; Moschetti \& Hudley, 2008; Pascarella et al., 2003; Thayer, 2000), SES (Billson \& Terry, 1982; Pascarella et al., 2003; Thayer, 2000), and work habits (Shumaker \& Wood, 2016; Warnock \& Hurst, 2016). Important pre-college attributes include high school grades and scores on college entrance exams such as the ACT or SAT (Billson \& Terry, 1982; Pascarella et al., 2003; Thayer, 2000). FGS are more likely to be low SES (Billson \& Terry, 1982; Coffman, 2011; Covarrubias \& Fryberg, 2015; Kezar et al., 2015; Pascarella et al., 2003; Thayer, 2000), and therefore likely have more demands on their time, leaving them less able to engage in traditional activities at the university which may, in turn, affect their ability to build social capital (Collier \& Morgan, 2008; Kezar et al., 2015). Information on SES was not readily available but students were asked to report the number of hours worked and if they planned work around school or vice versa as a proxy.

A cumulative scale was created for social capital. Twenty-eight survey items were developed using Kezar et al.'s (2015) cultural relevancy and Malecki and Damaray's (2006) social capital to measure social capital from a variety of sources including family, peer, faculty, and the institution (Brouwer et al., 2016; Collier \& Morgan, 2008; Malecki \& Demaray, 2006; Moshetti \& Hudley, 2006; Schwartz et al., 2018; Wohn et al., 2013). For the purpose of this study, social capital was assumed to be additive. In the initial construction of the social capital variable, a score of one was assigned for responses greater than neutral while a score of zero was assigned when a survey item was marked neutral or lower. It is unclear if the absence of social capital may have a negative impact on students and/or that higher levels of indicated comfort 
should be given greater weight. Therefore, a second scale was created where the Likert responses were given weights from -3 to +3 , where "strongly disagree" was given a weight of -3 and "strongly agree" was given a weight of +3 to create a weighted social capital variable and preserve the sensitivity captured by the seven-point Likert scale. The survey in its entirety is included in Appendix B.

\section{Data Analysis}

First, descriptive analysis was conducted. Descriptive analysis shows a summary of the data which illustrates important information regarding demographics of the sample. Additionally, descriptive analysis shows averages, standard deviations, and ranges for the scale variable. Averages and ranges are not appropriate for most of the survey items. Likert scales are a form of ordinal data. Frequencies and histograms allow for initial analysis of differences between FGS-none, FGS-some, and continuing-generation students.

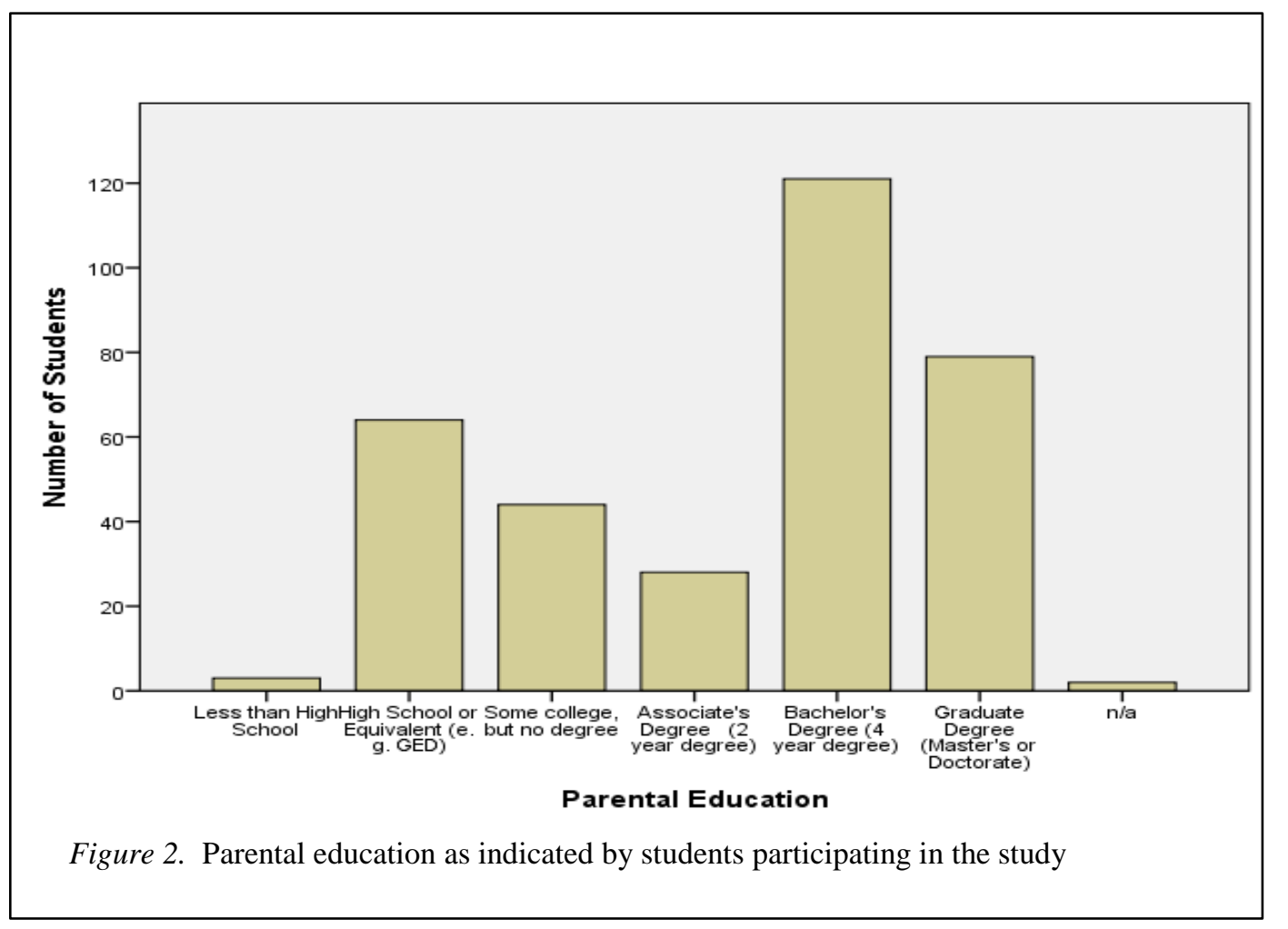


Initial analysis of the descriptive data highlights some interesting characteristics of the sample data. First, as seen in Figure 2, a number of continuing-generation students have parents completing advanced degrees. Additionally, using the current operational definition of FGS status at the university under study, 139 students in the sample would be classified as FGS. By using a more sensitive definition of FGS status, there are 67 FGS-none and 72 FGS-some.

Interestingly, as depicted in Figure 3, the majority of students completing the survey live on campus. Moreover, roughly equal numbers of FGS and continuinggeneration students live on-campus and off-campus. This is contrary to Billson and Terry (1982) and Terenzini's (1996) finding that FGS are more likely to live off campus. The apparent equity may also be a reflection of surveying full-time students rather than parttime students.

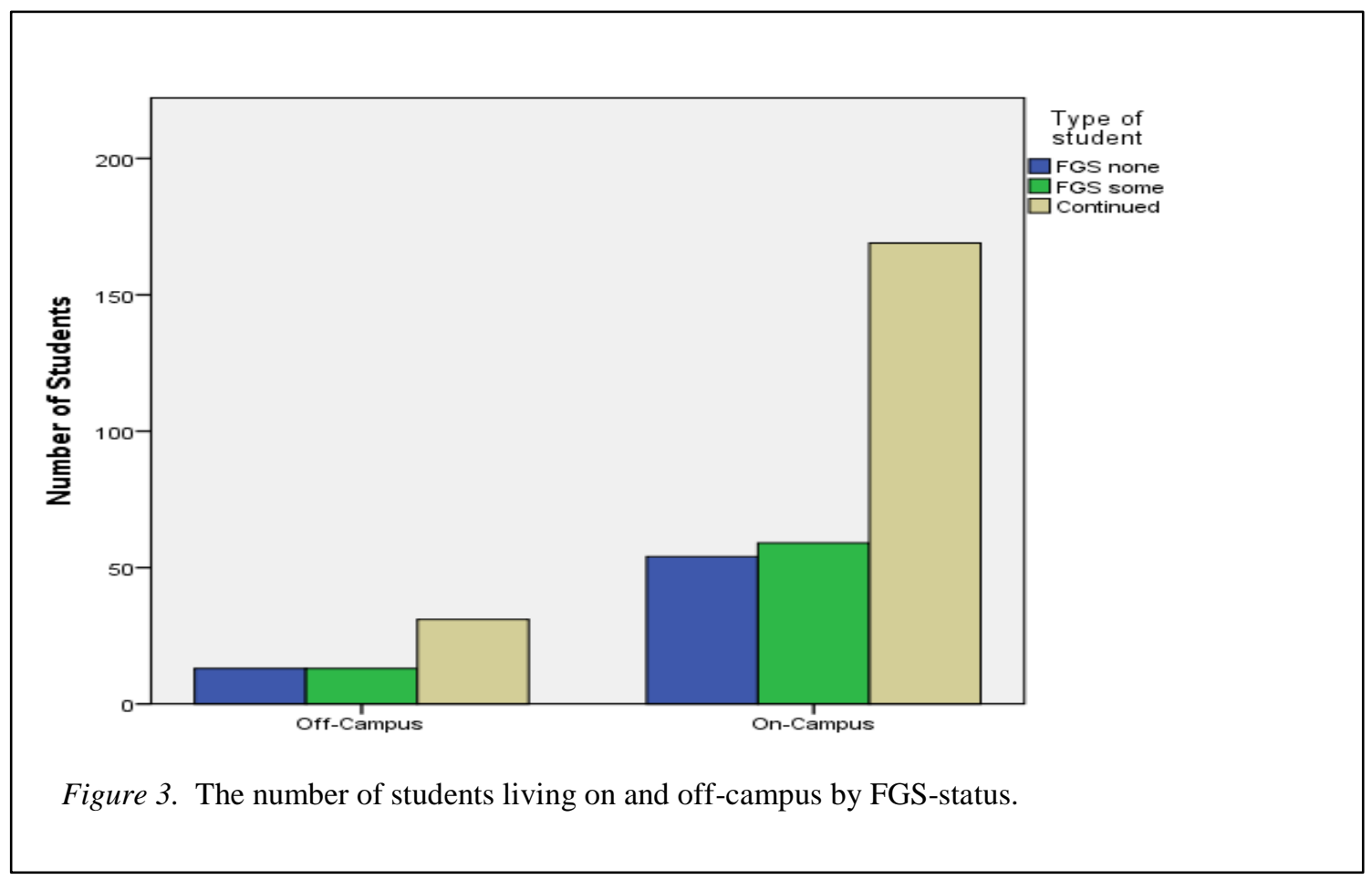




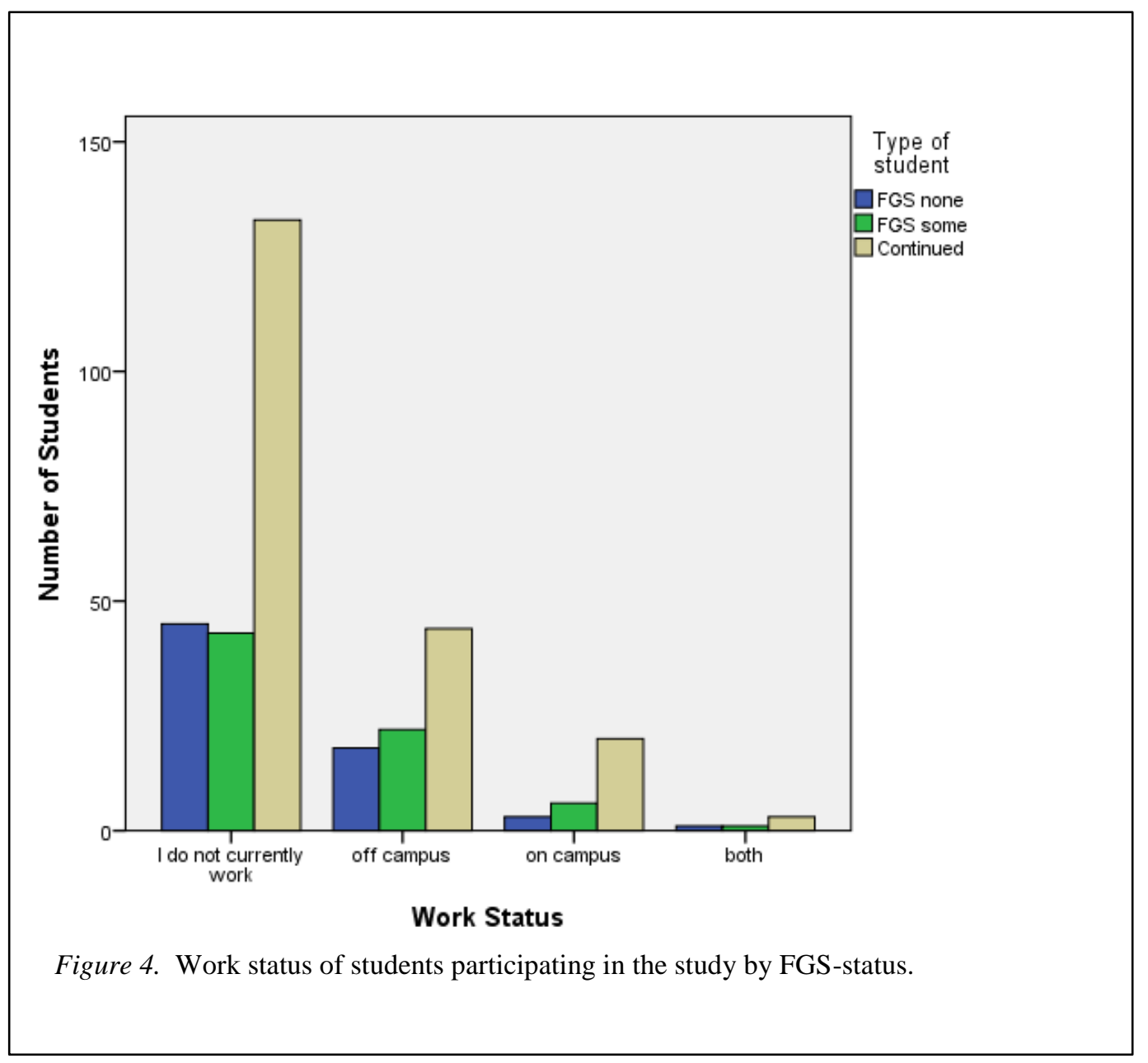

Contrary to findings in past research the majority of the FGS sampled do not work, as shown in Figure 4. Again, this may be a reflection of surveying full-time students rather than part-time students. Additionally, demographic information was collected during the initial survey. At that point in time students may not have found employment if they did not originate from the area. 


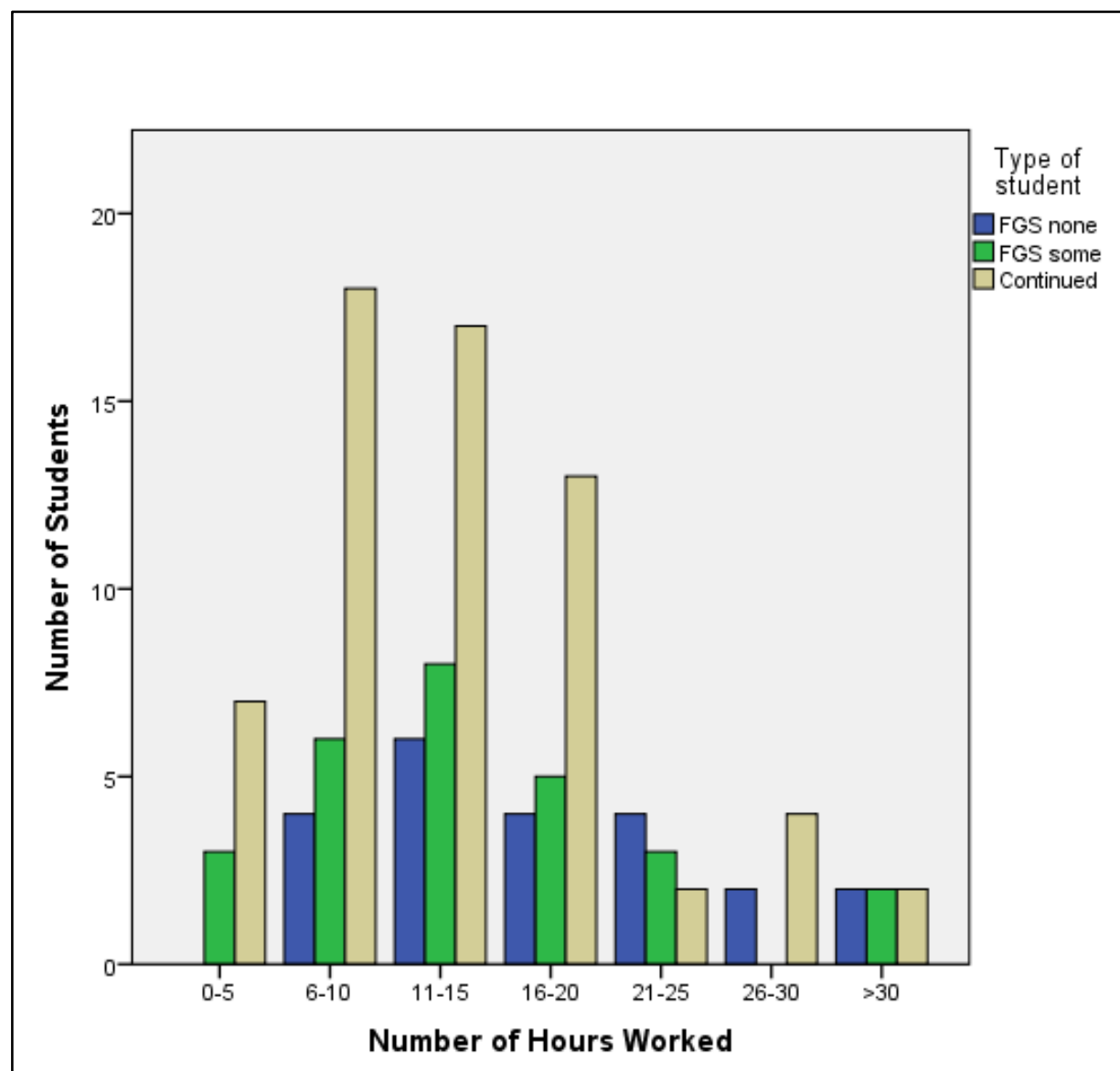

Figure 5. Number of hours worked by students participating in the study by FGS-status

Of those students who did indicate they worked, the majority worked less than 20 hours a week as shown in Figure 5. Both FGS groups have more students working greater than 20 hours a week than continuing-generation students. Moreover, more continuing-generation students worked on-campus compared to either FGS group.

The first research question (Is initial social capital significantly different for fulltime, first-time, new-in-college FGS-none, FGS-some, and continuing-generation students?) was analyzed using an ANOVA. An ANOVA compares more than two groups for outcomes (Creswell, 2014), specifically by comparing their means (Field, 2013). In this case, the categories are FGS-none, FGS-some, and continuing-generation 
students. Each group was analyzed for differences in social capital using both of the proposed social capital scales.

Cross-tabs is another option for answering the first research question. While cross-tabs allows for comparison between groups, it does not provide statistical significance (Fink, 2017). Therefore, ANOVA was utilized instead. For significant ANOVA results, an eta squared was used to calculate effect size. An effect size "shows the practical significance of the results apart from inferences being applied to the population" (Creswell, 2014, p. 165). The second research question (Is social capital significantly different for full-time, first-time, new-in-college FGS-none, FGS-some, and continuing-generation students when comparing FYS types?) was analyzed using a twoway ANOVA. A two-way ANOVA compares more than two independent variables for outcomes, specifically by comparing their means (Field, 2013). The means for end-ofsemester weighted social capital for each group were compared. The means of these scales were examined by FGS-none, FGS-some, and continuing-generation students to test for statistical significance by Intro type: general, college, and FGS college.

Additionally, the change in social capital was also examined. It was hypothesized FGS would have lower initial levels of social capital compared to continuing-generation students. In an ideal world, social capital at the end of the semester would not be significantly different between the three groups, while the change in social capital would be significant for FGS. The third research question (Is the change in social capital significantly different for full-time, first-time, new-in-college FGS-none, FGS-some, and continuing-generation students?) was analyzed using a paired $t$-test. Here, the emphasis was on examining the change in social capital by FGS status. 
The final research question (Is the change in social capital significantly different for full-time, first-time, new-in-college FGS-none, FGS-some, and continuing-generation students by social capital type: peer, advisor, faculty, institutional, and family?) was analyzed by first conducing a principal component analysis to identify survey items measuring different types of social capital. Based on those results, five social capital scales were created to compare peer social capital, advisor social capital, faculty social capital, institutional social capital, and family social capital. Initial differences in types of social capital were analyzed using an ANOVA while changes in types of social capital were analyzed using a paired $t$-test.

\section{Limitations, Assumptions, and Design Controls}

\section{Limitations}

There are a number of limitations concerning the study in question. To begin with, data collection occurred in the fall semester. The initial survey was sent in midSeptember and closed at the beginning of October to accommodate IRB completion. Therefore, students had some level of experience at the university and their Intro class, thus potentially influencing their answers.

This may be particularly troubling, as the experiences in Intro must sustain the student for an extended time period to be beneficial in terms of GPA and retention (Cambridge-Williams et al., 2013; Pascarella et al., 1986). Pascarella et al. (1986) suggested orientations may only be effective during the initial experience. Additionally, Cambridge-Williams et al. (2013) suggested students initially retained the first year may be lost in subsequent years once the extra support from the FYS is lost. It was not clear 
from this study if social capital extended even into the second semester, let alone subsequent years.

A further limitation of the study is it is only examining social capital. When it comes to determining the appropriate definition for FGS status or the effectiveness of FGS targeted Intro sections, other measures such as GPA or freshman-to-sophomore retention may be appropriate to consider as well. Additionally, social capital has not been linked to GPA or freshman-to-sophomore retention, and it was not clear from this study if social capital was able to significantly affect retention. Follow up studies should be done each year to accurately gauge the effectiveness of FGS focused Intro courses on long term retention and graduation rates. Future studies can also examine relationships between Intro and potential relationships to social capital in the long term as well.

Another limitation is that not all social capital is created equal. This survey looked at social capital generated from relationships with family, peers, advisors, faculty, and the institution. It was unclear in the results which of these might be of greater importance or if they are equally important. For instance, Brouwer et al., (2016) asserted the importance of family social capital reduces over time.

Additionally, as the student progress through their college career, social capital is unlikely to remain stagnant. If Intro is able to provide increased comfort in building social capital, then students may be able to translate these skills for years. Conversely, without explicit focus on relationship building, students may struggle to replicate early success. Further, the college specific Intros may have a more lasting impact since the students are more likely to be in the Intro course with other students, faculty, and advisors with whom they will be working for the next few years. Therefore, students 
may develop more relevant relationships early on which can be accessed for future help similar to what occurs in a cohort setting (Beattie \& Thiele, 2016).

It is important to note social capital is not the only factor affecting FGS and a conclusive link between social capital and retention has not been established. For students who ultimately are not retained, the exact reasons are unknown. Departures from higher education are voluntary as well as involuntary. Involuntary departures may stem from lack of financial availability or poor grades (Pascarella et al., 1986). Moreover, it is currently impossible to determine which departures, whether voluntary or involuntary, could be prevented with additional social capital.

Similarly, it was impossible to tell if retained students continued in their educational pursuits because of access to social capital, FYS involvement, or some other reason. Further, it was impossible to determine what aspect of Intro is the most critical or useful aspect to building social capital and the ultimate impact on a student's educational career (Fowler \& Boylan, 2010). The current study lacks the necessary design controls to determine causation (Creswell, 2014). Follow up studies will need to be done to examine what, if any, relationships may exist between social capital, Intro type, and outcomes such as GPA, retention, and graduation rates.

Finally, the underlying assumption of social capital should be further investigated. In a qualitative, in-depth study following a single FGS student from high school into college, Clemons (2010) determined social capital could also be a negative factor in student success. In this particular instance, the student relied on bad advice to take less challenging classes, which left the student feeling ill prepared for rigorous college courses (Clemons, 2010). 
Clemons (2016) further pointed out the disparity in dominant social capital and non-dominant social capital. His assertion was that mobilization of social capital from the non-dominant culture was less effective at helping students because of a lack of power to bring about change or outcomes (Clemons, 2016). His claim would imply a high level of social capital may not be effective for some students, such as those from low SES backgrounds. Trusted friends and/or advisors may provide bad advice leading to negative outcomes. Additionally, even positive social capital may not be sufficient to enable students to overcome significant challenges such as finances or poor academic performance leading to attrition.

Malecki and Demaray (2006) found no significant difference in social support and GPA among high SES students. Nevertheless, there was a significant moderate effect between social support and GPA for low SES students (Malecki \& Demaray, 2006). This suggests social capital may in fact be crucial for low SES students, such as FGS. The students in this study were in middle school, so it remains to be seen if social capital would be sufficiently beneficial for students in higher education.

\section{Assumptions}

There are a number of assumptions being made for this study. One such assumption is measures of social capital are positive and additive. For example, increased interactions and comfort approaching faculty is a form of positive social capital and adds to the student's overall level of social capital. This study originally assumed types of social capital should be given equal weight regardless of agreement or disagreement a student selects. This assumption was tested by comparing two social capital scales since the literature is unclear in this regard. Furthermore, the study focused 
on full-time students, defined as those taking more than 12 credit hours and first-time, new-in-college students, defined as students who are attending a university for the first time, excluding summer courses and dual credit classes (Office of Registrar, 2018). Honors students were assumed to be a distinct population and were excluded from the study since previous studies have found FGS to be less academically prepared (Bui, 2002; Coffman, 2011; Terenzini, 1996; Thayer, 2000). Finally, the study assumes students know the highest level of education attained by their parent or guardian, and/or siblings have achieved allowing them to accurately be classified as FGS-none, FGSsome, or continuing-generation students.

\section{Design Controls}

In order to address some of the limitations of the study, the following steps were taken. First, every effort was made to obtain a large sample size to increase confidence in the results (Field, 2013). The sample was tested for normal distribution and homogeneity of variance which were not violated. Additionally, the sample was compared to the overall population as a whole in key terms such as gender, ACT scores, race, ethnicity, and FGS status. The exact population of FGS-some and FGS-none at the university are unknown, but FGS status was examined at the university level. Further, effect sizes were calculated for all significant results to accurately reflect the importance of results.

Additional measures were taken to assure the students invited to participate were part of the intended population. Students were asked when they graduated high school, if they were part of the honors college, and how many credit hours they were enrolled in. Any student from the honors college, taking less than 12 hours or graduating from high school before May 2018 were excluded from the final sample since they were not part of 
the target population for the study. Students failing to complete the survey or who did not indicate their parent/guardian's highest level of educational attainment were also excluded from the final sample.

\section{Definition of Key Terms}

\section{Continuing-Generation Students}

Continuing-generation students are those with a least one parent who has obtained a four-year degree.

\section{Cultural Relevancy}

Cultural relevancy means that programs are culturally appropriate, congruent, and responsive to student needs (Robinson, Barrett, \& Robinson, 2016).

\section{First Generation Students (FGS)}

FGS are students where neither parent has graduated with a four-year degree (Billson \& Terry, 1982; Choy et al., 2000; Ishitani, 2006; Terenzini, 1996).

\section{First Generation Students None (FGS-none)}

FGS-none are students whose parents have had no education beyond high school.

\section{First Generation Students Some (FGS-some)}

FGS-some are students whose parents have had some additional education beyond high school, but have not earned a four-year degree.

\section{Full-Time Status}

An undergraduate student is considered full-time when they are enrolled in 12 or more credit hours in the fall or spring semester (Office of the Registrar, 2018). 


\section{First-Time, New-in-College}

Students are considered, first-time, new-in-college when they are attending a university for the first time, excluding summer courses and dual credit classes.

\section{First-Year Seminar (FYS)}

A FYS is a course taught over the course of several weeks with the goal of successfully transitioning students to college (Connolly et al., 2017).

\section{Social Capital}

Social capital in higher education is the "extent to which individuals are able to access and mobilize resources through their social network" (Wohn et al., 2013, p. 425).

\section{Significance of the Study}

This section places the study in the context of scholarship. Specifically, it addresses how gaps in the literature will be addressed. Next the study is placed in the context of practice. Specifically, the section outlines the relevance of the research for practitioners working in first-year programming at institutions of higher education.

\section{Scholarship}

This study will contribute in a number of ways to practice, the educational institution, and existing literature. First, it will provide evidence either supporting or contradicting the current operational definition of FGS status. Such a definition has the potential to provide uniformity in future research regarding FGS.

Moreover, this study filled a current gap in the literature. Presently there are no studies examining social capital generation in FGS through FYS. This study provided a foundation for such research going forward by examining the potential differences in social capital by FGS status in higher education. It further expanded the research in this 
area by investigating the potential for FYS to create social capital for students from all FGS status categories. Finally, the study examined if the potential generation of social capital varies by FYS focus.

\section{Practice}

FGS represent a significant percentage of students in higher education (U.S. Department of Education, 2014). Therefore, it is imperative they are correctly identified. Confirming the appropriate definition of FGS status will help ensure institutions are collecting appropriate information regarding parental education. Using a definition grounded in research will aid in determining funding and resource allocation to assist the most at-risk students.

If the study finds FGS specific FYS are most effective at the college level for increasing social capital in FGS, current sections can be reassigned or created to better meet students' needs. If, however, they are not as effective at increasing social capital for FGS, it may signal the university should examine alternative means to aid FGS as they transition to college. While a link between social capital and retention has not been definitely shown, there are studies showing the likelihood such a link exists (Pascarella et al., 1986; Ward et al., 2012). If social capital is in fact connected to retention, then showing a FYS can increase social capital for FGS will be very useful for university administration. Even small increases in retention can have significant financial implications for universities (Permzadian \& Credé, 2016).

State funding to the institution under examination was cut $9 \%$ for the $2017-2018$ academic year (Gochenauer, 2017) a trend in many institutions of higher education throughout the United States (Porter \& Swing, 2006). This led to a number of program 
cuts in a variety of areas. Current projections suggest further budget cuts are likely in future fiscal years as well. The institution must be intentional when it comes to programming. This study provided evidence regarding the effectiveness of a FGS college focused FYS. Additionally, strategies that are effective for FGS have a high likelihood of benefiting low SES students as well as continuing-generation students from all socioeconomic backgrounds (Thayer, 2000).

\section{Conclusion}

Graduating college is an important milestone for an increasing number of students. The investment in higher education is one that continues to pay off (Pew Research Center, 2014). For FGS graduating college can be more of a challenge than for continuing-education students (Billson \& Terry, 1982; McCarron \& Inkelas, 2006; Thayer, 2000). Numerous studies have examined factors that affect FGS students in higher education (Billson \& Terry, 1982; Blackwell \& Pinder, 2014; Bui, 2002; Byrd \& MacDonald, 2005; Cabrera et al., 2013; Choy, et al., 2000; Coffman, 2011; Kezar et al., 2015; Ishanti, 2006; McCarron \& Inkelas, 2006; Terenzini, 1996; Thayer, 2000; Tomasko et al., 2016; Wohn et al., 2013).

To date the literature has not addressed how social capital may be different based on parental education. Also missing from the literature is the role of social capital in FGS experiences in FYS. This study explored the role of social capital and FYS by answering the following research questions: (a) is initial social capital significantly different for first time, new in college FGS-none, FGS-some, and continuing-education students?, (b) is social capital significantly different at the end of the first semester for first time, new in college FGS-none, FGS-some, and continuing-education students when 
comparing FYS?, (c) is the change in social capital significantly different for first time, new in college FGS-none, FGS-some, and continuing education students?, and (d) is the change in social capital significantly different for full-time, first-time, new-in-college FGS-none, FGS-some, and continuing-generation students by social capital type: peer, advisor, faculty, institutional, and family?

Using an electronic survey information was collected on full-time, first-time, new-in-college freshmen at a four-year public university of higher education in the Midwest. The survey gathered important demographic data which allowed students to be examined by FGS-none, FGS-some, and continuing-generation student status. Using ANOVA analysis, initial social capital was examined by FGS status to see if significant differences exist between the three groups. Next a Two-Way ANOVA analysis was used to see if significant differences existed based on FGS status and student participation in different kinds of FYS. The change in social capital was examined for significant differences by FGS status using a paired $t$-test. Finally, a PCA was conducted to examine how different types of social capital varied by FGS-status and changed by the end of the semester.

The study furthers the literature by examining the appropriateness of two different definitions of FGS-status and social capital. How FGS-status is defined has implications for the admission process and resource allocation. Further, using one definition for FGSstatus can provide uniformity in future research. Complete results are located in Appendix C. 
Chapter 2:

Practitioner Setting for the Study 


\section{Practitioner Setting for the Study}

The focus of this study was to further explore the definition of FGS, focusing on social capital at a public, four-year institution of higher learning in the Midwest, USA. The researcher further explored the ability of FGS-centered FYS at the institution to generate social capital. To further understand the context of the study, this chapter will provide a brief history of FYS and FGS support at the institution. The chapter will also provide an organizational analysis, leadership analysis, and conclude with the implications for research in the practitioner setting.

\section{History of Organization}

In 2006, the Office of Student Success was renamed First-Year Programs; in 2018, First-Year Programs was housed in the newly formed Center for Academic Success and Transition. The mission of First-Year Programs is to successfully transition firstyear students to the university. In order to achieve this mission, all first-time, new-incollege students who have fewer than 24 credit hours post high school and/or not in the Honors College are required to enroll in Intro: First-Year Foundations. The class is a full semester, two credit hour class, graded A-F, taught by faculty and staff across campus. Sections of Intro cover similar content but may also have a general focus, a college focus, or a college and FGS focus. Sections of Intro are limited to 32 students. This is larger than some FYS sections, which can be as low as 15 students (Cambridge-Williams et al., 2013), but smaller than the critical inflection point of 60 identified by Beattie and Thiele (2016).

Intro has existed at the institution in some form since 1997 when it was taught as a one credit hour class. Specifically, Intro is designed to emphasize the public affairs 
mission of the university through a common reader, build necessary skills for college success, and assist students in building networks at college. Some sections of Intro have peer leaders, who serve as positive and academically successful role models. All selected instructors, whether faculty or staff, are required to participate in professional development opportunities related to Intro.

FYS come in a variety of formats including extended orientations, academic seminars, discipline-linked seminars, basic study skills, and any combination of the former (Permzadian \& Credé, 2016). FYS at the university under study most closely resemble what Permzadian and Credé (2016) describe as extended orientations and academic seminars. Extended orientations focus on introducing students to campus resources, policies and procedures, as well as study skills, time management and learning strategies. Academic seminars focus on development of critical thinking, writing, and public speaking (Permzadian \& Credé, 2016). Intro could also fall into what Porter and Swing (2006) classify as a "transition theme", designed to ease the transition to college by developing skills for academic success while encouraging engagement. Some Intro sections include aspects of discipline-linked seminars which allow students to learn more about their intended area of study (Permzadian \& Credé, 2016).

While the focus content matter is variable, course goals and objectives must be met and are achieved through required assignments and presentations. For example, all sections must cover a common reader designed to better acquaint students with the university's public affairs mission. Further, all teachers are required to meet with students in a one-on-one setting at least once during the student's first semester. Additionally, the instructors receive midterm grades for all students. Satisfactory grades 
are acknowledged, while students who are struggling are contacted in order to be connected to additional support services. Students must also learn about Title IX, academic advisement, information literacy, resources across campus, and participate in four hours of a public service project. Students are required to create a four-year plan as well as an annotated bibliography.

The strategies employed by Intro are beneficial to students transitioning to college. Numerous studies point to the benefit of emphasizing both academic and social aspects of transitioning in a FYS (Petty, 2014; Thayer, 2000; Ward et al., 2012). FYS allow students to develop important connections to peers and faculty (Pascarella et al., 2003; Terenzini, 1996) in a safe environment (Fowler \& Boylan, 2010). Further, one-onone interactions are critically important for FGS (Byrd \& MacDonald, 2005). Going a step further, proactive advising (when faculty proactively reach out to students when a student is consistently late, missing homework, or has poor mid-term grades) can serve as an early warning system (Fowler \& Boylan, 2010). While all of these strategies could take place in other settings, a FYS acts as a sort of insurance policy ensuring no student slips through the cracks (Porter \& Swing, 2006).

Some Intro sections also incorporate a peer leader. Peer leaders are responsible for working with the lead instructor, answering student questions, serving as a resource and problem solver, assisting with class activities and training, developing positive relationships with students, and making a difference in the lives of first-year students. Peer leaders are required to enroll in an additional course covering leadership instruction. The tuition for the course is either paid for by First Year Programs or scholarships already held by the peer leader. 
Instructors are faculty and staff across campus who apply to teach the course; most instructors are teaching the course beyond the scope of their primary role at the university. These individuals are passionate about teaching freshmen. Moreover, faculty and staff are paid a stipend to teach the course, ranging from $\$ 2,400$ to $\$ 3,200$, depending on rank. The course may also be considered part of their teaching load instead of receiving the stipend. Additionally, instructors may request to teach FGS Intro sections. On the Intro application, instructors have the option to indicate an interest in either teaching a college or FGS college section. The instructors teaching a FGS designated Intro section receive additional training focused on characteristics of FGS students, their unique perspectives and struggles, as well as strategies for meeting their needs. While there are enough Intro sections to serve every student, there are currently not enough FGS-focused Intro sections to serve every FGS enrolled in the university.

Again, the strategies for Intro are based on best practices guided by research. Permzadian and Credé (2016) found seminars were most successful at increasing firstyear cumulative GPA and retention when taught by trained faculty or staff rather than untrained individuals or students. It's important to note the peer leaders utilized in Intro act as an additional resource available to the students rather than playing an active, significant role in teaching the course. Additionally, Beattie and Thiele (2016) found larger class sizes may hinder the development of social capital. They theorized this is because resources are diluted among the students in addition to the professors having less time available to interact with individual students (Beattie \& Thiele, 2016). Utilizing peer leaders may help combat issues arising from larger section sizes by providing additional support for students. 
In response to on-going freshman-to-sophomore retention gaps between FGS and continuing-generation students, FGS-designated Intro sections began four years ago at the institution. FGS-designated sections used to be offered on a first come, first served basis during the university's summer Student Orientation Advisement and Registration (SOAR) program. During SOAR, students learn about the university, services, and register for their first-semester classes. The Associate Director for the Center of Academic Success and Transition conducts break-out sessions for self-identified FGS and their families.

At the end of the two-day program, students register for their fall courses including Intro. Sections of Intro are not publicly designated as FGS-focused in order to prevent any stigma for students. Instead, SOAR leaders and SOAR advisors assisting students in registering for classes were instructed to direct students into FGS-designated courses. Intro is capped at 32 students and sections reached capacity toward the beginning of summer, leaving very few options open for enrollment as there are not enough FGS-focused Intro sections to serve all incoming FGS. Perhaps students who were more motivated to succeed at college participate in earlier summer registration sessions for incoming freshmen, and they were therefore better able to get into the FGS Intro sections before the sections closed.

Starting in the summer of 2018, the registration process for Intro courses was redesigned. Students were pre-enrolled in Intro. The process was a combination of random and purposeful enrollment. FGS and students in colleges with college specific Intro sections were randomly assigned to college, FGS college, or general Intro sections. 
Continuing-generation students were randomly assigned to general Intro sections. This process should have eliminated the potential bias in early registration and self-selection.

\section{Organizational Analysis}

Currently, the FGS designated Intro sections are well placed to provide culturally relevant social capital for FGS students. The course is part of general education and required for all incoming students unless students are participating in the honors program or have transferred in with greater than 24 hours of college credit post high school. Honors students are required to take a similar seminar course with greater academic focus. No such requirement exists for transfer students. FYS are uniquely placed to aid FGS since they do not require students to self-select into the course (Hottell et al., 2014).

Since the class is required, FGS are not unduly burdened by additional time commitments or an increased cost beyond what is required in any course, which is an important consideration for FGS who work more hours (Billson \& Terry, 1982; Bui, 2002; Kezar et al., 2015; Thayer; 2000) and are often lower SES (Bui, 2002; Coffman, 2011; Covarrubias \& Fryberg, 2015; Kezar et al., 2014; McCarron \& Inkelas, 2006; Thayer, 2000). Further, the material covered in Intro has been suggested by researchers as being particularly relevant to FGS. Topics important to cover in an orientation course include note taking, value of class participation, faculty expectations, and academic etiquette (Collier \& Morgan, 2008), as well as time management (Byrd \& MacDonald, 2005; Collier \& Morgan, 2008; Rahm \& Moore, 2016). The course aims to enhance both academic and social experiences (Ward et al., 2012). Nevertheless, Intro has been a general education requirement since 1997 and, yet, significant gaps between FGS and 
continuing-generation students' freshman-to-sophomore retention persist. It appears the content alone is not enough to aid FGS in their persistence efforts.

Instead, perhaps the combination of content and instructors passionate about FGS equipped with additional relevant training will be more fruitful at closing the freshmanto-sophomore retention gap. Instructors teaching FGS designated Intro undergo additional training keying them into the unique perspectives of FGS. Topics for the training include demographics, academic preparation, research on FGS, and strategies to aid FGS navigate university life. For example, at the 2017-2018 academic year training, a vocabulary list with words likely to be unfamiliar to FGS was distributed. It included words such as "registrar" and "course registration number" which are commonly used at the university. Instructors were encouraged to post the sheet on their learning management site and/or incorporate it into an assignment. Collier and Morgan (2008) concluded the level of vocabulary and jargon used by a professor can affect a student's willingness to interact with the faculty member. FGS apprehension may be lowered by acquainting the students to university jargon.

It is unclear, however, if one training is adequate to orient instructors to the needs and values of FGS. For example, students are required to participate in a four-hour service project. During the 2017-2018 academic year training, one instructor talked about offering opportunities for the students to complete this requirement as a group. When asked if the professor took into account student work schedules, it was dismissed as unimportant since other opportunities for FGS to meet the requirement are offered. This response demonstrates a lack of understanding for FGS's reality. They work more hours than continuing-generation students and not being able to participate in a group 
service project may increase feelings of isolation (Billson \& Terry, 1982; Bui, 2002;

Kezar et al., 2015; Thayer; 2000). Not to mention, such bonding may be a missed opportunity to create social capital.

While interactions in Intro with fellow students, especially other FGS, may create social capital with FGS peers, additional elements incorporated in Intro provide opportunities to build social capital with faculty and upper-class students. Peer leaders are an excellent tool to orient students toward college success. Peer leaders work closely with both the instructor and students throughout the course. Successful interactions can help integrate FGS into clubs, organizations, and services as they transition to college. Additionally, the peer leader works closely with the Intro instructor and has a firm grasp on content and assignment expectations. FGS may not yet feel comfortable asking faculty for clarification to understand expectations (Collier \& Morgan, 2008); however, they may feel less intimidated to approach a peer leader. This has the potential to reduce the disconnect between faculty and student expectations. If the peer leaders are also FGS, they may serve as an example of success for FGS students enrolled in the course (Wohn et al., 2013).

Further, requiring one-on-one interactions with Intro instructors may also aid in the creation of faculty and institutional social capital. Through these interactions, students can begin to see how relationships with advisors operate. The students are also shown how important university processes work, such as the degree audit, trial schedule builder, and the registration process. This proactive approach aims to connect students to resources before the student needs them (Ward et al., 2012). 
Undoubtedly, these interactions are helpful; however, a single meeting is likely insufficient to form a trusting relationship between faculty and students. The university is currently piloting intrusive advising in one of the colleges. Intrusive advising goes beyond the traditional, passive advising model to be proactive. In the program, designated advisors receive special training. Further, their advising load is limited to roughly half the usual number of students advised by other faculty in the college. The advisors then initiate a minimum of three to four one-on-one interactions with their assigned FGS advisees. These advisors then work with the student for their first two years at the university. After two years, the student then begins to work with a faculty member in their field of concentration.

Intrusive advising has been recommended by a number of researchers as a useful strategy for students (Fowler \& Boylan, 2010; Kezar et al., 2015; Thayer, 2000). Intrusive advising may have potential for building culturally relevant social capital. Oneon-one meetings can be short, taking 15 minutes to an hour or longer depending on the student's need. Moreover, the meetings are scheduled around the student's and faculty's schedules, reducing the likelihood it will interfere significantly with work, class, or social obligations. Multiple meetings also increase the chances that meaningful relationships form between the student and advisor. Intrusive advising is a promising tool to increase FGS social capital, but it is beyond the scope of this study.

\section{Leadership Analysis}

First-Year Programs is part of the Center of Academic Success and Transitions. Staff in the office includes an Executive Director, an Associate Director, and an administrative assistant. These individuals oversee training for all Intro instructors. 
Training for Intro occurs on a yearly basis. These trainings are now further separated into FGS designated Intro sections and all other Intro sections. The office is also responsible for the recruitment, selection, and training of peer leaders.

In an effort to provide some level of uniformity across Intro sections, the office worked with university instructional designers to create a common shell on the online learning management platform. In this shell, instructors have access to common assignment guidelines, suggested assignments, and materials for their classroom. The instructor can then customize the shell to meet the needs of their specific section which is then made available to students.

The Associate Director for the Center of Academic Success and Transitions recently completed a doctorate in educational leadership and policy analysis. The focus of her dissertation was FGS with undeclared majors. Her research has spurred a number of programs at the university, including the Sustaining First Generation Students Conference. The first conference brought speakers and attendees from a five-state area. The focus of the conference was to share best practices for FGS. Speakers shared programs and research from their institutions in an effort to expand innovative programs in the Midwest. Topics covered included intrusive advising, creating programs, assessment strategies, high impact practices, and concluded with an address by the State Commissioner for Higher Education.

While the Center of Academic Success and Transitions continues to discover additional ways to support freshmen, the office has a large number of duties and limited staff. Moreover, in addition to their administrative duties, both the Executive Director and Associate Director have teaching assignments, serve on a number of university 
committees, and are active across campus. Such large demands on their time may hamper the effectiveness of the office to complete their mission.

An active FGS-centered student organization provides an additional source of leadership supporting FGS. The organization advisor is an active leader in the effort for FGS intrusive advising. Further, the organization's website includes an extensive catalog of online resources for students. These resources include web-links for university offices and services. The catalog includes tips compiled by fellow students and advisors such as "Tips for College Finals". Moreover, worksheets, such as "How to Complete the FASFA", are accessible to the students. There are financial aid check lists, PowerPoints, and even resources for parents.

The organization holds numerous meetings through the year. In addition to meetings, the organization hosts workshops and study sessions. The organization is student-led, with the student leaders themselves being FGS. As FGS, the leadership is therefore more in-tune with the reality FGS face at the university. Further, the leadership provides powerful role models of students who have successfully navigated the university system and persisted. Wohn et al. (2013) found FGS felt more confident about their potential for success if they had peers on social media who had been successful at college. Leadership in the student organization or even FGS peer leaders may serve as an example of a successful peer, bolstering FGS belief in their own ability to do well.

Moreover, through this network, social capital is potentially created. This social capital is more likely to be culturally relevant as well. While FGS are not a monolith, their status as FGS provides them with common ground. In their study of lower income students at an exclusive university, Warnock and Hurst (2016) found a student 
organization focused on bringing low SES students together was powerful for these students. In the study, low SES students reported feeling isolated because their experiences were so different from the typical student on campus. Since low SES or FGS status are not readily visible, organizations become critical to enable students to find each other and form a sense of community (Ward et al, 2012). Once connected, the students can then transfer institutional knowledge and support each other. FGS-designated sections of Intro may also aid in connecting FGS with each other, potentially affecting social capital.

\section{Implications for Research in the Practitioner Setting}

The first implication for research in the practitioner setting is evidence for viewing FGS-some as a distinct population from FGS-none at the university and in the related research. If significant differences exist between FGS-none and FGS-some such that FGS-some more closely resemble continuing-generation students in terms of social capital, it may signal the need for a policy shift. First, institutions will need to adjust the information collected on admission forms. Currently, FGS at the institution are identified by a single yes/no question "Did either of your parents or guardians complete a four-year degree?" A second question could added to say, "Did either of your parents or guardians attend college?" Additionally, a more complex question asking students to identify the highest level of education attained by either of their parents, guardians, or siblings could also be asked. On the other hand, if FGS-some more closely resemble FGS-none, and both have significantly lower social capital, then FGS should continue to be defined as neither parent or guardian graduating with a four-year degree. This definition captures FGS-some students as well as FGS-none. 
Once an appropriate definition has been established and appropriate information collected, future studies regarding FGS can provide more uniform results by using a common definition for determining FGS status. Moreover, at the university level, resources can be diverted to the most at-risk students. For example, if FGS-none are significantly more at risk of suffering lower social capital, than it might be worth prioritizing FGS-none in certain programs such as FGS designated Intro sections. Conversely, if FGS-some more closely resemble FGS-none, and both are at a significantly increased risk of having lower social capital then priority for programming should remain equal between the two groups.

The second research question aims to gauge the creation of social capital in FGS designated Intro sections. In theory, social capital for FGS should be higher in FGS college designated Intro sections than other sections of Intro. The answer to this question may help the university decide if general Intro sections, college or FGS college Intro sections are preferable. If all lead to similar outcomes, the general designated Intro may be preferable since it does not require targeted recruitment efforts to attract new instructors. If, on the other hand, FGS college Intro sections generate more social capital for FGS, than the focus should be on increasing efforts to attract instructors in various disciplines to offer a sufficient number of sections to cover all FGS in each college.

The third question aims to see if social capital is increased at similar rates in all students regardless of parental education. If certain types of Intro are more successful at increasing social capital, it will provide evidence of the need to increase the number of FGS designated sections. If students are able to maintain or increase social capital by the end of the first semester it may signal a more successful transition to college. 
Additionally, it may provide evidence that students will be able to operationalize this social capital for other purposes such as academic success, decreased involuntary departures, increased levels of well-being, and increased graduation rates.

Research question four aims to explore different types of social capital and the potential relationship to FGS-status. FGS-none and FGS-some will likely have lower social capital than continuing-generation students. If peer, advisor, faculty, and institutional social capital also vary it may signal a need to focus on connecting FGS to these valuable social networks. Intro may be one avenue through which targeted efforts can be made to increase certain types of social capital.

Increasing social capital will hopefully also lead to increased retention of FGS which has numerous implications. First, it will increase revenue for the university as more students continue their education beyond the first year. Secondly, retaining FGS is a moral consideration. The monetary gains from education are potentially more valuable to FGS (Schwartz et al., 2018). These students are more likely to come from low SES backgrounds (Bui, 2002; Coffman, 2011; Covarrubias \& Fryberg, 2015; Kezar et al., 2014; McCarron \& Inkelas, 2006; Thayer, 2000). Having access to better paying career fields could be instrumental in breaking the cycle of poverty. Incurring debt and not gaining a degree is more likely to perpetuate the cycle of poverty (Schawartz et al., 2018).

Finally, retention is not the only desirable outcome for FGS and social capital. Students may decide to remain at the university despite struggling financially, academically, and socially. Building social capital may help connect FGS with invaluable resources to ease these burdens. The overall goal, after all, should not be to 
graduate FGS no matter the cost. Rather, the focus should be helping FGS thrive while at the university. Social capital may be a vital piece for FGS. Unfortunately, the role of social capital in the overall wellbeing of FGS and retention is beyond the scope of this research.

\section{Summary}

The university under study has decades of experience with FYS. In recent years these programs have increasingly focused on providing extra support for FGS. Moreover, these programs show potential for providing social capital for all students in culturally relevant ways by focusing on the unique experiences of FGS and by honoring their time constraints. The courses also provide means for students to interact with peers and faculty. In addition to Intro, other services on campus, such as student organizations and intrusive advising, provide avenues for social capital generation. This study examined the effect FYS had on the creation of social capital in full-time, first-time, newin-college students by parental education status. 


\section{Chapter 3:}

Scholarly Review for the Study 


\section{Scholarly Review for the Study}

This chapter will place the study in context of the existing literature. First, the importance for FGS success and how FGS status is defined are discussed. Next, more detailed information is provided on the study's chosen framework, cultural relevancy, and social capital, followed by a discussion of the existent literature on factors affecting FGS in higher education. The chapter concludes with a discussion on FYS.

It is estimated that a college graduate will make an additional $\$ 800,000$ in their lifetime compared to their high school educated counterparts (Daly \& Bengali, 2014). Not only do college graduates enjoy higher wages, the Pew Research Center (2014) found college graduates were less likely to be unemployed or living in poverty. Only $3.8 \%$ of college educated Millennials in the survey were unemployed compared, to $12.2 \%$ of their less educated counterparts. Furthermore, Millennials were more likely to report their education has paid off already (Pew Research Center, 2014).

It should come as no surprise that more students are choosing to further their education. In 1995, 33\% of Generation X stopped their education after getting a high school diploma while 25\% went on to get a bachelor's degree (Pew Research Center, 2014). In 2013, those numbers had reversed for Millennials, with only $26 \%$ stopping after high school, and 34\% obtaining a bachelor's degree or higher.

While these numbers are encouraging, student debt is also on the rise. The average student graduated college with $\$ 28,950$ in debt in 2014 (Institute for College Access \& Success, 2015). Economists are concerned with the effect this debt will have on the overall economy, speculating students will delay important milestones such as purchasing a house or starting a family (Girouard, 2018). It was such a concern as to 
garner attention during the 2016 presidential election (Klein, 2016). Students who fail to complete their degrees are unable to reap the financial rewards, but are also likely saddled with debt, making them less likely to pay their loans back (Hechinger Report, 2015; Schwartz et al., 2018).

At particular risk are FGS. While a number of definitions exist, most universities define FGS as students where neither parent has graduated with a four-year degree (Billson \& Terry, 1982; Choy et al., 2000; Ishitani, 2006; Terenzini, 1996). Luckily, FGS retained into their second year of college are less likely to dropout, and have similar outcomes in scientific reasoning, writing skills, openness to diversity and challenge, learning for self-understanding, internal locus of attribution, and preference for higherorder thinking (Pascarella et al., 2003). Nevertheless, retaining FGS into the second year presents a significant challenge. Numerous studies have explored factors that either hinder or enhance the likelihood FGS will persist and graduate college.

While these studies provide insight on FGS, they have not all used the same definition. Definitions range from parents not attending college (Billson \& Terry, 1982; Choy et al., 2000; Ishitani, 2006; Terenzini, 1996) to not earning a four-year degree (Collier \& Morgan, 2008; Moschetti \& Hudley, 2008; Petty, 2014; Shumaker \& Wood, 2016; Thayer, 2000; Wohn et al., 2013). Further, a number of these studies utilized the same data set limiting the generalizability of the results (Choy et al., 2000; Ishitani, 2006; McCarron \& Inkelas, 2006). In some studies, a differentiation is made between FGS whose parents have had no education beyond high school (FGS-none), and FGS whose parents have had some additional education beyond high school, but have not earned a 
four-year degree (FGS-some), while continuing-generation students are those with at least one parent obtaining a four-year degree.

Confirming the appropriate definition of FGS status will help ensure institutions are collecting appropriate information regarding parental education. Using a definition grounded in research will aid in determining funding and resource allocation to retain the most at-risk students. Finally, such a definition has the potential to provide uniformity in future research.

Only one study has examined the differences in outcomes among definitions of FGS (Ishitani, 2006). Moreover, few studies have examined intervention strategies aimed at helping FGS complete college and their ability to generate social capital; a measure of a student's ability to adopt the dominate academic culture. This literature review will lay the groundwork for a study examining the definition of FGS status, and the ability of a FYS to build culturally relevant social capital for FGS. The review of literature will (a) examine how FGS status is defined, (b) explore two frameworks for studying FGS, (c) examine the existing research regarding FGS to identify the most likely factors affecting FGS and (d) examine the existing research regarding intervention strategies such as FYS. Throughout, gaps in the literature will be discussed, specifically, the lack of literature focusing on the definition of FGS status, the effectiveness of retention strategies, such as FYS on FGS, and the implications on social capital accumulation.

\section{Defining FGS Status}

Compounding the difficulty of identifying effective strategies for FGS is the lack of a common definition for FGS status. While universities tend to use the operational 
definition as "a college student whose parents did not graduate from college with at least a bachelor's degree" (Shumaker \& Wood, 2016, pp. 9-10), studies examining FGS use multiple definitions. A number of studies characterize FGS as those whose parents did not "attend" college (Billson \& Terry, 1982; Choy et al., 2000; Ishitani, 2006; Terenzini, 1996). It is unclear if this definition includes community colleges, universities, and/or trade schools.

Pascarella et al. (2003) defined FGS as those whose parents had no additional education after high school. This means if a parent attended some form of higher education but did not graduate, the student was considered a continuing-generation student. It would appear this definition does include community colleges, universities, and trade schools. Studies conducted by Collier and Morgan (2008), Moschetti and Hudley (2008), Petty (2014), Shumaker and Wood (2016), Thayer (2000), and Wohn et al. (2013) defined FGS status as no parent completing a four-year degree. Further, only one study has examined the difference in outcomes regarding FGS-none, FGS-some and continuing-generation students (Ishitani, 2006). Because of this, it remains unclear if the current operational definition is appropriate and if FGS-none and FGS-some should be considered distinct populations for research and/or admission purposes.

Ward et al. (2012) suggest FGS-none is the more appropriate definition for FGS. They contend a parent's college experience is not irrelevant simply because they stopped at a two-year degree or did not complete a four-year degree. Instead, they suggest FGSsome are better prepared in terms of parental social capital than FGS-none (Ward et al., 2012). Failing to establish a standard definition means the number of FGS in any sample will vary depending on the definition used (Ward et al., 2012). 
Instead, the definition for FGS used by many universities appears to be one of ease rather than grounded in research. In its current form, FGS status can be determined by a single yes or no question on a student's admission application. Choy et al. (2000) examined parental education status and its impact on college attendance. In their sample of 1992 high school graduates, 27\% of students' parents had no college experience, $42 \%$ had some college experience but no degree, and 32\% had a bachelor's degree. Using the operational definition of FGS, 69\% of the sample would be considered FGS, while using Ward et al.'s (2012) preferred definition would classify $27 \%$ of the sample as FGS.

In Choy et al. (2000) FGS-some shared characteristics with FGS-none and continuing-generation students. FGS-some and FGS-none parents were similar in parental involvement in their discussion of ACT preparation and postsecondary plans. FGS-some scored in the middle of FGS-none and continuing-generation students in discussing educational opportunities and attending college visits. Nonetheless, FGSsome were more similar to continuing-generation students when it comes to parents seeking financial aid and attending a program on financial aid. It appears FGS-some may be a distinct population from FGS-none and continuing-generation students.

Similarly, Bui (2002) examined FGS-none, FGS-some, and continuing-generation students and their experiences in their first year of college. FGS-some appeared to come from a higher SES than FGS-none. They were also more likely to be white and speak only English at home. Finally, FGS-some scored higher on the verbal and quantitative sections of the SAT. In regard to experiences in their first year, FGS-some shared characteristics with both of the other parental education groups (Bui, 2002). In terms of motivating factors for attending college, FGS-some and FGS-none were similar in 
dimensions related to family. Continuing-generation students and FGS-some were similarly unmotivated to attend college for respect, the need for skills, and social status compared to FGS-none (Bui, 2002). The two groups' first-year experiences were similar in terms of feeling prepared and knowledge of their program. FGS-some and FGS-none had similar first-year experiences in decision making, financial aid, and making friends. Again, it appears FGS-some may be a distinct population from FGS-none and continuing-generation students.

Ishitani (2006) analyzed data from a longitudinal study of 4,427 students to examine differences in retention and graduation by parental educational attainment. FGS-none and FGS-some were 8.5 times and 4.5 times more likely to leave by year two compared to continuing-generation students. FGS-none were 1.3 times more likely to leave higher education for good, and FGS-some were $99 \%$ more likely to leave prior to graduating than continuing-generation students. FGS-some were more likely than FGSnone to graduate by year five.

Ishitani (2006) is the only study to date examining the definition of FGS status and its relationship to retention and graduation. The data were last collected in 2000, and followed 1992 high school graduates. Since then, universities have developed a number of strategies to increase FGS retention. It is unclear if these strategies are equally effective for FGS-none and FGS-some. Further, Ishitani (2006) noted national data sets are inadequate and lack necessary detail and context available through localized samples. The population of FGS analyzed for this study, for example, have traditionally been as prepared as continuing-generation students in terms of ACT and SAT scores. Additionally, the FGS in this study are not as diverse as researchers have found in other 
samples of FGS. Therefore, using a localized sample will give the institution more accurate information for developing strategies for retaining and defining FGS. Finally, some studies imply other members of a student's immediate family, such as a siblings, may provide institutional knowledge offsetting the parents' lack of knowledge (McCarron \& Inkelas, 2006; Wohn et al., 2013). The relationship between siblings' education and FGS persistence and time to graduation was not explored in Ishitani's (2006) study.

\section{Framework}

This study will utilize two frameworks to answer the following research questions: (a) is initial social capital significantly different for full-time, first-time, newin-college FGS-none, FGS-some, and continuing-generation students?, (b) Is social capital significantly different for full-time, first-time, new-in-college FGS-none, FGSsome, and continuing-generation students when comparing FYS type?, (c) Is the change in social capital significantly different for full-time, first-time, new-in-college FGS-none, FGS-some, and continuing-generation students?, and (d) Is the change in social capital significantly different for full-time, first-time, new-in-college FGS-none, FGS-some, and continuing-generation students by social capital type: peer, advisor, faculty, institutional, and faculty? The frameworks used for the study are cultural relevancy and social support. The following two sections present each framework in more detail.

\section{Cultural Relevancy}

The first framework utilized for this study is cultural relevancy. Robinson et al. (2016) defined culturally relevant education as culturally appropriate, congruent, and responsive. According to Kezar et al. (2015), cultural relevancy requires universities to 
reduce barriers that prevent diverse individuals from fully engaging in programs, activities, or services. Particular sensitivity should be given to the experiences or perspectives of potential end users, which includes considering content, cost, and timing (Kezar et al., 2015) in an effort to reduce barriers (Shumaker \& Wood, 2016). Cultural relevancy is especially pertinent for FGS. Shumaker \& Wood (2016) noted, "a student's ability to navigate the college culture has been closely tied to exposure to college-going culture including parents who are college students" (p. 10). FGS are at risk of not being exposed to academic culture because parents are unable to acculturate their children through discussions of their college experiences (Ward et al., 2012).

Research indicates FGS can come from a distinctly different cultural background than continuing-generation students. Studies have shown FGS are more likely to be low SES (Bui, 2002; Coffman, 2011; Covarrubias \& Fryberg, 2015; Kezar et al, 2015; McCarron \& Inkelas, 2006; \& Thayer, 2000) and have less parental involvement in their education and preparation (Choy et al., 2000; Collier \& Morgan, 2008). Rahm and Moore (2016) found mixed results in their longitudinal study of four FGS youths in a STEM preparation program. Two students had completed a four-year degree while two more continued to struggle toward completion. The authors found FGS students were not "necessarily positioned by society as those going to and succeeding in college" (Rahm \& Moore, 2016, p. 771). While to some this may seem trivial, educational aspirations have been shown to affect educational attainment (McCarron \& Inkelas, 2006).

Dumais (2002) explored educational expectations through the concept of habitus. Habitus is an individual's view of the world and their place in it (Dumais, 2002). According to Dumais (2002), understanding FGS orientation to higher education can help 
educators understand how FGS navigate through higher education. Ward et al. (2012) stress that the higher education system must be intentional for FGS success, although Kezar et al. (2015) contend intentionality alone may not be enough to overcome barriers in place for years. Dumais (2002) defined students' understanding of the system as institutionalized cultural capital.

In addition to understanding the system, students must also believe in their ability to successfully use the system. Dumais (2002) asserted where a student perceives their location on the social structure directly influences what they think is possible. This belief then influences students' actions. In other words, a student may be aware of institutional resources, but not believe in their ability to use the resource. For example, a student may be aware their advisor can help resolve issues with prerequisite classes, but may not feel it is worthy of their advisor's time. This may cause the student to take unnecessary classes costing time and money. Moreover, FGS may not understand the role of an advisor to begin with, regardless of their confidence in using the advisor as a resource highlighting the potential importance of institutional and faculty social capital.

Blackwell and Pinder (2014) agreed beliefs shape action. Their grounded theory study comparing FGS from large families and continuing-generation students examined self-efficacy. Self-efficacy indicates what a person believes is more important than the truth (Blackwell \& Pinder, 2014). Blackwell and Pinder (2014) ascertained behavior could be predicted based on a person's believed capabilities which are directly influenced by family support. In their study, the decision to go to college was described as being already made essentially for third generation students (Blackwell \& Pinder, 2014). The parents expected their children to go to college. The students internalized this thinking, 
and college attendance became the norm rather than the exception. This is not necessarily true for FGS. Indeed, FGS may feel guilty for attending college and leaving family behind (Covarrubias \& Fryberg, 2015). Further, the lack of family social capital may mean FGS never make it to college in the first place (Brouwer et al., 2016).

Students must also believe in their ability to effect outcomes (Morales, 2014) and that they are capable of succeeding (Porter \& Swing, 2006).

In fact, Porter and Swing (2006) found a student's intention to persist was significantly and positively related to a student's belief in their ability to succeed. Moreover, Woosley and Shepler (2011) found FGS perceptions of the campus environment were important for their ability to adjust socially and academically to college. Integrating students into the campus culture quickly is of vital importance (Pascarella et al., 2003; Petty, 2014; Thayer, 2000; Ward et al., 2012) as is validating student's ability to succeed (Terenzini, 1996).

Christopher, Wendt, Marecek, and Goodman (2014) examined culture and worldview and psychology practice. According to Christopher et al. (2014):

Moral visions inform people about what is worthy, good, and desirable, and about what constitutes virtue, morality, health and well-being. In this way, moral visions provide guidance about how a person ought to behave, relate to others, think and feel, as well as about what constitutes the good life and the good or ideal person. (p. 649)

The idea of self and accompanying moral vision is formed by the societal norms students are exposed to early in life before the student even has a chance to consciously decide for themselves (Christopher et al., 2014). If a professor does not consciously 
think about the cultural background of their FGS, it can affect the FGS transition to college. In truth, higher education expects students to assimilate and adopt values of the institution and the majority with or without the institution intentionally helping students in the transition.

In their upbringing, FGS have not necessarily been oriented to higher education in the same way as continuing-generation students. Billson and Terry (1982) found the lower parental education, the higher the incongruity between the value students assigned to education and perceived parental value. Low congruence was significant for persistence with lower levels of parental education (Billson \& Terry, 1982). In other words, when FGS felt their parents valued education, the student was more likely to persist. Moreover, parents with less education were more likely to be perceived as not valuing education (Billson \& Terry, 1982). Failure to recognize the cultural disconnect of FGS and higher education may leave FGS without valuable support, as they may not receive support from home through family social capital.

Expecting assimilation to college culture has led authors to note that knowledge of the dominant culture can even be a form of capital (Collier \& Morgan, 2008). Cultural capital is "preexisting knowledge about interacting successfully in academic settings, including such essential social skills as the ability to recognize and respond to the standards faculty members use when they evaluate assignments" (Collier \& Morgan, 2008, p. 429). In this view, cultural capital is similar to money and can be used, saved, and invested to earn additional capital (Kingston, 2001). Unfortunately, institutions of higher learning expect students to already possess all of the prerequisite skills necessary for the accumulation of social capital (Dumais, 2002). Those most likely to have access 
to and which benefit from cultural capital are social elites (Dumais, 2002; Kingston, 2001), and in this context are continuing-generation students.

FGS are not necessarily able to learn about college culture from their parents, which affects their initial cultural capital in college (Collier \& Morgan, 2008, Ward et al, 2012). Brouwer et al. (2016) found a measure of family social capital was not significantly related to study success, leading them to theorize FGS with little family support never make it to college in the first place. This may, in turn, lead to ineffective, frustrating, or even disastrous interactions between FGS and the institution, leaving FGS feeling even more like they do not belong (Hottell et al., 2014).

\section{Cultural Relevancy and FGS Students}

Unfortunately, a lack of cultural capital can have serious consequences for FGS. To begin, FGS may not attend college in the first place (Brouwer et al, 2016; Choy et al., 2000; Hottell et al., 2014). Those who do enroll may find themselves at a distinct disadvantage. As Collier and Morgan (2008) point out, success in higher education goes beyond a student's academic ability. Rather, as Kingston (2001) found in his review of literature pertaining to cultural capital, high school students in the dominant culture are ultimately rewarded for fitting in. In the study, teachers were asked if a student was a hard worker, related well, was likely to go to college, and was attractive. Students who were perceived favorably had higher English and math grades (Kingston, 2001). Favorability is ultimately determined by the teacher and their definition of "good", which is not a culture-free, objective concept (Christopher et al., 2014; Kingston, 2001). Ultimately, academic rewards depend in some part on cultural capital passed down by family (Dumais, 2002) 
While teachers may have innate bias toward like-minded students, students' understanding of teacher expectations also play a role in student success. Collier and Morgan (2008) theorize that differences in academic outcomes are not solely a product of intellectual ability, but rather also reflect how well a student understands faculty expectations on coursework. Continuing-generation students have an advantage in understanding faculty expectations (Collier \& Morgan, 2008). These students have grown up hearing their parents talk about college. Additionally, their parents have also likely coached them on how to respond to teachers appropriately (Collier \& Morgan, 2008). Therefore, FGS may find themselves more often in conflict with faculty. For example, a student may address an email to Mr./Mrs. Faculty instead of Dr. Faculty. In a recent personal conversation with a FGS, the student indicated a professor's response to such an email left the student reluctant to attend class.

In a study comparing faculty and student expectations, the authors found a number of key differences (Collier \& Morgan, 2008). First, faculty believed students should prioritize school over everything else including work and extracurricular activities. FGS have been found to feel the opposite. Instead, they prioritized work over school and social activities (Billson \& Terry, 1982). Secondly, faculty prefered to use communication as a way to problem solve (Collier \& Morgan, 2008). Students, on the other hand, wanted to use communication as a way to build relationships with faculty members (Collier \& Morgan, 2008). This clash of culture and expectations is another barrier to success for FGS. In an effort to establish a positive relationship with a professor and show their dedication, a FGS may instead "pester" the professor and develop a negative relationship. 


\section{Implications for FGS}

Ensuring activities are culturally relevant for FGS has the potential for increasing social capital. From this viewpoint, the burden shifts from students to assimilate to strategies an institution can adopt to help students meaningfully engage (Kezar et al., 2015; Porter \& Swing, 2006; Shumaker \& Wood, 2016) by reducing barriers (Terenzini, 1996). Grassi et al. (2006) viewed this activity as collaborative; "the student must adapt to the requirements of our college and our state's teacher-licensure program, and we must adapt the program to our students and their distinctive needs and talents" (p. 28).

One way instructors can start to generate culturally relevant activities is by offering additional opportunities for engagement inside, as well as outside, of the classroom (Kezar et al., 2015). FGS may participate in fewer activities outside of the classroom due to work commitments as they are more likely to work longer hours leaving them less opportunity to engage (Billson \& Terry, 1982; Kezar et al., 2015; Pascarella et al., 2003; Warnock \& Hurst, 2016; Williams \& Ferrari, 2015). Further, FGS are more likely to live off campus, meaning activities outside of the class will require additional drive time (Billson \& Terry, 1982; Terenzini, 1996). FGS may also have less time for voluntary engagement because of family commitments and making up for academic deficiencies (Hottell et al., 2014).

Strategies utilized in the classroom can be of great benefit to students due to the large amount of time spent there (Morales, 2014). Required orientations, such as a FYS, have been suggested by a number of authors as a culturally relevant way to engage and help FGS (Collier \& Morgan, 2008; Terenzini, 1996; Thayer, 2000). By incorporating activities into a required class, work/school pressure could be relieved. A required course 
will have more of an impact than support services or organizations in which participation is voluntary (Beatti \& Thiele, 2016). Incorporating such culturally relevant activities allows students to build social capital while respecting the different cultural backgrounds FGS originate from.

Potential topics to cover in a FYS include note taking, value of class participation, faculty expectations, and academic etiquette (Collier and Morgan, 2008) as well as time management (Byrd \& MacDonald, 2005; Collier \& Morgan, 2008; Rahm \& Moore, 2016). These programs can also highlight resources across campus. Ward et al. (2012) suggested these programs should focus on helping students grow academically and socially.

A word of caution: it is not enough to solely inform students about resources available for their use (Dumais, 2002; Malecki \& Demaray, 2006; Terenzeni, 1996). A number of factors can influence students' use of these services, as students may not feel the resources are available to them (Collier \& Morgan, 2008; Dumais, 2002). Collier and Morgan (2008) found jargon and the level of vocabulary used by faculty influenced students' willingness to approach professors outside of class. The more jargon and higher level of vocabulary used, the more confusion and fear students reported.

The authors also found FGS relied almost exclusively on information gained from hearing, observing, and interpreting professor's actions (Collier \& Morgan, 2008). Continuing-generation students, on the other hand, relied on the syllabus and information directly from the professor. Further, students may not understand the relevancy of the information regardless of how it is presented. One FGS shared 'I didn't understand what 
office hours were all about...what am I supposed to do with 'office hours'?” (Collier \& Morgan, 2008, p. 439).

In their study, Shumaker and Wood (2016) found no significant difference between FGS and continuing-generation students' use of services at a university. FGS reported higher perceived service access, but lower perceived service efficacy (Shumaker \& Wood, 2016). Both results had a small effect size. The authors concluded while FGS utilized services at the same rate, the use did not produce similar results (Shumaker \& Wood, 2016). Service use was measured in time, which FGS have less of due to myriad commitments (Bui, 2002; Billson \& Terry, 1982; Collier \& Morgan, 2008; Hottell et al., 2014; Kezar et al., 2015; McCarron \& Inkelas, 2006; Pascarella et al., 2003; Thayer, 2000; Warnock \& Hurst, 2016; Williams \& Ferrari, 2015). Measuring service use in time may be a faulty measure. Part of the difference in outcomes might be due to services not being culturally relevant to FGS, and requiring more time to be effective than FGS have to spare. Additionally, the students may not feel they are able to use the resources to their advantage (Collier \& Morgan, 2008; Dumais, 2002).

While a measure of cultural relevancy does not exist, the theory is a useful framework to utilize when studying social capital in a FYS. Recognizing and respecting the challenges of FGS as they enter college are key to cultural relevancy (Robinson et al., 2016). A required FYS has potential to engage students without placing additional burdens on their time or money (Collier \& Morgan, 2008; Terenzini, 1996; Thayer, 2000). 


\section{Social Capital}

The second framework utilized in this study is the concept of social capital. Social capital is the ability to access and use resources within an individual's social network (Wohn et al., 2013). An alternative definition of social capital in the context of higher education was put forth by Soria and Stebleton (2013):

the ease with which students find a faculty or staff member who can help them navigate the university, have instructors think they are capable of producing quality work, talk with faculty outside of class, find people on campus who share their background and experiences, deal with the size and complexity of the university, have an active social life, and find students in their classes with whom to study. (p.143)

Social capital resources can come in a variety of formats such as physical or emotional support (Wohn et al., 2013), appraisal support, and instrumental support (Malecki \& Demaray, 2006). Malecki and Demaray (2006) noted social support is support students believe is available for their use. These resources, in all their many forms, are usually a product of relationships. Moschetti and Hudley (2008) pointed out the value of relationships to provide support in social settings. The quality and quantity of relationships is an important aspect of social support and may affect engagement and persistence for FGS (Moschetti \& Hudley, 2008).

One way students obtain social capital in college is through their parents. Parents of continuing-generation students share stories of college with their children. Additionally, parents can serve as a resource for students when issues occur (Collier \& Morgan, 2008). Unfortunately, FGS are not able to access this family social capital from 
their parents (Ward et al., 2012). Their parents may not be familiar with the system enough to direct them to vital resources.

Additionally, parents of FGS are not always supportive of students' educational aspirations. Wohn et al. (2013) found FGS receive less instrumental and emotional support from their parents compared to continuing-generation students. Instrumental support can encompass a variety of things such as financial support. FGS are more likely to be low SES, meaning their parents are less able to provide support by helping with finances (Bui, 2002; Coffman, 2011; Covarrubias \& Fryberg, 2015; Kezar et al., 2015; McCarron \& Inkelas, 2006; Thayer, 2000). Further, it is unclear if FGS and their families are able to qualify for students loans or be competitive for academic merit scholarships (Pascarella et al., 2004; Ward et al., 2012).

Luckily, relevant social relationships are not limited to parents. These relationships may come from other students, friends, extended family, or even individuals at the university (Malecki \& Demaray, 2006; Moshetti \& Hudley, 2008; Wohn et al., 2013). Moshetti and Hudley (2008) referred to individuals at the university as institutional agents. Institutional agents facilitate opportunities and resources at the institution. For example, a student's advisor may connect a student with a representative in the financial aid office to resolve an issue.

In their quantitative study at a public research university, Soria and Stebleton (2013) studied social capital in working class students. The authors noted that social capital increased as students built social networks with student affairs staff, faculty, and students. These individuals provided valuable social capital as students advanced through their education (Soria \& Stebleton, 2013). Ward et al. (2012) echo the 
importance of interactions with staff in student affairs as well as peers. Soria and Stebleton (2013) studied engagement as measured by time and effort put into studies, activities and organizations, learning opportunities, and services to encourage participation. The authors found students who self-identified as working class had significantly less social capital with a modest effect size than middle class students, while there was no significant differences in academic engagement (Soria \& Stebleton, 2013).

Further, working-class students reported having a harder time finding students to study with, faculty members to help, they went out with friends less, and had more difficulty dealing with the size of the university (Soria \& Stebleton, 2013). They found social capital was positively associated with sense of belonging and academic engagement. Finally, the working-class students in the study were found to have more difficulty connecting with institutional agents who help build social capital (Soria \& Stebleton, 2013).

Moschetti and Hudley (2008) examined FGS and continuing-generation students' interactions with institutional agents. In their sample, there was no difference between the two groups and their interactions with institutional agents. Nevertheless, for all students, communicating with institutional agents and institutional help with coursework was more strongly related to GPA than institutional emotional support defined as interactions with institutional agents for social or emotional support. Institutional communication, help with coursework, and emotional support were significantly correlated with FGS expectations for the future. These three variables may also serve as an example of social capital such as institutional social capital. There were no significant correlations between any of these measures and continuing-generation students in the 
study (Moschetti \& Hudley, 2008). As the authors noted, it is impossible to know if more communication with institutional agents increased FGS beliefs they could do well, or they already believed they could succeed and therefore communicated more (Moschetti \& Hudley, 2008).

FGS view communication as a way to build relationships (Collier \& Morgan, 2008). It is possible FGS felt more comfortable approaching faculty to resolve issues in situations where more communication was present. This communication may also develop cultural and social capital to help students learn college culture and connect with resources to resolve issues. Further, it is possible communicating with institutional agents may aid students in better understanding faculty expectations and build faculty social capital.

Clemens (2016) referred to institutional agents who help students build social capital as resource brokers. In his in-depth, qualitative study following one FGS student, the student used her resource brokers to contact the universities who initially rejected her for admission. As a result, one of the universities reconsidered their decision and ultimately admitted the student (Clemons, 2016). This demonstrates the potential importance of institutional social capital in FGS success in higher education.

In addition to institutional agents and resource brokers, Wohn et al. (2013) postulated FGS may be able to expand their social capital through the use of social media. The authors compared FGS and continuing-generation students' use of extended networks through their use of social media (Wohn et al., 2013). They found FGS felt less prepared to apply for college, were less optimistic about success in college, and received less instrumental and emotional support from their parents. No significant differences 
were found between FGS and continuing-generation students' social capital through social media (Wohn et al., 2013). FGS also did not utilize extended family for social support, and peer norms were the strongest predictor of application efficacy. However, having friends on social media who were successful in college increased student expectations for success (Wohn el al., 2013).

Strayhorn (2012) examined the effects of social networking sites on first-year college students' sense of belonging. Sense of belonging was defined as students feeling connected, like they mattered, and they were important. In his analysis of 755 first-time, full-time, first-year students he found FGS were more likely to use social networking sites more frequently but that increased use of social networking sites also led to a lower sense of belonging. Strayhorn (2012) theorized students who felt out-of-place at college turned to social media to maintain connections at home. This is at odds with Hottell et al.'s (2014) suggestion that social networking sites provide valuable links to home which ultimately allow students the resilience necessary to stay. The effects of social media use on social capital appear to be mixed.

Wohn et al. (2013) also found having a sibling in college increased college efficacy for FGS. This may indicate, while other forms of social capital exist, immediate family play an important social role for FGS. McCarron and Inkelas (2006) and Wohn et al. (2013), contended siblings can be an important source of social capital. This may be due to changing FGS perception of their ability to succeed. Seeing a sibling succeed in college may reorient a younger FGS to believe success is also possible for them. The sibling or peer could provide social capital by helping the FGS navigate an unfamiliar system. 
Researchers suggest social capital can be a great benefit to FGS (Beattie \& Thiele, 2016; Brouwer et al., 2016; Moschetti \& Hudley, 2008; Schwartz et al., 2018; Ward et al., 2012). This is likely due, in part, because the marginal benefit for FGS is probably the greatest. Marginal benefit refers to the increase or 'extra' benefit when adding an additional resource (McConnell, Brue, \& Flynn, 2012). Because of the lower amount of social capital FGS have from their parents, additional social capital may lead to larger increases in overall benefit. Continuing-generation students have less room to grow because they start off with at least some social capital from their parents. Helping students increase social capital in culturally relevant ways has the potential to increase FGS success in higher education.

Social and cultural capital are complimentary concepts. According to McCarron and Inkelas (2006):

in the college going process, cultural and social capital are defined as knowledge of the campus environment and campus values, access to human and financial resources, and familiarity with terminology and the general functioning of a higher education setting. (p. 535)

Knowing where to go for help and believing the resources are accessible and believing in their capacity for success may go a long way in helping students remain in college (Morales, 2014; Porter \& Swing, 2006). Social capital likely increases cultural capital by acclimating students to the university. The resulting social network teaches newcomers about expectations, values, and resources. Further, as cultural capital increases, it can be used to increase social capital through successful interactions with faculty, staff, peers, and the institution. 
There are a number of ways in which social capital can be increased. Rahm and Moore (2016) found a science college preparatory program, COSMOS, was successful in building a support network for FGS. Blackwell and Pinder (2014) suggested alternate programs aimed at developing peer support can increase social capital and should be offered by schools. In a review of strategies for retaining FGS and low-income students, Thayer (2000) asserted the best programs increase social support, as well as academic competence, and promote engagement with peers, the institution, and faculty-a view shared by Ward et al. (2012). It is not enough to tell students about resources institutions must help students utilize the resources (Dumais, 2002; Malecki \& Demaray, 2006; Terenzeni, 1996). Peer networks are one way to connect students with and instill confidence in their ability to use resources.

Schwartz et al. (2018) found in their mixed methods study that even a relatively short intervention can change social capital. Their program provided four, one-hour training sessions discussing (a) the role of social capital to achieve goals, (b) the challenges to networking, (c) mapping social networks and designating strong and weak ties, (d) role playing, (e) interviews to strengthen networks, and (f) strategies to further social capital (Schwartz et al., 2018). At the end of the program students reported better relationships with instructors, an increased intention to recruit support, better network orientation, and lower help-seeking avoidance. Those participating also had higher first year GPAs compared to a control group (Schwartz et al., 2018). Finally, students who were also interviewed as part of the study were found to be persistent even after they perceived some professors to be too busy or judgmental to help them. Instead of giving up, the students reached out to other sources for help (Schwartz et al., 2018). 
A required FYS has potential to help FGS build social capital without placing a large burden on the students (Collier \& Morgan, 2008; Terenzini, 1996; Thayer, 2000). At the study site, all incoming freshmen are required to enroll in a FYS their first semester unless students are participating in the honors program or have transferred in with greater than 24 hours of college credit post high school. This course focuses on successfully transitioning students to college. For three years, the institution has offered sections intentionally designed for FGS. The faculty teaching the course receive special training orienting them to the unique strengths and challenges of FGS. This training potentially increases the likelihood the course is culturally relevant to FGS. Since the course is required of most students, it does not increase the financial or time burden on FGS students (Beattie \& Thiele, 2016). No studies to date have examined the effectiveness of a required FYS designed specifically for FGS, and the effect such a course might have on social capital generation or types of social capital. In fact, while studies have pointed toward different potential sources of social capital, none have examined different types of social capital, let alone how they may be related to FGSstatus.

\section{Factors Aiding FGS Success}

Multiple factors have been shown to help FGS successfully apply to and stay in higher education. For instance, Choy et al. (2000) found students participating in advanced mathematics courses in high school had a significant effect on applying for college, regardless of their parental education status. Unfortunately, FGS parents were less likely to advise their children to take more advanced math courses in high school (Choy et al., 2000). McCarron and Inkelas (2006) found a clear link between aspirations 
and degree attainment. In a longitudinal study examining persistence, the researchers found while $40.2 \%$ of FGS 10th-graders in 1990 had aspirations for a bachelor's degree, only $29.5 \%$ had acquired the degree within eight years after high school (McCarron \& Inkelas, 2006). In contrast, $28.4 \%$ of continuing-generation students planned on completing a bachelor's and 55.9\% had completed the degree within eight years after graduating high school. Additionally, only $6.5 \%$ of students in the sample attained a degree higher than they aspired to in the 10th-grade (McCarron \& Inkelas, 2006).

Perhaps tied to educational aspirations is the concept of motivation. Researchers have established a link between students' motivations, their desire to go to college, and their success in college. Bui (2002) found FGS-none wanted to attend college as a way to gain respect and bring honor to their family. FGS-none and FGS-some were both motivated to attend college to assist their family afterwards. In his review of literature, Coffman (2011) found FGS were motivated by their desire to have a better life than their parents, as well as a desire to find meaningful work. In their grounded theory study comparing FGS with a large number of siblings and third generation continuinggeneration students, Blackwell and Pinder (2014) similarly found the desire for a better life was a strong motivating factor for FGS.

An additional contributing factor to FGS success related to motivation is selfadvocacy, defined as the ability to advocate and seek help for yourself (Byrd \& MacDonald, 2005). In their qualitative study, Byrd and McDonald (2005) found upper division, non-traditional FGS stressed the importance of time-management, ability to focus on achieving a goal, and self-advocacy as necessary skills for college. For these students, the ability to approach a professor was important for their success (Byrd \& 
McDonald, 2005), potentially a form of social capital. As previously discussed, talking to professors may be one way students better understand faculty expectations, thereby increasing their ability to perform well (Collier \& Morgan, 2008). However, a professor's actions in the classroom can directly impact how comfortable a student feels approaching the faculty member (Collier \& Morgan, 2008). Further, CambridgeWilliams et al. (2013) found in their study of FYS, higher retention and graduation rates were best explained by self-efficacy and self-regulated learning.

Grassi et al. (2006) shared strategies meaningful in their teacher preparation program for working-class students. One of the strategies the authors emphasized was the ability for working-class students to draw meaningful connections between their experiences, coursework and future endeavors (Grassi et al., 2006). Since FGS are more likely to be lower SES, these strategies are likely to translate. Working-class students in the teacher preparation program under study were found to flourish when trusted with responsibilities that allowed the students to showcase their strengths (Grassi et al., 2006).

All of these factors may also be influenced by cultural relevancy and social capital. Educational aspirations are likely directly influenced by a student's orientation to education and their perceived ability to succeed. Believing education is a worthy endeavor (Christopher et al., 2014) and a student can successfully navigate the system (Dumais, 2002; Shumaker \& Wood, 2016) likely influence students' educational aspirations. These, in turn, affect students' motivation and ability to self-advocate. Further, access to financial support has also been identified as key for FGS success. Ishitani (2006) found grants and work-study led FGS to be less likely to leave the university than FGS receiving no aid. Grants and work study may be particularly 
meaningful if FGS and their parents do not qualify for student loans and are not able to be competitive for academic merit scholarships (Ward et al., 2012). Pascarella et al. (2004) suggested state and federal agencies should reexamine existing financial aid policies to address potential barriers for FGS.

Rahm and Moore (2016) found parental financial support and scholarships can play a role in FGS persistence. In Rahm and Moore's (2016) longitudinal study of four FGS in a STEM bridge program, two of the students stressed the importance of finances. One student shared how her mother used her retirement funds to help supplement educational costs beyond what scholarships covered (Rahm \& Moore, 2016). A second student noted he changed his degree because his first choice was taking too long, and finances prevented him from delaying graduation (Rahm \& Moore, 2016).

One theory of why financial support may help retain FGS, beyond the obvious, is by allowing FGS to be more engaged on campus by having to work fewer hours. Engagement has been shown to increase FGS retention, but time to participate is "a luxury that affluent students are most able to afford....time is something that is acquired through wealth" (Kezar et al., 2015, p. 237). Indeed, Pascarella et al. (2003) found FGS were less likely to join Greek organizations and worked more hours than peers where both parents had earned a degree.

Warnock and Hurst (2016) found low SES students at an exclusive university stressed the importance clubs had in connecting them to students with similar backgrounds. As another hidden population, the same is potentially true for FGS (Ward et al., 2012). However, this type of meaningful interaction does not have to be relegated to activities outside of the classroom. In fact, classrooms might be uniquely positioned 
for increasing social capital since participation is mandatory while social organizations are voluntary (Beattie \& Thiele, 2016). Moreover, all students spend the vast majority of their time in the classroom (Morales, 2014).

Billson and Terry (1982) emphasized the importance of increasing social support in academic settings for FGS, as did Ward et al. (2012). In their study of faculty and student expectations, Collier and Morgan (2008) found both FGS and continuinggeneration students wanted to use communication as a way to build relationships with faculty. Grassi et al. (2006) also stressed the importance of mentoring and relationship building for working-class students. Likewise, Coffman (2011) emphasized the positive impact social support can have on FGS. Students benefit from connecting to both faculty and peers making early academic and social integration critical (Ward et al., 2012).

Further, efforts to increase engagement and social capital can be more intense than occasional interactions with faculty and peers. Thayer (2000) examined learning community strategies which included summer bridge programs, academic programs, and linked summer bridge programs and academic programs. Analyzing learning community strategies for FGS and/or low-income students the authors found learning communities either in residence halls or in classrooms were highly effective for student retention (Thayer, 2000). At Colorado State University, students' grades were monitored and they receive weekly feedback in three core courses (Thayer, 2000). The program provided students with a connection to faculty, advisors, resources, and opportunities. As a result, retention was higher than the university average (Thayer, 2000). Michigan State University's learning community program also resulted in higher than average retention 
at the university. Further, participation in the learning community led to high levels of expressed comfort and supportive friends among participants (Thayer, 2000).

Finally, bridge programs provide an additional tool to increase retention and potentially social capital as well. Bridge programs are intensive programs that tend to take place the summer between a student's senior year of high school and their freshman year of college. Bridge programs can vary in their focus, but most aim to familiarize students with campus and provide coursework to address academic deficiencies (Cabrera, et al., 2013).

A bridge program in Arizona was found to have positive effects on both freshman GPA and retention (Cabrera et al., 2013). Nevertheless, once the researchers controlled for the "freshman experience" these effects became insignificant (Cabrera et al., 2013). Tomasko et al. (2016) found a summer bridge program in STEM increased feelings of preparedness for college, sense of belonging, and GPA. These students were retained at a higher rate than those who did not participate. Additionally, the bridge program was more successful at retaining underrepresented minority students (Tomasko et al., 2016). At Drexel University, in yet another bridge program, retention rates of FGS and lowincome students were higher than any other identified group except for the honors program (Thayer, 2000). Similarly, Petty (2014) asserted bridge programs are able to build academic and social pathways capable of overcoming deficiencies.

While bridge programs tend to have a positive impact on FGS retention, they are not a silver bullet. Perhaps students who participate in summer bridge programs are more likely to be motivated to complete a degree and are better able to seek resources for aid. Additionally, bridge programs increase costs, in terms of both time and money. Because 
FGS are more likely to be low-income (Bui, 2002; Kezar et al., 2015; McCarron \& Inkelas, 2006; Thayer, 2000), bridge programs may remain inaccessible to them. None of the aforementioned studies directly examined social capital and FGS.

\section{Factors Hindering FGS Success}

Researchers have identified a number of factors impeding FGS access and persistence in higher education. Unsurprisingly, lack of finances has been found to negatively impact FGS persistence in numerous studies (Bui, 2002; Thayer, 2000). While not studying retention, Bui (2002) found FGS reported significantly higher concerns regarding finances. Rahm and Moore (2016) identified a lack of finances was also a contributing factor to major selection. One subject in their study changed majors from the STEM field because the periodicity of courses meant delaying graduation (Rahm \& Moore, 2016). The student said he could not wait to enter the job market for financial reasons and therefore changed his major to communications (Rahm \& Moore, 2016).

In their study of FGS and first-generation United States citizens, Williams and Ferrari (2015) pointed out financial issues make retention and integration on campus difficult for both groups. Indeed, a lack of money leads many FGS to work more hours, leaving them less time to engage on campus (Billson \& Terry, 1982; Pascarella et al., 2003; Warnock \& Hurst, 2016; Williams \& Ferrari, 2015), potentially exacerbated by not qualifying for student loans and/or being competitive for academic merit scholarships (Ward et al., 2012). This may, in turn, impact their ability to cultivate social capital.

The need to work led to FGS giving priority to work over coursework in at least one study (Billson \& Terry, 1982). Additionally, these students were more likely to give 
priority to work when determining their class schedule and prioritized overtime above studying. All students in the sample were found to have a stronger sense of responsibility to work the more hours they worked (Billson \& Terry, 1982). Similarly, Pascarella et al. (2004) found FGS involvement in work, volunteer work, and intercollegiate sports had strong negative impacts on cognitive growth for FGS. Further, FGS were more likely to work more hours and work off campus putting them at a distinct risk for leaving (Billson \& Terry, 1982; Terenzini, 1996). The difference in priorities also puts FGS at odds with faculty (Collier \& Morgan, 2008). Faculty may be unsympathetic to missed class or deadlines due to work commitments.

Billson and Terry (1982) suggested dedication to work makes FGS less committed to their role as students. As a result, they are less likely to join student organizations or study as hard (Hottell et al., 2014). This can ultimately lead to poor grades and departure from the university (Billson \& Terry, 1982). Billson and Terry (1982) compared FGS and continuing-generation students who persisted and those who left. FGS who left college had the lowest grades in the sample and were not as involved on campus. Collier and Morgan (2008) also found FGS were more likely to fit studying into available time rather than devoting sufficient time to studying which likely affects subsequent grades earned. In fact, Terenzini (1996) found FGS spent less time studying per week than continuing-generation students. Moreover, FGS recognize struggles with time management (Collier \& Morgan, 2008) and study habits as barriers to success (Rahm \& Moore, 2016). The difference in priorities may also reflect a difference in cultural orientation toward higher education and a lack of culturally relevant ways for 
FGS to engage at the institution, namely those that do not require large time commitments.

Lack of finances and working are not the sole contributor to FGS lack of persistence. Lack of knowledge has also been tied to lower FGS retention. This lack of knowledge typically manifests in two ways: (a) lack of knowledge regarding college (Bui, 2002; Byrd \& MacDonald, 2005; Coffman, 2011; McCarron \& Inkelas, 2006; Thayer, 2000; Wohn et al., 2013) and (b) lack of academic preparation (Choy et al., 2000; Coffman, 2011; Terenzini, 1996). Lack of knowledge regarding college can leave students feeling apprehensive about attending college (Bui, 2002; Byrd \& MacDonald, 2005; McCarron \& Inkelas, 2006; Thayer, 2000). Further, the lack of knowledge can discourage students from completing the application process for college (Choy et al., 2000; Wohn et al., 2013). Bui (2002) suggested the lack of knowledge could also result in FGS making poor decisions. McCarron and Inkelas (2006) noted the lack of information FGS receive is due in part to a lack of clear messaging the students receive in high school. This lack of knowledge may signal a cultural disconnect with higher education.

Further, academic preparation, can affect access to college (Choy et al., 2000) and persistence in college (Terenznini, 1996). Choy et al. (2000) found students participating in advanced mathematics courses were significantly more likely to attend college. However, only $56 \%$ of FGS-none parents encouraged their students to take advanced courses in high school compared to $66 \%$ of FGS-some, and $74 \%$ of continuinggeneration students (Choy et al., 2000). Beyond encouragement from parents to take advanced courses, FGS have reported feeling less prepared for college (Bui, 2002). 
Additionally, researchers have found FGS are less academically prepared for college (Coffman, 2011; Terenzini, 1996; Thayer, 2000) and therefore spend more time studying (Hottell et al., 2014). Again, none of these studies examined social capital directly.

\section{Factors with an Unclear Relationship to FGS Success}

Family appears to have an unclear relationship to FGS success. Byrd and MacDonald (2005) found three FGS in their sample reported family concerns had kept them from attending college. An additional three students were motivated to do well in college to make a better life for themselves compared to the life their parents lived (Byrd \& MacDonald, 2005). Six FGS reported positive stories about parental support in college. Finally, four FGS with children wanted to provide a better life for their children than their parents had been able to provide for them (Byrd \& MacDonald, 2005).

FGS family can also be actively unsupportive or stand in the way. Billson and Terry (1982) found only 61\% of FGS reported having emotionally supportive parents compared to $73 \%$ of continuing-generation students. Of the FGS who left college in the study, only 50\% reported their parents as emotionally supportive (Billson \& Terry, 1982). Further, continuing-generation students also gave a broader range of parental support than FGS, such as financial support and help with homework. Billson and Terry (1982) found when FGS felt their parents valued education, FGS were more likely to persist; however, parents with less education were more likely to be perceived as not valuing education.

Clemons (2016) found an unclear relationship between family social capital and FGS. In his in-depth qualitative study following a single FGS, the social capital provided by the student's family was both beneficial and a hindrance. The student's mother 
actively worked to support the student's education even though the student noted the mother was unable to help with college admission applications (Clemons, 2016). Additionally, the student had support from her sister as well. Unfortunately, this support also led to conflicting experiences for the student. She noted difficulty settling on a major because she and her mother did not agree on her future career path (Clemons, 2016).

As previously noted, FGS have lower levels of beginning family social capital (Billson \& Terry, 1982; Ward et al., 2012). In one study, social capital from family led to higher GPAs in reading, language, and social studies as well as overall GPA in middle school (Malecki \& Demaray, 2006). Further, pre-college family social capital was found to mitigate students' interactions in larger class sizes (Beattie \& Thiele, 2016). Beattie and Thiele (2016) found negative associations with academic social capital such as discussing course material with professors, ideas, and careers in classes larger than 60 students.

Rahm and Moore (2016) also found parental financial support can help FGS persistence. It would be safe to say the mother withdrawing money from her retirement account to help pay for college sends a clear message about the value she placed on her daughter's education. The daughter ended up completing a master's degree (Rahm \& Moore, 2016). Clearly parental attitudes toward education can have a significant impact, for better or worse, on FGS access and persistence.

A second variable with an unclear relationship to FGS success is engagement. While previous studies have shown a positive relationship between engagement and persistence (Kezar et al., 2015; Ward et al., 2012), not all have taken into account 
parental financial support, non-parental financial support (scholarships, grants, and/or work study), and the number of hours a student works. A student has a higher likelihood to be able to engage with the university if they can afford not to work or work fewer hours (Kezar et al., 2015). Without proper controls, it is difficult to say if engagement or financial ability is actually being measured in some previous studies. Further confounding the variable is academic ability. The student in Clemens' (2016) study noted she spent more time on homework and studying. This eventually led to her peers not inviting her to activities anymore because she was always saying no so she could study instead.

\section{First Year Seminars}

According to Connolly et al. (2017), the purpose of FYS is (a) to transition students to college, (b) facilitate social engagement with peers, teachers, and peer leaders, (c) promote learning skills, and (d) encourage participation in activities with other students in an effort to connect students with similar interests. Fowler and Boylan (2010) concurred adding FYS are a way to achieve continuous engagement and interaction with faculty. These interactions ideally build professional relationships and a sense of connectedness; i.e. social capital. Escobedo (2007) concluded the first term for a student is "critical in connecting them to the services of the college and to staff members who were not only champions but guided them to communicate with their instructors" (p. 16), a sentiment echoed by Ward et al. (2012).

In their review of the literature, Fowler and Boylan (2010) identified essential components for effective FYS. One component is a mandatory transition orientation. The authors stress a FYS transition course is not the same as an orientation (Fowler \& 
Boylan, 2010). Rather, an orientation begins to familiarize students with the campus environment, typically lasts less than a week and is completed prior to the start of the first semester and are of particular importance for FGS (Fowler \& Boylan, 2010).

On the other hand, a FYS course goes beyond introducing students to campus and begins to develop support structures to aid in student success (Fowler \& Boylan, 2010). FYS come in a variety of formats including extended orientations, academic seminars, discipline-linked seminars, basic study skills and any combination of the former (Permzadian \& Credé, 2016). FYS vary in length, lasting a few weeks to a full semester, as well as being offered for credit or no credit, pass/fail or graded, and targeting only academically underprepared students to targeting all incoming freshmen (CambridgeWilliams et al., 2013; Permzadian \& Credé, 2016). Porter and Swing (2006) found college success and transitive themed FYS, aimed at developing study skills for academic success while encouraging engagement, were the most common type of FYS in their study sample of 20,000 first-year students at 45, four-year institutions.

FYS are also typically offered for credit whereas orientations are not. The amount of credit offered varies from one credit hour, the most common form, to three credit hours, the second most common (Barton \& Donahue, 2009). Barton and Donahue (2009) examined the difference between a one credit hour FYS and a four credit hour FYS. There was no significant differences in retention. Further, once SAT scores were taken into account, there were no significant differences in GPA between the two courses (Barton \& Donahue, 2009). Students in the four credit hour courses did have a higher expectancy for academic help, as well as higher expectations and outcomes for campus 
events and activities (Barton \& Donahue, 2009). A four-credit hour FYS represents a substantial investment for students in terms of time and money.

Additionally, some FYS are required while others are treated as an elective. Pascarella et al. (1986) studied a two to three day voluntary orientation program. After controlling for parental combined education, parental combined annual income, sex, ethnicity, SAT scores, liberal arts major, percentile rank in graduating class, high school involvement, and institutional commitment, the authors found students who participated in the orientation participated in more extra-curriculars, had more outside classroom interactions with faculty, and reported higher quality and impact of faculty interactions (Pascarella et al., 1986). The authors found no significant difference in persistence, but the orientation did have significant direct effects on social integration and commitment to the university (Pascarella et al., 1986). In theory, a required FYS should have similar positive impacts. Further, social integration and commitment to the university had the largest direct effects on freshmen persistence in the study (Pascarella et al., 1986). The authors proposed the orientation therefore had an indirect impact on persistence (Pascarella et al., 1986). Potentially, the orientation may have increased social capital as evidenced by the increased interactions with faculty and participation in extra-curricular activities. Whether students used this social capital to overcome challenges or simply felt more connected and therefore committed to the university is unknown.

The wide variety of formats for FYS courses make direct comparisons of outcomes difficult. Despite the variety of FYS in format and focus, there are several common themes and topics covered in FYS. These topics include time management (Cambridge-Williams et al., 2013; Connoly et al., 2017; Fowler \& Boylan, 2010), 
learning strategies such as note taking (Connolly, et al., 2017; Fowler \& Boylan, 2010), critical thinking (Cambridge-Williams et al., 2013), study skills (Connolly et al., 2017) reading comprehension (Connolly et al., 2017; Fowler \& Boylan, 2010), health (Connolly et al., 2017; Cambridge-Williams et al., 2013; Porter \& Swing, 2006), campus policies, engagement, and peer connections (Porter \& Swing, 2006).

\section{Outcomes}

Numerous researchers have examined the effects of FYS and orientations. In their study, Cambridge-Williams et al. (2013) found a 14 week freshman orientation course had positive influences on academic performance and freshman-to-sophomore retention rates. Further, the authors found no significant difference between those who voluntarily enrolled and those who did not in terms of high school GPA or SAT scores, father's education, annual family income, immigrant status, ethnicity, gender, first language, and FGS status (Cambridge-Williams et al., 2013). It appears in their sample at least that self-selection bias may not have been a significant problem. There was a significant difference in mother's education, but the difference was classified as small (Cambridge-Williams et al., 2013).

Cambridge-Williams et al. (2013) found $83 \%$ of the students who had taken the orientation course returned for their junior year compared to $71 \%$ of the students who did not take the course. Further, after five years, $75 \%$ of these students were still enrolled or had graduated, compared to $59.9 \%$ of the control group (Cambridge-Williams et al., 2013). The authors found no significant differences in time management. Those attending the orientation reported higher university satisfaction, greater ease making 
friends, and increased satisfaction with the college experience (Cambridge-Williams et al., 2013).

Connolly et al. (2017) examined at-risk students enrolled in a FYS for nine weeks. Students were identified as at-risk if they had a high school GPA less than 2.8 and an SAT score less than 800 (Connolly et al., 2017). The students participating had higher GPAs compared to the control group, but they were not able to significantly avoid academic probation (Connolly et al., 2017). There were also no differences in retention. The sample size was limited to 21 students enrolled in the program and 19 in the control group (Connolly et al., 2017).

Interestingly, Pascarella et al. (1986) found students who participated in a twoday orientation program reported higher quality and impact of faculty interactions. While there was no significant direct effect on persistence, there was a significant indirect impact on persistence. The authors found a significant direct impact on orientation participation and social integration and commitment to the university. Social integration and commitment to the university had the largest direct effect on freshman persistence in the study (Pascarella et al., 1986). Orientation courses have been shown to increase student interactions with other students potentially increasing peer social capital (Pascarella et al., 1986).

Permzadian and Credé (2016) conducted a meta-analysis of 284 independent samples of FYS effects on first-year cumulative GPA and freshman-to-sophomore retention. Overall, the authors found a very small effect on first-year cumulative GPA and a slightly larger effect on first-year retention. They concluded the average FYS was not effective at increasing first-year cumulative GPA and only slightly effective for 
increasing first-year retention. With additional analysis, it was discovered hybrid courses combining academic skills and extended orientation FYS taught by trained faculty or staff were most effective for increasing cumulative first-year GPA. The most successful FYS for increasing GPA were also taught at two-year institutions. FYS were most effective at increasing retention when they were an extended orientation, taught by trained faculty and staff and targeted all incoming freshmen.

None of the existing literature has examined the effect of FYS on FGS in any capacity or the direct relationship of overall social capital or types of social capital. This study attempted to address this gap by examining the ability of FYS to generate overall social capital for FGS and potential types of social capital. Further, social capital generation was examined by FGS-none, FGS-some, and continuing-generation students to explore how FGS status is defined.

\section{Conclusion}

The current definition for FGS does not appear to be grounded in research. FGS may be defined as (a) students whose parents did not attend college (Choy et al., 2000; Billson \& Terry, 1982; Ishitani, 2006; Terenzini, 1996), (b) students whose parents had no additional education since high school (Pascarella et al., 2003), or (c) students with no parent completing a four-year degree (Collier \& Morgan, 2008; Moschetti \& Hudley, 2008; Petty, 2014; Shumaker \& Wood, 2016; Thayer, 2000; Wohn et al., 2013). Further, only one study has examined the difference in outcomes regarding FGS-none, FGS-some, and continuing-generation students (Ishitani, 2006). Therefore, it remains unclear if the current operational definition is appropriate. 
Numerous studies have examined the unique challenges FGS experience when applying and persisting in college. Some of these challenges include lack of high school preparation (Bui, 2002; Choy et al., 2000; Coffman, 2011; Terenzini, 1996; Thayer, 2000), finances (Bui, 2002; Thayer, 2000), lack of college knowledge (Bui, 2002; Byrd \& MacDonald, 2005; Coffman, 2011; McCarron \& Inkelas, 2006; Thayer, 2000; Wohn et al., 2013), and lack of family support (Billson \& Terry, 1982; Byrd \& MacDonald, 2005). Additional research has discovered factors that aid FGS in their educational pursuits, including self-advocacy (Byrd \& MacDonald, 2005), taking advanced math courses in high school (Choy et al., 2000), grants and work study (Ishitani, 2006), wanting a better life (Byrd \& MacDonald, 2005), engagement (Kezar et al., 2015; Ward et al., 2012), and bridge programs (Cabrera et al., 2013; Thayer, 2000; Tomasko et al., 2016).

Largely missing from the literature are studies aimed at assessing FYS on social capital and potential impacts on FGS. Research has suggested such programs show promise for FGS success (Collier \& Morgan, 2008; Terenzini, 1996; Thayer, 2000; Ward et al., 2012). The results for first-year students taking FYS are mixed. Some studies have shown positive influences on academic performance, ease of making friends (Cambridge-Williams et al., 2013), more extra-curricular participation, higher quality and quantity of interactions with faculty (Pascarella et al., 1986), and retention (CambridgeWilliams et al., 2013; Permzadian \& Credé, 2016).

Cambridge-Williams et al. (2013) found a positive relationship between FYS and freshman-to-sophomore retention rates. Pascarella et al. (1986) and Connolly et al. (2017) found no statistically significant differences in persistence and retention. Pascarella et al. (1986) did find an orientation had a significant indirect impact on 
persistence. The FYS in each study encompassed a wide variety of formats. Permzadian \& Credé (2016) found how a FYS is structured and taught can impact how successful a FYS is an increasing cumulative first-year GPA or freshman-to-sophomore retention. Further, the studies did not examine the effect on FYS on FGS, their retention, or the ability to build social capital.

Two potential frameworks for examining FGS retention in a FYS are cultural relevancy and social capital. Cultural relevancy focuses on adapting programs to meet the unique cultural backgrounds of FGS (Kezar et al., 2015). Social capital centers on a student's ability to create and access support systems at the university (Malecki \& Demaray, 2006).

As more FGS enter the university system, it is imperative to retain these students. In addition to lost revenue from losing the students or state performance funding, retaining FGS is a moral obligation. Providing access to higher paying jobs may be a critical piece to breaking the cycle of poverty for these students and their families (Schwartz et al., 2018). Confirming the appropriate definition of FGS status will help ensure institutions are collecting appropriate information regarding parental education. Using a definition grounded in research will aid in determining funding and resource allocation to retain the most at-risk students. Finally, such a definition has the potential to provide uniformity in future research. Increasing social capital through FYS may be one strategy to help FGS on their college journey. Further, looking at the differences in social capital may be one way to explore potential definitions of FGS status. 
Chapter 4:

Contribution to Practice 
The results of this research will be submitted to the Celebrating FGS: From Convocation to Graduation conference. The conference will be help on September 27, 2019. The call for proposals requested topics related to high impact practices, the college transition, best practices, and research which helps practitioners better understand or serve FGS. Selected presentations will last 50 minutes which includes time for questions. With this is mind, a PowerPoint presentation targeting practitioners in higher education working with FGS is presented in this chapter.

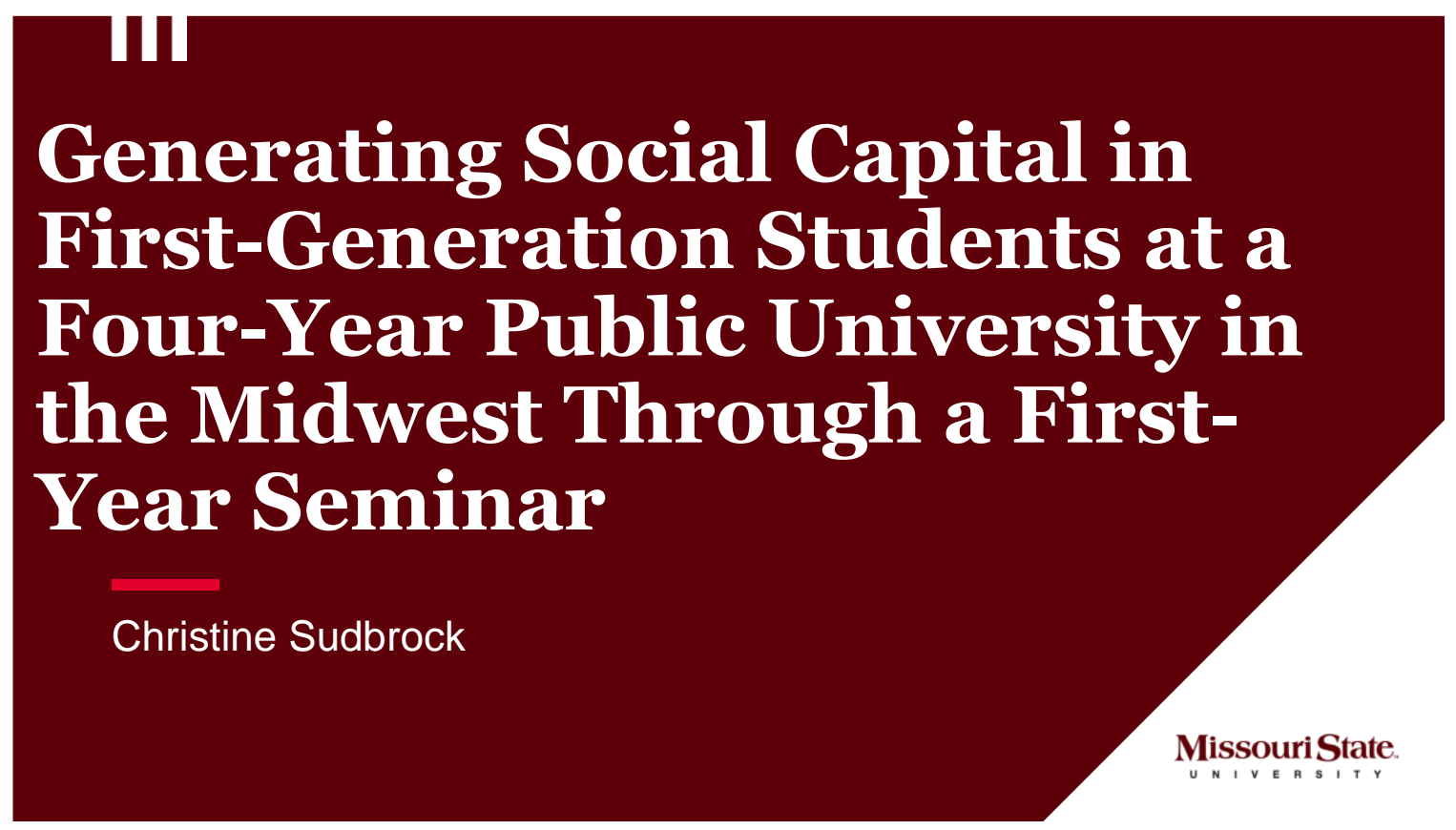




\section{Introduction}

- A college graduate will make an additional $\$ 800,000$ (Daly \& Bengali, 2014)

- $3.8 \%$ of college educated Millennials unemployed vs. $12.2 \%$ of less educated Millennials (Pew Research Center, 2014)

- In 2013,34\% of Millennials pursuing a bachelor's degree or higher compared to $25 \%$ of Generation X (Pew Research Center, 2014)

- Unfortunately First-Generation Students continue to lag in graduation rates (Billson \& Terry, 1982; McCarron \& Inkelas, 2006; Thayer, 2000)

MissouriState

\section{III}

\section{Defining First-Generation Students (FGS)}

- There are three definitions for FGS commonly used

- Neither parent completed a four-year degree (Collier \& Morgan, 2008; Moschetti \& Hudley, 2008; Petty, 2014; Shumaker \& Wood, 2016;

Thayer, 2000)

- Most universities also use this definition

- Neither parent attended college (Billson \& Terry, 1982; Choy, Horn, Nunez, \& Chen, 2000; Ishitanti, 2006; Terenzini, 1996

- Neither parent had an education past high school (Pascarella, Pierson, Wolniak \& Terenzini, 2003) 


\section{III}

\section{Defining FGS for this Study}

- FGS-none: students where neither parent has had any education beyond high school.

- FGS-some: students where a parent has had some education beyond high school, but did not complete a four-year degree

- Continuing Generation: students where at least one student completed a four-year degree

MissouriState

un 1 V e n B T T

\section{III}

\section{Social capital in higher education:}

- A student's ability to create and access support systems at a university (Malecki \& Demaray, 2006)

- Getting professors to believe students "are capable of quality work, talking with faculty outside of class, find peers with similar background/interests, transition to the university, have a social life, and find study partners" (Soria \& Stebleton, 2013, p.143) 


\section{III}

\section{Sources of Social Capital}

- Students obtain social capital in college through

- Parents

- Faulty and Advisors

- Friends

- Extended family such as siblings

- Institutional agents at the university

- (Collier \& Morgan, 2008; Malecki \& Demaray, 2006; Moshetti \& Hudley, 2008; Wohn, Ellison, Khan, Fewins-Bliss, \& Gray, 2013).

\section{MissouriState}

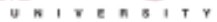

\section{III}

\section{Benefits of Social Capital}

- Teaches students things like jargon, cultural understanding, values, faculty expectations, etc. (Collier \& Morgan,2008; Ward, Siegel, \& Davenport, 2012)

- Social capital can be used to successfully transition to college (Permzadian \& Credé, 2016) 
III

\section{FGS and Social Capital}

- Lower social capital from family (Billson \&Terry, 1982; Terenzini, 1996; Ward et al., 2012)

- FGS-none have less than FGS-some (Ward et al., 2012)

- Family social capital was found to be a significant mitigating factor for students in large (>60 student) classes (Beattie \& Thiele, 2016)

MissouriState

M

\section{III}

\section{First-Year Seminars (FYS)}

- Transition students to college, facilitate engagement with peers, teachers, and peer leaders, promote learning skills, and encourage participation with other students (Connolly, Flynn, Jemmott \& Oestreicher, 2017)

- Types (Permzadian \& Credé, 2016)

- Extended Orientation

- Academic Seminar

- Discipline Linked Seminar

- Basic Study Skills

- Combination of all

MissouriState 


\section{III}

\section{FYS}

- Format (Permzadian \& Credé, 2016)

- Credit or No credit

- Credit offered ranges from 1 credit hour to 4 credit hours

- Pass/Fail or Graded

- Only academically underprepared or all students

- Few weeks to full semester

- Distinct from summer orientation

MissouriState

\section{III}

\section{FYS \& Social Capital}

- Students must adjust to academic culture and create new social networks (Brouwer, Jansen, Flache, \& Hofman, 2016; Permzadian \& Credé, 2016)

- FYS are designed to help students connect to peers, faculty, and the institution

- To date there have been no studies examining the ability of FYS to generate social capital in FGS students. 


\section{III}

\section{Research Questions}

- 1. Is initial social capital significantly different for full-time, first-time, new-in-college FGS-none, FGS-some, and continuing-generation students?

- 2. Is social capital at the end of the semester significantly different for full-time, first-time, new-in-college FGS-none, FGS-some, and continuing-generation students when comparing FYS programs?

- 3 . Is the change in social capital significantly different for full-time, first-time, newin-college FGS-none, FGS-some, and continuing-generation students?

- 4 . Is the change in social capital significantly different for full-time, first-time, newin-college FGS-none, FGS-some, and continuing-generation students by social capital type: peer, advisor, faculty, institutional, and family?

\section{MissouriState}

\section{III}

\section{Survey Instrument}

- Survey students in FYS at beginning and end of semester

- Use university emails for contact

- 343 completed initial survey

- 148 completed follow up survey

- 28 survey items to measure social capital

- Unweighted social capital scale

- Weighted social capital scale

\section{MissouriState}


III

\section{Participants}

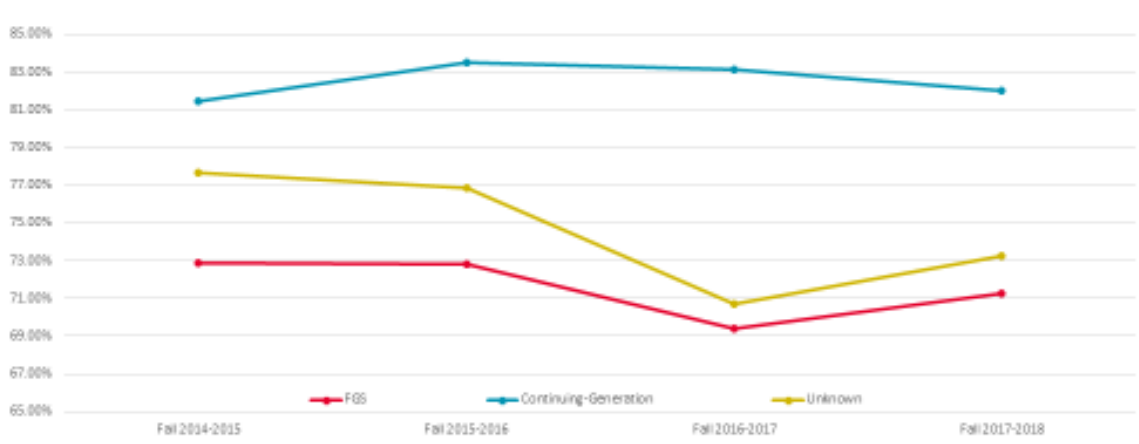

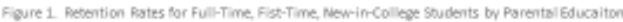

MissouriState

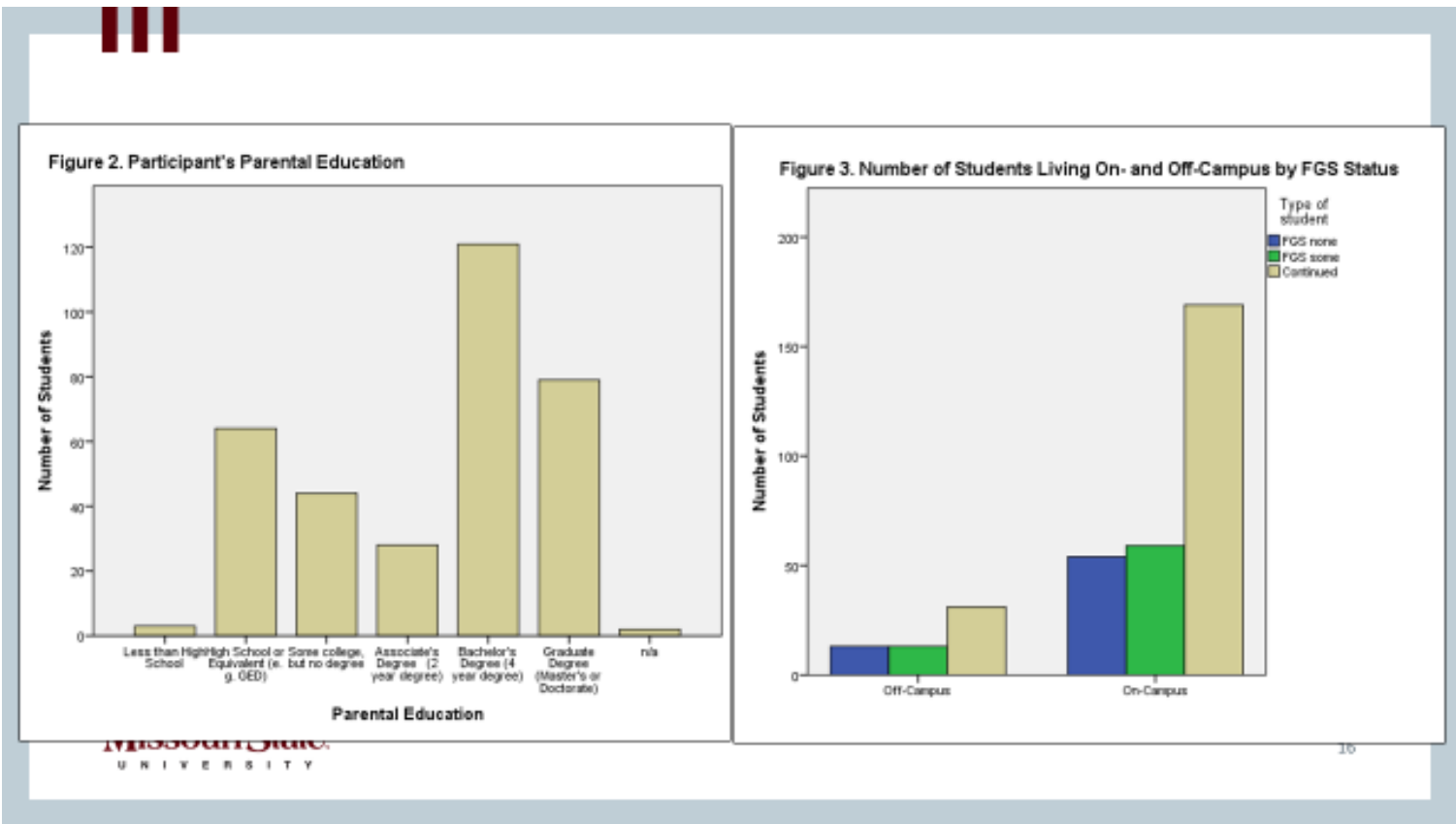




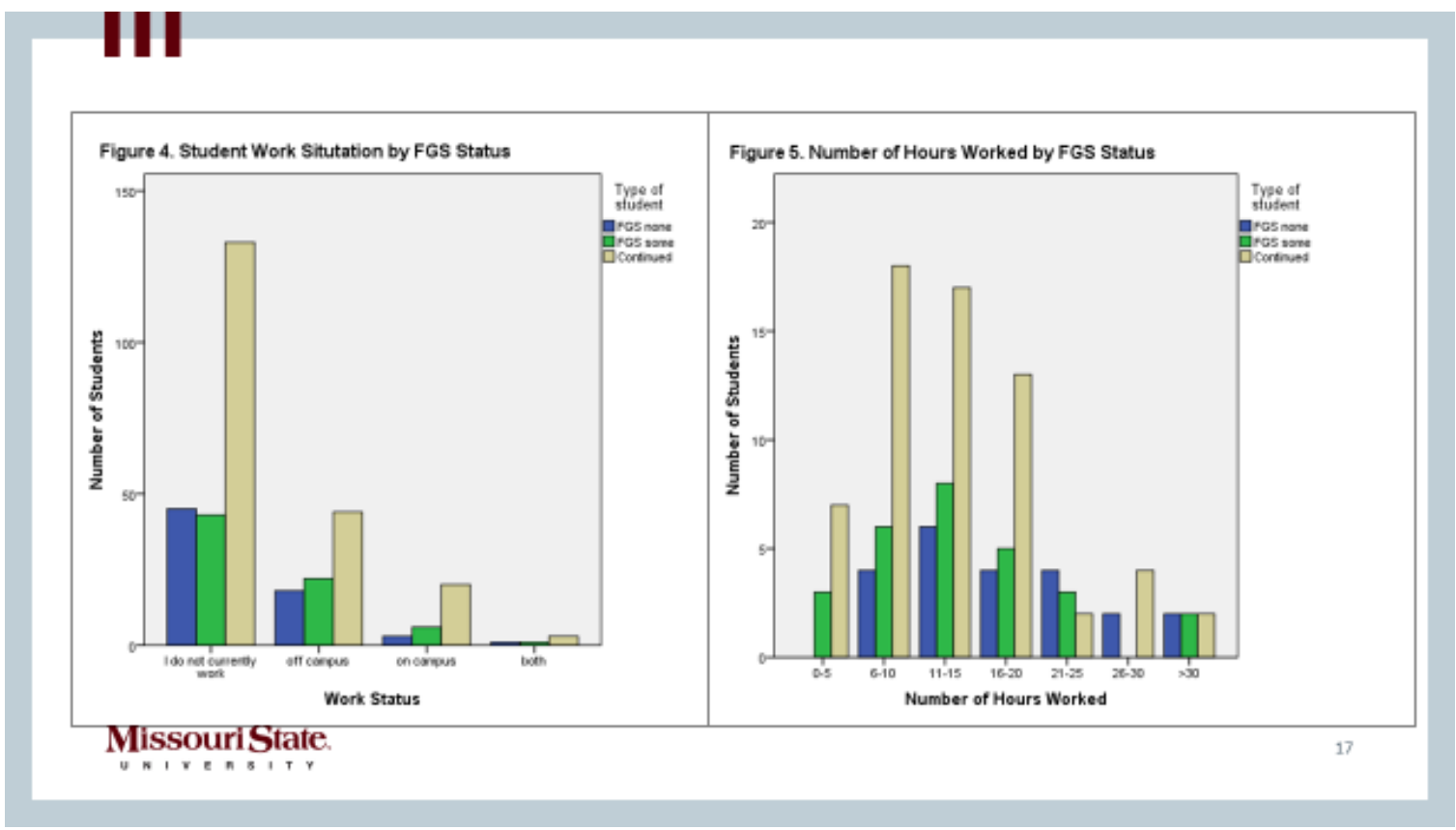

\section{III}

\section{FYS at University}

- Hybrid course: extended orientation and academic skill development (Permzadian \& Credé, 2016)

- Three areas of focus

- General Content

- College

- FGS College 


\section{III}

Is initial social capital significantly different for full-time, firsttime, new-in-college FGS-none, FGS-some, and continuinggeneration students?

- Analyzed using one-way ANOVA

- Initial Social Capital

- No significant differences using unweighted or weighted social capital

- Social Capital at the end of the semester

- Significantly lower for FGS-none $(M=43.28, S D=21.343)$ compared to continuing-education $(M=55.23, S D=20.23), p=.025$

- No significant differences found for FGS-some

\section{MissouriState.}

\section{III}

Is social capital at the end of the semester significantly different for fulltime, first-time, new-in-college FGS-none, FGS-some, and continuinggeneration students when comparing FYS programs?

- Analyzed using two-way ANOVA

- No significant differences found

- FYS x FGS-none, FGS-some, and Continuing-Education

- FYS x FGS and Continuing-Education

- FYS general content and specialized content x FGS-none, FGS-some, and Continuing-Education 


\section{III}

Is the change in social capital significantly different for full-time, firsttime, new-in-college FGS-none, FGS-some, and continuing-generation students?

- Analyzed using paired $t$-test

- FGS-none

- Significantly higher $(M=32.72, S D=29.91) ;(M=43.28, S D=21.34) p=.008$

- Eta squared .565

- FGS-some

- No significant difference

- Continuing-Education

- Significantly higher $(M=46.78, S D=21.90) ;(M=55.23, S D=20.23) p=.000$

- Eta squared .167

\section{MissouriState.}

\section{III}

\section{Types of Social Capital}

- Principal Component Analysis was conducted on the weighted social capital scale

- Five types of social capital were identified

- Advisor

- Faculty

- Peer

- Institutional

- Family

MissouriState. 
III

\section{Types of Social Capital}

- Initial and End of the Semester

- No significant differences in Institutional, Advisor, and Faculty social capital

- FGS-none and FGS-some had lower family social capital than continuinggeneration students, $p<.01$

- FGS-none had significantly less peer social capital than continuinggeneration students, $p<.05$

MissouriState

\section{Changes in Social Capital Types}

- Advisor

- FGS-none and continuing-generation students were able to increase

- Faculty

- FGS-some and continuing-generation were able to to significantly increase

- Peer

- FGS-some were able to significantly increase

- Institutional

- continuing-generation students were able to significantly increase

- Family

- No significant changes

\section{MissouriState.}


III

Defining FGS status

- No significant differences were found between FGS-none and FGS-some

- Family Social Capital

- Peer Social Capital

- Combining FGS-none and FGS-some did not change significance or direction of any results

- Use broader definition for FGS status

MissouriState

\section{III}

\section{FYS}

- Social Capital increases regardless of FYS focus

- Strategies utilized benefit all students (Thayer, 2000)

- Small sample size

- Final sample size $<30$ per FYS by FGS group

- More research is needed

- Larger sample size

- Look at other outcomes

MissouriState. 


\section{III}

\section{Changes in Social Capital}

- FGS-none increased social capital the most

- Marginal effect (McConnell, Brue, \& Flynn, 2012)

- Peer

- Less time to socialize because of work, family commitments, and studying (Bui, 2002; Collier \& Morgan, 2008; Hottell, Martinez-Aleman, \& Rowan-Kenyon, 2014; Kezar, Walpole, \& Perna, 2015; McCarron \& Inkelas, 2006; Thayer, 2000)

- Faculty

- Larger class sizes (Beattie \& Thiele, 2016)

- Family unable to coach them on how to approach situations (Collier \& Morgan, 2008)

MissouriState.

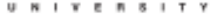

\section{Changes in Social Capital}

- Advisors

- Intrusive Advising (Fowler \& Boylan, 2010; Kezar et al., 2015; Thayer, 2000)

- University policies

- Institution

- FGS may need more time to use resources on campus effectively (Shumaker \& Wood, 2016) 


\section{III}

\section{Changes in Social Capital}

- More can be done in classrooms to aid first-year students transition to college

- Training

- Outlining expectations

- Advisors may be a key aspect to building social capital in first-year students

MissouriState

\section{III}

\section{Limitations}

- Experiences measured in the first semester may not persist as students continue education (Cambridge-Williams et al., 2013; Pascarella, Terenzini, \& Wolfe, 1986)

- No link between Social Capital and retention has been established 


\section{Limitations}

- Low response rate to survey

- Survey has not been validated

- Need to control for confounding factors

- Race, ethnicity, gender, SES, sibling's education, on/off campus living, number of hours spent in various activities

- Look at additional outcomes

- First-year cumulative GPA

- Freshman-to-sophomore retention

\section{MissouriState.}

\section{III}

\section{References}

- Beattie, I. R., \& Thiele, M. (2016), Connecting in class? College class size and inequality in academic social capital. The Joumal of Higher Education 87(3), 332-362

- Billson, J. M., \& Terry, M. B. (1982). In search of the silken purse: Factors in attrition among first-generation students College \& University, 58, 57-75.

- Brouwer, J., Jansen, E., Flache, A., \& Hofman, A. (2016). The impact of social capital on self-efficacy and study success among first-year university students. Learning and Individual Differences 52, 109-118

- Bui, V. T. (2002). First-generation college students at a four-year university: Background characteristics, reasons for pursuing higher education, and first-year experiences. College Student Journal, 36(1), 3-11.

- Cabrera, N., Miner, D., \& Milem, J. (2013). Can a summer bridge program impact first-year persistence and performance?: A case study of the new start summer program. Research in Higher Education, 54(5), 481-498. doi: $10.1007 / \mathrm{s} 11162-013-9286-7$

- Cambridge-Williams, T., Winsler, A., Kitsantas, A., \& Bernard, E. (2013). University 100 orientation courses and livinglearning communities boost academic retention and graduation via enhanced self-efficacy and self-regulated learning. The Joumal of College Student Retention 15(2), 243-268. doi:10.2190/CS.15.2.f

- Choy, S. P., Horn, L. J., Nunez, A., \& Chen, X. (2000). Transition to college: What helps at-risk students and students whose parents did not attend college. New Directions for institutional Research, 2000(107), 45-63.

\section{MissouriState.}




\section{References}

- Coffman, S. (2011). A social constructionist view of issues confronting first-generation college students. New Directions for Teaching \& Learning, 2011(127), 81-90. doi.org/10.1002/t1.459

- Collier, P. J., \& Morgan, D. L. (2008). "Is that paper really due today?": Differences in first-generation and traditional college students' understandings of faculty expectations. Higher Education, 55(4), 425-446. doi.org/ $10.1007 / \mathrm{s} 10734-007-9065-5$

- Connolly, S., Flynn, E. E., Jemmott, J., \& Oestreicher, E. (2017). First year experience for at-risk college students. College Student Joumal, 51(1), 1-6

- Daly, M. C., \& Bengali, L. (2014). FRBSF economic letter. Retrieved from http:I/unww.frbsf.org/economicresearch/publications/economic-letter/2014/may/is-college-worth-it-education-tuition-wages/

- Fowler, P. R., \& Boylan, H. R. (2010). Increasing student success and retention: A multidimensional approach. Joumal of Developmental Education, 34(2), 2-10.

- Ishitani, T. T. (2006). Studying attrition and degree completion behavior among first-generation college students in the United States. The Journal of Higher Education, 77(5), 861-885.

- Kezar, A. J., Walpole, M., \& Perna, L. W. (2015). Engaging low-income students. In S. J. Quaye, \& S. R. Harper (Eds.), Student engagement in higher education: theoretical perspectives and practical approaches for diverse populations (pp. 237-255). New York, NY: Routledge.

MissouriState.

\section{References}

- Malecki, C. K., \& Demaray, M. K. (2006). Social support as a buffer in the relationship between socioeconomic status and academic performance. School Psychology Quarterly, 21(4), 375-395.

- McCarron, G.P., \& Inkelas, K. K. (2006). The gap between educational aspirations and attainment for first-generation college students and the role of parental involvement. Journal of College Student Development, 47(5), $534-549$.

- McConnell, C. R., Brue, S. L., \& Flynn, S. M. (2012). Economics: Principles, problems, and policies (19th ed.). New York, NY: McGraw-Hill.

- Moschetti, R., \& Hudley, C. (2008). Measuring social capital among first-generation and non-first-generation, workingclass, white males. Journal of College Admission, 198, 25-30.

- Pascarella, E. T., Pierson, C. T., Wolniak, G. C., \& Terenzini, P. T. (2003). Experiences and outcomes of first-generation students in community colleges. Journal of College Student Development, 44(3), 420-429.

- Pascarella, E. T., Terenzini, P. T., \& Wolfe. (1986). Orientation to college and freshman year persistence/withdrawal decisions. The Joumal of Higher Education, 57(2), 155-174.

- Permzadian, V., \& Credé, M. (2016). Do first-year seminars improve college grades and retention? A quantitative review of their overall effectiveness and an examination of moderators of effectiveness. Review of Educational Research, 86(1), 277-316. DOI: 10.3102/0034654315584955

\section{MissouriState}




\section{III}

\section{References}

- Petty, T. (2014). Motivating first-generation students to academic success and college completion. College Student Joumal, 48(2), 257-264.

- Pew Research Center. (2014, February 11). The rising cost of not going to college. Retrieved from http://www.pewsocialtrends.org/2014/02/11/the-rising-cost-of-not-going-to-college/

- Shumaker, R., \& Wood, J. L. (2016), Understanding first-generation community college students: An analysis of covariance examining use of, access to, and efficacy regarding institutionally offered services. Community College Enterprise, 22(2), 9-17.

- Soria, K. M., \& Stebleton, M. J. (2013). Social capital, academic engagement, and sense of belonging among working-class college students. College Student Affairs Journal 31(2), 139-153.

- Terenzini, P. T. (1996). First-generation college students: Characteristics, experiences, and cognitive development. Research in Higher Education, 37(1), 1-22.

- Thayer, P. B. (2000). Retention of students from first generation and low income backgrounds. The Journal of the Council for Opportunity in Education, 1, 3-9.

- Ward, L., Siegel, M. J., \& Davenport, Z. (2012). First generation college students: Understanding and improving the experience from recruitment to commencement. San Francisco, CA: John Wiley \& Sons.

- Wohn, D., Ellison, N., Khan, M., Fewins-Bliss, R., \& Gray, R. (2013). The role of social media in shaping first-generation high school students' college aspirations: A social capital lens. Computers \& Education, 63, 424-436.

- MissouriState. 
Chapter 5:

Contribution for Scholarship 
The results of this research will be submitted to the Journal of the First-Year Experience \& Students in Transition. The call for papers requested topics related to the personal and social experiences of students transitioning into higher education including the first-year. The Journal is also interested in targeted populations such as FGS. Manuscripts must be between 15 and 20 pages in length which does not include references, tables, or figures. The abstract accompanying the manuscript must be less than 150 words. Finally, the manuscript must be formatted using the sixth edition APA manual.

\title{
GENERATING SOCIAL CAPITAL IN FIRST-GENERATION STUDENTS THROUGH A FIRST-YEAR SEMINAR AT A MIDWEST UNIVERSITY
}

\author{
Abstract \\ Graduating college is an important milestone, but, for first-generation students \\ (FGS), this can be more of a challenge than continuing-generation students. First-year \\ seminars (FYS) aim to integrate students academically and socially to university life. \\ The literature has not measured how social capital may differ based on parental education \\ or in different types of FYS. Though no evidence was found for considering FGS-none \\ and FGS-some distinct populations, social capital at the end of the semester for FGS- \\ none was significantly smaller than continuing-generation students. There were \\ significant increases in total social capital for FGS-none and continuing-generation \\ students but not FGS-some. Factor analysis revealed five dimensions of social capital in \\ the survey instrument: advisor, faculty, institutional, family, and peer. FGS-none and \\ continuing-generation students increased advisor social capital; FGS-some and
}


continuing-generation students increased faculty social capital; FGS-some increased peer social capital; and continuing-generation students increased institutional social capital.

\section{Background}

A college graduate will make an estimated additional $\$ 800,000$ in their lifetime compared to their high school educated counterparts (Daly \& Bengali, 2014) and less likely to be unemployed or living in poverty (Pew Research Center, 2014). Unsurprisingly, more students are choosing to further their education. Unfortunately, for many first-generation students, graduating from college remains out of reach (Ishitani, 2006).

The current definition for FGS does not appear to be grounded in research. FGS may be defined as (a) students whose parents did not attend college (Billson \& Terry, 1982; Choy, Horn, Nunez, \& Chen, 2000; Ishitani, 2006; Terenzini, 1996), (b) students whose parents had no additional education after high school (Pascarella, Pierson, Wolniak, \& Terenzini, 2003), or (c) students with no parent completing a four-year degree (Collier \& Morgan, 2008; Moschetti \& Hudley, 2008; Petty, 2014; Shumaker \& Wood, 2016; Thayer, 2000; Wohn, Ellison, Khan, Fewins-Bliss \& Gray, 2013). Further, only one study has examined the difference in outcomes regarding FGS-none, FGS-some, and continuing-generation students (Ishitani, 2006). Therefore, it remains unclear if the current operational definition is appropriate. How FGS status is defined will determine the number of FGS identified and has implications for programming in higher education and resource allocation.

Numerous studies have examined the unique challenges FGS experience when applying to and persisting in college. Some of these challenges include lack of high 
school preparation (Bui, 2002; Choy et al., 2000; Coffman, 2011; Terenzini, 1996; Thayer, 2000), finances (Bui, 2002; Thayer, 2000), lack of college knowledge (Bui, 2002; Byrd \& MacDonald, 2005; Coffman, 2011; McCarron \& Inkelas, 2006; Thayer, 2000; Wohn et al., 2013), and lack of family support (Billson \& Terry, 1982; Byrd \& MacDonald, 2005). Additionally, factors that aid FGS in their educational pursuits include self-advocacy (Byrd \& MacDonald, 2005), taking advanced math courses in high school (Choy et al., 2000), grants and work study (Ishitani, 2006), engagement (Kezar, Walpole, \& Perna, 2015), and bridge programs (Cabrera, Miner, \& Milem, 2013; Thayer, 2000; Tomasko, Ridgway, Waller, \& Olesik, 2016).

Largely missing from the literature are studies aimed at assessing first-year seminars (FYS) on social capital and potential impacts on FGS. FYS are distinct from summer orientation and come in a variety of formats including extended orientations, academic seminars, discipline-linked seminars, basic study skills, and a combination of all the former (Permzadian \& Credé, 2016). FYS vary in length, lasting a few weeks to a full semester, as well as being offered for credit or no credit, pass/fail or graded, and targeting only academically underprepared students to targeting all incoming freshmen (Permzadian \& Credé, 2016). While content may vary, FYS facilitate interactions with faculty and peers, orient students to college culture (Permzadian \& Credé, 2016), and focus on both social and academic integration in the first semester which is critical for shaping academic and social perspectives (Malecki \& Demaray, 2006; Pascarella et al., 2003; Petty, 2014; Thayer, 2000; Ward, Siegel, \& Davenport, 2012). Research has suggested such programs show promise for FGS success (Collier \& Morgan, 2008; Terenzini, 1996; Thayer, 2000). Positive effects resulting from FYS include academic 
performance (Permzadian \& Credé, 2016), ease of making friends (Cambridge-Williams, Winsler, Kitsantas, \& Bernard, 2013), more extra-curricular participation, and higher retention (Permzadian \& Credé, 2016).

The transition from high school to college is inherently a stressful experience (Permzadian \& Credé, 2016) and is particularly more difficult for FGS (Pascarella, Pierson, Wolniak, \& Terenzini, 2004). Students must adjust to a new academic culture as well as form new social contacts (Brouwer, Jansen, Flache, \& Hofman, 2016; Permzadian \& Credé, 2016). Permzadian and Credé (2016) contended students must possess coping skills such as social support or social capital in order to successfully transition to college. Social capital centers on a student's ability to create and access support systems at the university (Malecki \& Demaray, 2006). Social capital can come from a variety of sources, including family, peer, and faculty (Brouwer et al., 2016). FGS are at a disadvantage because their parents are unable to pass on information and beliefs that aid in college success (Ward et al., 2012). Continuing-generation parents pass along information on college, jargon, cultural understanding, experience, and emotional bearings from their lived experience at college to their children (Ward et al., 2012).

As more FGS enter the university system, it is imperative to retain these students. In addition to lost revenue, fewer students, or state performance funding, retaining FGS is a moral obligation. Providing access to higher paying jobs may be a critical piece to breaking the cycle of poverty for these students and their families (Schwartz et al., 2018). Furthermore, confirming the appropriate definition of FGS status will help ensure institutions are collecting appropriate information regarding parental education. Using a definition grounded in research will aid in determining funding and resource allocation to 
retain the most at-risk students. Finally, such a definition has the potential to provide uniformity in future research. As such, this study posed the following research questions: (a) is initial social capital significantly different for full-time, first-time, new-in-college FGS-none, FGS-some, and continuing-generation students?, (b) Is social capital significantly different for full-time, first-time, new-in-college FGS-none, FGS-some, and continuing-generation students when comparing FYS type?, (c) Is the change in social capital significantly different for full-time, first-time, new-in-college FGS-none, FGSsome, and continuing-generation students?, and (d) Is the change in social capital significantly different for full-time, first-time, new-in-college FGS-none, FGS-some, and continuing-generation students by social capital type: peer, advisor, faculty, institutional, and faculty?

\section{Setting}

\section{Design of the Study}

The study was conducted at a public, four-year institution of higher education in the Midwest. In fall 2018, 32\% of full-time, first-time, new-in-college students were classified by the university as FGS as defined by neither parent graduating with a fouryear degree. All incoming freshmen are required to take a FYS called "Intro" unless they are enrolled in the honors college or enter the university with 24 hours after high school. The content of the FYS most closely resembles what Permzadian and Credé (2016) describe as a hybrid course; combining an extended orientation and academic skill development. Intro courses may focus on (a) a student's college, (b) FGS and college, or (c) general content. The faculty teaching the FGS, college sections receive special training, orienting them to the unique strengths and challenges of FGS. It is important to note, historically, FGS at the institution under study have differed from traditional 
FGS. FGS at this institution are generally as well prepared as continuing-generation students in terms of admission scores such as the ACT, whereas most FGS at other institutions are less prepared than continuing-generation students (Bui, 2002; Coffman, 2011; Terenzini, 1996; Thayer, 2000). This may limit the generalizability of the results for other institutions.

\section{Participants}

The overall population consisted of full-time, first-time, new-in-college students. There were 2,953 freshmen in fall 2018 matching this description. Of these, 951 were FGS. Parental education was captured for students in each group via the survey instrument, as the university's definition of FGS lacked the necessary detail to separate FGS-none and FGS-some. To ensure accuracy of the list, students were asked to indicate when they graduated high school. Additionally, honors students, as indicated on the survey, were not included in the final sample as they are assumed to be a distinct population. In total, 343 completed the initial survey and, of those, an additional 148 completed the follow up survey. Key demographics of the sample compared to the university are shown in Table 1. 
Table 1

Selected Demographics of Full-Time, First-Time, New-in-College Students at the University and Participants Completing the Survey

\begin{tabular}{|c|c|c|c|c|}
\hline & \multirow{2}{*}{\multicolumn{2}{|c|}{$\begin{array}{l}\text { University } \\
(n=2953)\end{array}$}} & \multirow{2}{*}{\multicolumn{2}{|c|}{$\begin{array}{l}\text { Sample } \\
(n=343)\end{array}$}} \\
\hline & & & & \\
\hline & Total & Percent & Total & Percent \\
\hline Male & 1,136 & $38 \%$ & 55 & $16 \%$ \\
\hline Female & 1,817 & $62 \%$ & 286 & $84 \%$ \\
\hline Hispanic or Latino & 127 & $4 \%$ & 15 & $4 \%$ \\
\hline Not Hispanic or Latino & 3,001 & $96 \%$ & 323 & $94 \%$ \\
\hline \multicolumn{5}{|l|}{ American Native or Alaska } \\
\hline Native & 7 & $0 \%$ & 4 & $1 \%$ \\
\hline Asian & 53 & $2 \%$ & 7 & $2 \%$ \\
\hline Black or African American & 143 & $5 \%$ & 10 & $3 \%$ \\
\hline \multicolumn{5}{|l|}{ Native Hawaiian or other } \\
\hline Pacific Islander & $\mathrm{n} / \mathrm{a}$ & $\mathrm{n} / \mathrm{a}$ & 3 & $1 \%$ \\
\hline White or Caucasian & 2,629 & $84 \%$ & 314 & $92 \%$ \\
\hline FGS & 951 & $32 \%$ & 139 & $41 \%$ \\
\hline Continuing-Generation & 1,838 & $62 \%$ & 200 & $58 \%$ \\
\hline
\end{tabular}




\section{Data Collection Tools}

\section{Survey}

The survey was administered toward the beginning and end of the fall semester. Participants answered a seven-point Likert scale ranging from strongly disagree to strongly agree for 28 survey items to measure college social capital. Participants provided information on parental education, ethnicity, and other demographics. Prior to administering the survey, it was examined by experts in the field of first-year programs. This process improved the format, questions, and resulting scales as well as improved validity by verifying the questions were grounded in theory and experience (Fink, 2017). The Cronbach's alpha coefficient was .94 for initial social capital and .91 for social capital at the end of the semester.

\section{Variables}

A cumulative scale was created for social capital. Twenty-eight survey items were developed based on past literature to measure social capital from a variety of sources including family, peer, faculty, and the institution (Brouwer et al., 2016; Collier \& Morgan, 2008; Kezar et al., 2015; Malecki \& Demaray, 2006; Moshetti \& Hudley, 2006; Schwartz et al., 2018; Wohn et al., 2013). For the purpose of this study, social capital is assumed to be additive. The literature is unclear regarding if the absence of social capital may be a negative factor and/or that higher levels of indicated comfort should be given greater weight. Therefore, a scale was created in which the Likert responses were given weights from -3 to +3 , where strongly disagree was given a weight of -3 and strongly agree was given a weight of +3 . 


\section{Data Analysis}

The first research question "Is initial social capital significantly different for fulltime, first-time, new in college FGS-none, FGS-some, and continuing-generation students?" was analyzed using an ANOVA. The second research question, "Is social capital significantly different for first time, new in college FGS-none, FGS-some, and continuing-generation students when comparing FYS types?" was analyzed using a two-way ANOVA. The means of these scales were examined by FGS-none, FGS-some, and continuing-generation students to test for statistical significance by Intro type: general, college, and FGS, college. Additionally, the change in social capital was examined using a paired $t$-test. Finally, a principal component analysis (PCA) was conducted to examine differences in types of social capital which were then analyzed using an ANOVA and paired $t$-test.

\section{Results}

\section{Social Capital and Parental Education}

No statistically significant differences were found using the weighted social capital scale. The results were significant at the $7 \%$ level, but do not meet the standard significance level of 5\%. The effect size calculated by using eta squared was .015 and is considered small (Pallant, 2001). There was no statistically significant difference in initial social capital between FGS-none, FGS-some, and continuing-generation students.

Next, the weighted social capital scale was used to examine differences in social capital at the end of the semester. Levene's test for homogeneity was not violated at .343. There was a statistically significant difference in ending social capital between FGS-none, FGS-some, and continuing-generation students at a $2 \%$ level $[\mathrm{F}(2$, 
$145)=3.774, p=.025]$. The effect size calculated by using eta squared was .0494 , bordering on a small to medium effect (Field, 2013; Pallant, 2001). Post hoc comparisons using the Tukey HSD test indicated the mean score for FGS-none ( $M=43.28, S D=21.343)$ was significantly lower than continuing-generation students $(M=55.23, S D=20.23)$. FGS-some $(M=49.78, S D=17.97)$ was not statistically significantly different from FGS-none or continuing-generation students.

\section{Social Capital and FYS Type}

Next, differences in social capital by FYS and FGS status were examined.

Levene's test of equality of error variances was insignificant. There were no statistically significant effects found for any of the Intro or FGS status groups. Combining FGS-none and FGS-some did not produce significant results. Further combining college and FGS college sections compared to general content sections did not yield significant results.

\section{Change in Social Capital and Parental Education}

Next, the change in social capital was examined. There was statistically significant increases in social capital for FGS-none from initial social capital ( $M=32.72, S D=29.91)$ to social capital at the end of the semester, $(M=43.28, S D=21.34) t(24)=-2.881, p<.008$. The eta squared statistic $(-.565)$ indicates a large effect size (Field, 2013; Pallant, 2001). There was no statistically significant difference in social capital for FGS-some. There was a statistically significant difference in social capital for continuing-generation students from initial social capital ( $M=46.78, S D=21.90)$ to social capital at the end of the semester, $(M=55.23, S D=20.23$ ) $t(90)=-4.229, p<.000$. The eta squared statistic (.167) indicates a small effect (Pallant, 2001). 


\section{Factor Analysis}

The 28 items of the social capital scale were subjected to PCA using SPSS. Assessing the suitability of the data found many of the coefficients on the correlation matrix were .3 or above. The Kaiser-Meyer-Oklin (KMO) value was .915 for initial social capital and .847 for social capital at the end of the semester exceeding the recommended value of .6 (Field, 2013; Pallant, 2001). Barlett's test of sphericity for both measures was significant at $p<.000$ indicating the data is well suited for PCA (Field, 2013; Pallant, 2001).

The PCA using the initial weighted social capital scale found five components with Eignvalues greater than one explaining 39.96\%, 12.51\%, 7.94\%, 5.55\%, and 4.91\% of the variance respectively. Inspection of the screeplot showed a clear break after the fifth component, therefore, all five components were kept for further analysis. A Varimax rotation was performed. The rotated solution is presented in Table 2. All five components showed strong loadings explaining a total of $70.86 \%$ of the variance with each component contributing $19.06 \%, 16.23 \%, 14.283 \%, 10.92 \%$ and $10.36 \%$ of the variance, respectively. This process was repeated with the weighted social capital scale at the end of the semester with similar results.

The PCA supports the grouping of certain types of social capital together. In each iteration the components grouped into roughly five categories: (a) advisor social capital, (b) faculty social capital, (c) institutional social capital, (d) family social capital, and (e) peer social capital. For both initial social capital and social capital at the end of the semester, the components of advising and faculty explained the most variance (19.06\% 
and $16.89 \%$ in initial social capital, and $16.23 \%$ and $16.15 \%$ in social capital at the end of the semester).

Table 2

Varimax Rotated Component Matrix for Initial Social Capital Scale

\begin{tabular}{|c|c|c|c|c|c|}
\hline \multicolumn{6}{|c|}{ Varimax Rotated Component Matrix Initial Social Capital } \\
\hline & 1 & 2 & 3 & 4 & 5 \\
\hline Advisor listens & 0.912 & - & - & - & - \\
\hline Important to advisor & 0.892 & - & - & - & - \\
\hline Matter to advisor & 0.89 & - & - & - & - \\
\hline Advisor helps explain & 0.886 & - & - & - & - \\
\hline Advisor gives ideas & 0.876 & - & - & - & - \\
\hline Comfortable with advisor & 0.863 & - & - & - & - \\
\hline Matter to faculty & - & 0.861 & - & - & - \\
\hline Faculty listen & - & 0.845 & - & - & - \\
\hline Important to faculty & - & 0.827 & - & - & - \\
\hline Faculty help with homework & - & 0.75 & - & - & - \\
\hline Faculty helps explain & - & 0.633 & - & - & - \\
\hline Comfortable with faculty & - & 0.573 & - & 0.398 & - \\
\hline Important to GEP instructor & - & 0.527 & - & - & - \\
\hline Friends listen & - & - & 0.777 & - & - \\
\hline Made new friend & - & - & 0.758 & - & - \\
\hline Friends give ideas & - & - & 0.722 & - & - \\
\hline Comfortable talking with classmates & - & - & 0.709 & - & - \\
\hline Classmates will help with class & - & - & 0.623 & - & - \\
\hline Classmates will help with homework & - & - & 0.591 & - & 0.338 \\
\hline Joined new club & - & - & 0.547 & - & - \\
\hline Know about financial services & - & - & - & 0.826 & - \\
\hline Know about university services & - & - & - & 0.733 & - \\
\hline Can use financial services & - & 0.346 & - & 0.733 & - \\
\hline Can use university services & - & - & 0.303 & 0.733 & - \\
\hline Parents proud & - & - & - & - & 0.836 \\
\hline Parents give ideas & - & - & - & - & 0.799 \\
\hline Family listens & - & - & 0.315 & - & 0.779 \\
\hline Parents support college & - & - & - & - & 0.713 \\
\hline
\end{tabular}

Note. Factor loadings less than .30 are not reported 


\section{Differences in Types of Social Capital}

One-way ANOVAs were conducted for each proposed type of social capital to examine potential significant differences by FGS status. Initial institutional, advisor, and faculty social capital were not significantly different for any of the FGS status groups. Initial peer social capital was significantly different for FGS-none $(M=10.40, S D=8.17)$ and continuing-generation students $(M=13.12, S D=6.28),[\mathrm{F}(2$, 334) $=9.607, p=.011)]$, with a calculated small effect size of .027 (Pallant, 2001). Initial family social capital was significantly different as well $[\mathrm{F}(2,334)=9.607, p=.000)]$, but Levene's test of homogeneity was violated. Therefore, a Kruskal-Wallis test was conducted. FGS-none and FGS-some were not significantly different in initial family social capital, but both were significantly different from continuing-generation students at $p<.006$ and $p<.015$.

Advisor $[\mathrm{F}(2,150)=.937, p=.394)]$, and faculty $[\mathrm{F}(2,153)=.45, p=.693)]$, social capital at the end of the semester were not significantly different for any of the FGS status groups. Family capital at the end of the semester was significantly different but Levene's test for homogeneity was violated. A Kruskal-Wallis test was conducted and found significant differences between FGS-none and continuing-generation students, $p<.05$, but no significant differences between FGS-some and either of the parental education groups.

Peer capital at the end of the semester was also significantly different for FGSnone $(M=11.2, S D=5.58)$, and continuing-generation students $(M=14.18, S D=5.68)$, $[\mathrm{F}(2,145)=3.774 p=.054]$. The calculated effect size was .0378, a small effect (Pallant, 2001). Institutional social capital at the end of the semester was significantly different, 
but Levene's test for homogeneity was violated. When the Kruskal-Wallis test was conducted, there were no significant differences found.

\section{Changes in Types of Social Capital}

Using a paired $t$-test, changes in the types of social capital were examined. The results are presented in Table 3 along with calculated effect sizes for significant results.

Table 3

Changes in Type of Social Capital

Continuing-

FGS-None FGS-Some Generation

\begin{tabular}{|c|c|c|c|c|c|c|c|c|c|}
\hline \multirow[b]{2}{*}{ FGS Status } & & & \\
\hline & $n$ & $M(S D)$ & eta & $n$ & $M(S D)$ & eta & $n$ & $M(S D)$ & eta \\
\hline & & & - & & & & & & \\
\hline Advisor & 25 & $\begin{array}{l}4.44 * * \\
(6.88)\end{array}$ & .256 & 31 & $\begin{array}{c}.453 \\
(8.37)\end{array}$ & & 92 & $\begin{array}{c}3.185 * * \\
(7.619)\end{array}$ & -.0543 \\
\hline Faculty & 25 & $\begin{array}{c}2.84 \\
(7.684)\end{array}$ & & 32 & $\begin{array}{c}2.563 * * \\
(5.593)\end{array}$ & -.111 & 97 & $\begin{array}{l}2.68 * * \\
(7.338)\end{array}$ & -.0439 \\
\hline Institutional & 25 & $\begin{array}{c}.16 \\
(5.21)\end{array}$ & & 32 & $\begin{array}{c}.0938 \\
(4.075)\end{array}$ & & 97 & $\begin{array}{l}1.773 * * \\
(4.492)\end{array}$ & -.0481 \\
\hline Family & 25 & .4 & & 31 & .226 & & 98 & .196 & \\
\hline Peer & 25 & $\begin{array}{l}(2.693) \\
2.72 \\
(8.08)\end{array}$ & & 31 & $\begin{array}{c}(2.291) \\
1.742 * \\
(4.633)\end{array}$ & .0817 & 98 & $\begin{array}{c}(1.869) \\
.735 \\
(4.663) \\
\end{array}$ & \\
\hline
\end{tabular}

Note. $* * p<.01, * p<.05$.

Changes in advisor social capital were significantly different for FGS-none and

continuing-generation students. The change in faculty social capital was not significantly

different for FGS-none but was significant for FGS-some and continuing-generation

students with large calculated effect sizes. Changes in peer social capital were

insignificant for FGS-none and continuing-generation students, but significant for FGS-

some. Changes in institutional social capital were insignificant for FGS-none and FGS- 
some, while it was significant for continuing-generation students with a large calculated effect size. Changes in family social capital were insignificant for all FGS status groups.

\section{Discussion}

\section{Defining FGS}

Upon first inspection, there were no significant differences between FGS status and initial scores of social capital. Looking at the five types of social capital as identified by factor analysis provides additional evidence for considering FGS-none and FGS-some as one FGS population. There were no statistically significant differences between FGSnone and FGS-some in initial family social capital, but both were significantly lower than continuing-generation students.

A lack of difference in family social capital between FGS-none and FGS-some is seemingly at odds with the suggestion that FGS-some have greater levels of family social capital than FGS-none (Ward et al, 2012). The proposed difference in family social capital is the cornerstone of the argument for using a more restrictive definition of FGS status. Ward et al. (2012) assert social capital is accrued throughout a parent's education and is not granted magical relevancy upon earning a degree. In this sample of FGS-none and FGS-some, this does not appear to be the case. Rather, both groups appear to have similarly lower levels of family social capital.

There were no statistically significant differences between FGS-none and FGSsome students in terms of initial social capital or social capital at the end of the semester. Further. while statistically significant differences were found between FGS-none and continuing-generation students and some types of social capital, there were no 
statistically significant differences found between FGS-none and FGS-some. In fact, the only significant difference between FGS-none and FGS-some was that FGS-some were able to significantly increase faculty and peer social capital where as FGS-none were not.

Moreover, analysis on each of the three research questions combining FGS-none and FGS-some did not change the significance or direction of the results. The literature has used a variety of definitions to examine a multitude of outcomes for FGS. The overwhelming consensus is FGS are less likely to persist to graduation (CambridgeWilliams et al., 2013; Ishitani, 2006). Therefore, a less restrictive definition of FGS status should be used to catch all at-risk students. Using a broader definition means resources will need to be sufficient for a larger number of students. Further, the current information collected by college admissions is appropriate for the time being.

\section{Social Capital and FYS}

No statistically significant results were found for social capital by FYS and FGS status. This may indicate students are able to effectively generate social capital regardless of the type of FYS. If this is the case, the university might be better served by focusing resources on general content Intro sections rather than devoting more resources on recruiting instructors for FGS college sections. Moreover, the strategies utilized in FGS college sections are likely to benefit all students (Thayer, 2000). FGS in particular want detailed information on notetaking, descriptions of assignments, faculty expectations, and the value of class participation (Collier \& Morgan, 2008). Intro covers these topics for all students (Permzadian \& Credé, 2016).

Another consideration is that the sample size may have been too small to detect significant effects by Intro type. Sample sizes for FGS-none and FGS-some in each of 
the Intro types were less than 30, even when FGS-none and FGS-some were combined into a single sample, which did not yield significant results. Moreover, combining the college and FGS college sections did not produce significant results. It is also important to note three continuing-generation students were enrolled in FGS college sections. It is unclear if students were erroneously enrolled, misclassified as FGS by the university, or misclassified themselves on the survey.

\section{Types of Social Capital}

Family social capital was significantly lower for FGS-none at the beginning and end of the semester compared to continuing-generation students while family social capital for FGS-some was significantly different from continuing-generation students at the beginning of the semester only. An important aspect of family social capital is the ability for a parent to act as a mentor, providing advice about college culture and their own academic experiences (Evert, 2015). Unfortunately, the parents of FGS, especially FGS-none, are unable to share their experiences, acculturating students to college culture (Shumaker \& Wood, 2016).

In addition to orienting students to college culture, parents provide valuable support once students are at college, helping with problem solving and coaching on appropriate ways to handle situations (Collier \& Morgan, 2008). For example, Beattie and Thiele (2016) found pre-college family social capital was a valuable mitigating factor for students in large classes. Likewise, FGS may not believe their parents value their pursuits of higher education, which may, in turn, influence family social capital as it was measured in the survey. Specifically, the survey included the item "my parents are supportive of my coming to college." Terenzini (1996) found FGS were less likely to 
receive encouragement from family to attend college while Billson and Terry (1982) found FGS were less likely to believe their parents valued education.

Brouwer et al. (2016) contended the importance of family social capital diminishes as students transition to college and instead other sources of social capital including peers and faculty become more important. Unfortunately, in addition to having lower family social capital, FGS-none also had significantly lower peer capital. Two potential theories to explain lower peer social capital come to mind. The first theory is that as a hidden population (Ward et al., 2012), FGS-none have a harder time finding peers with similar life experiences and therefore may feel more isolated much like the low SES students in Warnock and Hurst's (2016) study. Similarly, Soria and Stebleton (2013) found working-class students reported having a harder time finding peers.

The second theory is because FGS are more likely to be low SES (Bui, 2002; Coffman, 2011; Covarrubias \& Fryberg, 2015; Kezar et al., 2015; McCarron \& Inkelas, 2006; Thayer, 2000) and have more commitments vying for their time such as work (Bui, 2002; Kezar et al., 2015; McCarron \& Inkelas, 2006; Thayer; 2000), family (Collier \& Morgan, 2008; Hottell, Martinez-Aleman, \& Rowan-Kenyon, 2014), and studying (Bui, 2002; Hottell et al., 2014), FGS have less time to interact with friends. In fact, Billson and Terry (1982) found FGS were more likely to cite having their best friend at work compared to continuing-generation students who were more likely to claim their best friend was at college. Similarly, Soria and Stebleton (2013) found working class students had lower social capital and reported going out less with friends. 
During the transition to college, students must manage not only the academic transition but build new social networks as well (Brouwer et al., 2016; Permzadian \& Credé, 2016). FGS are more likely to commute than continuing-generation students (Billson \& Terry, 1982; Terenzini, 1996). At the university under study, all incoming freshmen are required to live on campus in a residence hall unless they are married or live within 60 miles of the university. Strayhorn (2012) found FGS who spent more time on social networking sites had lower levels of sense of belonging and theorized students used social networking sites to cope with feeling disconnected to the university. In the same way, commuting students, such as FGS, may turn to their existing social ties instead of creating new ones at college. If these friends are not also at the university, it may further exacerbate lack of integrating on campus and developing peer social capital, which may explain why the change in peer social capital was not significant for FGSnone.

Encouragingly, the overall effect size of peer social capital was small. Intro may, in fact, be responsible for the small effect size. Cambridge-Williams et al. (2013) found students reported higher satisfaction with the university and college experience after participating in a FYS, as well as greater ease of making friends. FYS aim to integrate students academically and socially as they transition to college (Pascarella et al., 2003; Petty, 2014; Thayer, 2000; Ward et al., 2012).

It remains unclear if the strategies employed by Intro help FGS-none better connect with peers than they would without the aid of Intro. For example, Intro requires a four-hour service project which would ideally be utilized to increase peer social capital. Unfortunately, FGS may not be available to participate at the same times as other 
students, such as weekends or evenings (Collier \& Morgan, 2008; Hottell et al., 2014; Ward et al., 2012). At the least, this is a missed opportunity for connecting with peers and, at worst, may make FGS feel isolated. Unfortunately, completing the service project as currently designed during class time would use considerable time and take away autonomy from students to pick a project they are passionate about.

One potential advantage of the FGS college Intro sections is the potential to act as a cohort through which more meaningful relationships can be developed (Beattie and Thiele, 2016) as students may find themselves enrolled in additional classes together. Similarly, the college and FGS college sections have the potential to mimic a learning community, which has been shown to increase the ease of making friends (Cambridge-Williams et al., 2013; Thayer, 2000).

\section{Changing Social Capital}

Significant results were found for ending social capital scores and change in social capital scores. FGS-none had significantly lower social capital at the end of the semester than continuing-generation students, whereas, at the beginning of the semester, there were no statistically significant differences. Part of this effect may be attributed to attrition of students from the sample. FGS-some did not have statistically significant ending social capital or change in social capital compared to FGS-none or continuinggeneration students.

As theorized, FGS-none were able to increase their social capital the most by the end of the semester and had the largest effect size. This is potentially because of the marginal effect; they have the most room to grow (McConnell, Brue, \& Flynn, 2012). Further, continuing-generation students are likely already partially oriented to 
academic culture, meaning they have less room to grow in terms of social capital. First, their parents are able to share key pieces of information with them like academic jargon. Secondly, continuing-generation students may know how to act in an academic setting thanks parental coaching (Collier \& Morgan, 2008). This may lead to individuals at the university viewing them more favorably and giving continuing-generation students an easier time transitioning to college compared to FGS-none (Kingston, 2001). Further, continuing-generation students may have more confidence in their ability to do good work and are therefore may be more comfortable talking to faculty. This theory is further supported by the increase in faculty social capital for continuing-generation students compared to FGS-none.

Another important consideration for social capital generation is that FGS-none may also require more time to generate social capital than the first 16 weeks of college. The additional time commitments of many FGS for work and family commitments (Collier \& Morgan, 2008; Hottell et al., 2014) combined with increased time spent studying (Bui, 2002; Hottell et al., 2014) may mean it takes FGS longer to fully integrate into college and therefore build social capital (Ward et al., 2012). This may be more apparent for students working in excess of 20 hours per week who may even be advised to attend college part-time (Fowler \& Boylan, 2010).

Delving further into the change in types of social capital by FGS status provides further insight. Family social capital did not significantly change for any of the groups by the end of the semester. Continuing-generation students were the only group to increase institutional social capital. There were four survey items related to institutional social capital. These items asked how familiar students were to services on campus 
related to helping with coursework and financial aid and how confident students were in their ability to use those services to solve problems. Again, time may partially explain why FGS-none and FGS-some were not able to significantly increase institutional social capital.

In their study, Shumaker and Wood (2016) found no significant difference between FGS and continuing-generation students' use of services, as measured in time, at a university while FGS reported higher perceived service access, but lower perceived service efficacy (Shumaker \& Wood, 2016). The authors concluded while FGS utilized services at the same rate, the use did not produce similar results (Shumaker \& Wood, 2016). It appears FGS-none and FGS-some need additional help connecting with institutional resources.

Both FGS-some and continuing-generation students were able to significantly increase faculty social capital while FGS-none did not. FGS-none may have difficulty building faculty social capital because of larger class sizes. At many universities, incoming students enroll in entry-level and general education courses, both of which tend to have higher enrollment and class sizes. Beattie and Thiele (2016) theorized large class sizes make it more difficult to generate social capital since faculty are less able to develop interpersonal relationships with students.

It was found that large class sizes negatively affected all six of the study's academic social capital measures either directly or indirectly (Beattie \& Thiele, 2016). In classes greater than 60 students, all students were less likely to talk about course materials with professors and FGS were less likely to talk about ideas from the course (Beattie \& Thiele, 2016). Pre-college family social capital aided students in interacting 
in these large classes. These findings do not bode well for FGS who are more likely to have lower levels of family and faculty social capital. Moreover, talking with professors may also be critical for understanding their expectations (Collier \& Morgan, 2008).

Another factor potentially affecting faculty social capital generation is expectations of communication. Through focus groups, Collier and Morgan (2008) found students regard communication as a key factor for college success. Unfortunately, students had differing opinions on who is ultimately responsible for initiating communication. In their study, both FGS and continuing-generation students viewed communication as a way to build relationships, while faculty felt communication should be used to problem solve (Collier \& Morgan, 2008).

The orientation toward communication and relationship building may also be why all students were able to increase advisor social capital with FGS-none having the largest effect size. FGS might find it easier to connect with advisors, while they struggle to connect with faculty. Particularly, intrusive advising has shown to have positive impacts on FGS (Fowler \& Boylan, 2010; Kezar et al., 2015; Thayer, 2000). Advisors may also play an important role in connecting students with additional resources. Escobedo (2007), for instance, found staff members were instrumental for encouraging students to communicate with their instructors.

An additional consideration explaining the change in advisor social capital is the university's policy for registration. First-year students are not permitted to enroll in classes until their academic advisor provides a registration release. It is likely students had not yet met with their advisor prior to completing the initial social capital survey. Likewise, it is unlikely students had not yet met with their advisor prior to 
completing the follow up survey. The large effect size connected to the change in advisor social capital for FGS-none may also indicate that FGS-none were the most apprehensive about advising prior to meeting with their advisor.

\section{Recommendations}

(1) The current operational definition of FGS status should remain

unchanged. Evidence was not found to support considering FGS-none and FGS-some as distinct populations. Universities should not change the language on admission applications. Furthermore, resources need to be sufficient to provide for a large number of FGS students.

(2) FGS college-focused FYS should not be expanded without additional indicators of success such as cumulative first-year GPA and/or freshmen-to-sophomore retention. Instead, students might be best served by expanding the FGS Intro training to all Intro instructors. The tactics which aid FGS will likely also benefit continuinggeneration students in general content sections.

(3) FGS training should also be expanded to include advisors. FGS-none were able to significantly increase advising social capital with the largest effect size. The oneon-one setting may also be more appropriate for FGS to build meaningful social capital (Grassi, Armun, \& Barker, 2006). Further, advisors can be an asset in helping connect FGS with other sources of social capital at the university (Escobedo, 2007).

(4) Instructors teaching freshmen-level courses should also participate in FGS centered training since students spend a majority of their time in classes (Fowler \& Boylan, 2010; Morales, 2014). This would not only likely help build faculty social capital, but also has the potential to increase other types of social capital. Adopting 
policies and strategies sensitive to FGS could have profound effects. Such strategies should include explicitly stating expectations for coursework, class participation, and office hours (Collier \& Morgan, 2008) as well as being available before and after class to answer questions (Kezar et al., 2015) or even occasionally ending class earlier to allow for faculty/student interactions. Faculty can also incorporate assignments to connect students with peers and institutional resources. Moreover, to facilitate faculty/student interactions, freshmen level class sizes could be decreased. The financial implications including hiring more faculty and paying for overload teaching must also be considered.

\section{Limitations}

There are a number of limitations relevant to the study at hand that warrant reflection. First, there was a low response rate to the initial and follow up surveys. Additionally, the survey instrument was not validated. There is a risk that non-response bias might exist. Further, the research methods used are unable to control for confounding factors. Conducting a regression analysis can also aid in the discussion by controlling for other potentially confounding factors such as race, ethnicity, gender, SES, siblings' education, living arrangement (specifically on-campus vs. off-campus), and the number of hours worked.

A potential confounding variable in the generation of social capital through different types of FYS is the amount of time students have available. In the future, information should not only be gathered on the number of hours worked per week, but also of time spent studying, socializing, and with family. Collecting more detailed information on the amount of time devoted to various pursuits will make it easier to isolate the effects of FYS on social capital generation. 
Future studies should examine additional outcomes related to FGS-none and FGSsome to see if significant differences exist to further explore the implications of defining FGS status. Studies could examine potential differences in retention and first-year cumulative GPA, for instance. Moreover, additional research should be done to further explore the effectiveness of different types of FYS. In addition to a larger sample, to examine social capital generation, other outcomes can be studied such as first-year cumulative GPA and freshmen-to-sophomore retention, which are of particular interest to university administration.

\section{Conclusion}

Graduating college is an important milestone for an increasing number of students. The investment in higher education is one that continues to pay off (Pew Research Center, 2014). For FGS, graduating college can be more of a challenge than for continuing-generation students (Billson \& Terry, 1982; McCarron \& Inkelas, 2006; Thayer, 2000). Numerous studies have examined factors that affect FGS students in higher education (Billson \& Terry, 1982; Blackwell \& Pinder, 2014; Bui, 2002; Byrd \& MacDonald, 2005; Cabrera et al., 2013; Choy et al., 2000; Coffman, 2011; Kezar et al., 2015; Ishitani, 2006; McCarron \& Inkelas, 2006; Terenzini, 1996; Thayer, 2000; Tomasko et al., 2016; Wohn et al., 2013).

To date, the literature has not measured how social capital may be affected by parental education as well as the role of social capital in FGS experiences in FYS. This study did not find any evidence for considering FGS-none and FGS-some as distinct populations. Evidence was found that social capital at the end of the semester for FGSnone was significantly smaller than social capital at the end of the semester for 
continuing-generation students. Moreover, the increase in social capital was significant for FGS-none and continuing-generation students while it was insignificant for FGSsome. Factor analysis revealed support for five dimensions of social capital as captured by the survey instrument; (a) advisor social capital, (b) faculty social capital, (c) institutional social capital, (d) family social capital, and (e) peer social capital.

All FGS status groups increased advisor social capital by the end of the semester while FGS-some and continuing-generation students increased faculty social capital. FGS-some increased peer social capital and continuing-generation students increased institutional social capital. One of the factors potentially impacting social capital generation for FGS is time. More can be done in classrooms to aid FGS develop social capital while respecting their time constraints (Fowler \& Boylan, 2010; Kezar et al., 2015; Morales, 2014). 


\section{References}

Beattie, I. R., \& Thiele, M. (2016). Connecting in class? College class size and inequality in academic social capital. The Journal of Higher Education 87(3), $332-362$

Billson, J. M., \& Terry, M. B. (1982). In search of the silken purse: Factors in attrition among first-generation students. College \& University, 58, 57-75.

Blackwell, E., \& Pinder, P. J. (2014). What are the motivational factors of firstgeneration minority college students who overcome their family histories to pursue higher educations? College Student Journal, 48(1), 45-56.

Brouwer, J., Jansen, E., Flache, A., \& Hofman, A. (2016). The impact of social capital on self-efficacy and study success among first-year university students. Learning and Individual Differences 52, 109-118

Bui, V. T. (2002). First-generation college students at a four-year university: Background characteristics, reasons for pursuing higher education, and first-year experiences. College Student Journal, 36(1), 3-11.

Byrd, K. L., \& MacDonald, G. (2005). Defining college readiness from the inside out: First-generation college student perspectives. Community College Review 33(1), 22-37.

Cabrera, N., Miner, D., \& Milem, J. (2013). Can a summer bridge program impact firstyear persistence and performance?: A case study of the new start summer program. Research in Higher Education, 54(5), 481-498. doi:10.1007/s11162013-9286-7 
Cambridge-Williams, T., Winsler, A., Kitsantas, A., \& Bernard, E. (2013). University 100 orientation courses and living-learning communities boost academic retention and graduation via enhanced self-efficacy and self-regulated learning. The Journal of College Student Retention 15(2), 243-268. doi:10.2190/CS.15.2.f

Choy, S. P., Horn, L. J., Nunez, A., \& Chen, X. (2000). Transition to college: What helps at-risk students and students whose parents did not attend college. New Directions for Institutional Research, 2000(107), 45-63.

Coffman, S. (2011). A social constructionist view of issues confronting first-generation college students. New Directions for Teaching \& Learning, 2011(127), 81-90. doi.org/10.1002/t1.459

Collier, P. J., \& Morgan, D. L. (2008). “Is that paper really due today?”: Differences in first-generation and traditional college students' understandings of faculty expectations. Higher Education, 55(4), 425-446. doi.org/10.1007/s10734-0079065-5

Covarrubias, R., \& Fryberg, S. A. (2015). Movin’ on up (to College): First-generation college students' experiences with family achievement guilt. Cultural Diversity \& Ethnic Minority Psychology, 21(3), 420-429. doi:10.1037/a0037844

Daly, M. C., \& Bengali, L. (2014). FRBSF economic letter. Retrieved from http://www.frbsf.org/economic-research/publications/economicletter/2014/may/is-college-worth-it-education-tuition-wages/

Escobedo, G. (2007). A retention/persistence intervention model: Improving success across cultures. Journal of Developmental Education 31(1), 12-17.

Field, A. (2013). Discovering statistics using IBM SPSS Statistics (4th ed.). Thousand 
Oaks, CA: Sage.

Fink, A. (2017). How to conduct surveys: A step-by-step guide (6th ed.). Thousand Oaks, CA: Sage.

Fowler, P. R., \& Boylan, H. R. (2010). Increasing student success and retention: A multidimensional approach. Journal of Developmental Education, 34(2), 2-10.

Grassi, E., Armun, J., \& Barker, H. B. (2006). Don’t lose your working-class students. Academe, 92(5), 26-28. doi.org/10.2307/40253488

Hottell, D. L., Martinez-Aleman, A. M., \& Rowan-Kenyon, H. T. (2014). Summer bridge program 2.0: Using social media to develop students' campus capital. Change: The Magazine of Higher Learning, 46(5), 34-38

Ishitani, T. T. (2006). Studying attrition and degree completion behavior among firstgeneration college students in the United States. The Journal of Higher Education, 77(5), 861-885.

Kezar, A. J., Walpole, M., \& Perna, L. W. (2015). Engaging low-income students. In S. J. Quaye, \& S. R. Harper (Eds.), Student engagement in higher education: theoretical perspectives and practical approaches for diverse populations (pp. 237-255). New York, NY: Routledge.

Malecki, C. K., \& Demaray, M. K. (2006). Social support as a buffer in the relationship between socioeconomic status and academic performance. School Psychology Quarterly, 21(4), 375-395.

McCarron, G. P., \& Inkelas, K. K. (2006). The gap between educational aspirations and attainment for first-generation college students and the role of parental involvement. Journal of College Student Development, 47(5), 534-549. 
McConnell, C. R., Brue, S. L., \& Flynn, S. M. (2012). Economics: Principles, problems, and policies (19th ed.). New York, NY: McGraw-Hill.

Morales, E. E. (2014). Learning from success: How original research on academic resilience informs what college faculty can do to increase the retention of low socioeconomic status students. International Journal of Higher Education, 3(3),92-102.

Moschetti, R., \& Hudley, C. (2008). Measuring social capital among first-generation and non-first-generation, working-class, white males. Journal of College Admission, 198, 25-30.

Pallant, J. (2001). SPSS survival manual: A step by step guide to data analysis using SPSS for Windows (versions 10 and 11). Berkshire, UK: Open University Press.

Pascarella, E. T., Pierson, C. T., Wolniak, G. C., \& Terenzini, P. T. (2003). Experiences and outcomes of first-generation students in community colleges. Journal of College Student Development, 44(3), 420-429.

Pascarella, E. T., Pierson, C. T., Wolniak, G. C., \& Terenzini, P. T. (2004). Additional evidence on college experiences and outcomes. The Journal of Higher Education, 75(3), 249-284.

Permzadian, V., \& Credé, M. (2016). Do first-year seminars improve college grades and retention? A quantitative review of their overall effectiveness and an examination of moderators of effectiveness, Review of Educational Research 86(1), 277-316. DOI: $10.3102 / 0034654315584955$

Petty, T. (2014). Motivating first-generation students to academic success and college completion. College Student Journal, 48(2), 257-264. 
Pew Research Center. (2014, February 11). The rising cost of not going to college. Retrieved from http://www.pewsocialtrends.org/2014/02/11/the-rising-cost-ofnot-going-to-college/

Schwartz, S. E., Kanchewa, S. S., Rhodes, J. E., Gowdy, G., Stark, A. M., Horn, J. P., Parnes, M., \& Spencer R. (2018). I'm having a little struggle with this, can you help me out? Examining impacts and processes of a social capital intervention for first-generation college students. American Journal of Community Psychology 61, 166-178. DOI 10.1002/ajep.12206

Shumaker, R., \& Wood, J. L. (2016). Understanding first- generation community college students: An analysis of covariance examining use of, access to, and efficacy regarding institutionally offered services. Community College Enterprise, 22(2), 9-17.

Soria, K. M., \& Stebleton, M. J. (2013). Social capital, academic engagement, and sense of belonging among working-class college students. College Student Affairs Journal, 31(2), 139-153.

Strayhorn, T. L. (2012). Exploring the impact of facebook and myspace use on first-year students' sense of belonging and persistence decisions. Journal of College Student Development, 53(6), 783-796.

Terenzini, P. T. (1996). First-generation college students: Characteristics, experiences, and cognitive development. Research in Higher Education, 37(1), 1-22.

Thayer, P. B. (2000). Retention of students from first generation and low income backgrounds. The Journal of the Council for Opportunity in Education, 1, 3-9.

Tomasko, D. L., Ridgway, J. S., Waller, R. J., \& Olesik, S. V. (2016). Association of 
summer bridge program outcomes with STEM retention of targeted demographic groups. Journal of College Science Teaching, 45(4), 90-99.

Ward, L., Siegel, M. J., \& Davenport, Z. (2012). First generation college students: Understanding and improving the experience from recruitment to commencement. San Francisco, CA: John Wiley \& Sons.

Warnock, D. M., \& Hurst, A. L. (2016). “The poor kids' table": Organizing around an invisible and stigmatized identity in flux. Journal of Diversity in Higher Education, 9(3), 261-276.

Wohn, D., Ellison, N., Khan, M., Fewins-Bliss, R., \& Gray, R. (2013). The role of social media in shaping first-generation high school students' college aspirations: A social capital lens. Computers \& Education, 63, 424-436. 
Chapter 6:

Scholarly Practitioner Reflection 
In reflecting on the last four years, there are many ways in which the dissertation in practice (DIP) has influenced my development as a leader and scholar. One of the unique challenges of the DIP is completing the program while balancing one's career and family life. Being able to incorporate the lessons learned through the DIP into immediate practice is also, quite possibly, its greatest strength and has greatly impacted my leadership and scholarly journey. I distinctly remember during the admission interview process one of the interviewers asking multiple questions along this line, which I now realize foreshadowed this unique aspect of the program. As I reflect back on the process and my current work in academia, I can pinpoint a number of growth areas due to the DIP.

\section{Educational Leadership}

The DIP has had a profound impact in my educational career, both in how I approach the classroom and work with my colleagues. One such way has been by experiencing and coming to appreciate the value of good mentors and advisors. I am exceedingly thankful for the examples of educational leaders I have come into contact with throughout the process. These educational leaders not only provided guidance, brainstormed with me, problem solved, and provided technical expertise, but were also an important source of encouragement.

New to my professional role is the ability to serve as a committee member for students working to complete their master of science. In this capacity, I attempt to emulate those who have been instrumental to my own success. One particular point of frustration for students is when they begin getting feedback on their thesis. The students can be discouraged by "all the red". Now, I make sure to set up a meeting before 
providing any feedback regarding their writing. In this meeting we talk about a number of things, but mostly I remind them part of the thesis process is becoming a better writer. Unfortunately, that process can be painful. I then show them examples of my own work that has been "inked" as a way to demonstrate all of us can improve our writing. At the end of the day, they will be proud of their final project.

The subject matter of my dissertation has also influenced how I approach these students. An important aspect of student success is a student's belief in their ability to succeed and effect outcomes (Morales, 2014; Porter \& Swing, 2006). With this in mind, I try early on to provide validation to the students. Namely, I try to promote confidence in the students that they are competent learners and capable of success (Terenzini, 1996).

While individual contributions have been key to my success, it really does take a village. This process has really driven home the importance of teamwork. My advisor was instrumental in pulling together a team with the right mix of skills to aid in my development as a leader and scholar. Good leaders set teams up for success by putting together the right people to perform a task, and they must combine resources effectively to complete a task (Levi, 2014). As I reflect on the process, I can see how each member of the committee brings different but equally vital experience to the project. The intentionality of team composition is something I attempt to replicate in my work not only with students, but colleagues as well.

One of the most significant areas of growth for me started the first summer when we were tasked with reading Lencioni's (2002) Five Dysfunctions of a Team. My top five strengths, as identified by completing the Clifton StrengthsQuest Finder, were positivity, relator, includer, empathy, and harmony (Gallup, 2015). All of these strengths 
are in the relationship category. When I first received these results, I remember being very pleased. I did (and do) place high value on relationships. It had never occurred to me that my orientation toward relationships could, in fact, be harmful.

Unfortunately, my concern for relationships manifested in a deep-seated belief that any kind of group conflict was unhealthy, and, quite frankly, toxic. Through this process. I have learned that avoiding conflict is, in fact, toxic, leading to poor decisions (Lencioni, 2002) and group think (Garvin \& Roberto, 2001). Now when approaching projects, my orientation is more balanced between the quality of the outcome and attention to the group relationship. One way to accomplish this balance learned through the DIP is establishing group norms as well in an effort to reduce unhealthy conflict which lessens productivity and wastes time (Lencioni, 2002; Levi, 2014). Group norms provide a sort of social contract outlining how business should be conducted and appropriate group behavior (Levi, 2014). As a consequence, I have found my group experiences lead to better outcomes and overall are more enjoyable. I also utilize these strategies for helping students build cohesive teams in the classroom when assigning group projects.

Another area the DIP has influenced my development is by honing my organization skills, specifically by focusing on the importance of prioritizing. As mentioned, one of the challenges of the program is continuing in your career while completing a doctorate and balancing family life. I realize now I did not fully appreciate how difficult that would be. By outlining tasks and prioritizing, I was able to keep moving forward. I think it would be interesting to see how my top five strengths have changed since that first summer. I wonder if this reorientation toward task behavior, 
relationships, etc. would also be reflected differently in my top five strengths if I were to retake the assessment.

An additional lesson gleaned from the DIP is dedication and perseverance. There were times I thought I would not be able to finish. There were times I doubted my abilities as a scholar. With the constant encouragement of my support team, each time I was able to rally. While I may not have finished as quickly as I hoped, I am glad to see the process come to an end.

While providing a source of challenge, the duality of the DIP is also one of its greatest strengths as we are able to implement our new knowledge in action. Utilizing the lessons learned through the DIP has been the most prominent for me in the classroom. I teach an entry level class comprised mostly of freshmen students, a population in many ways similar to those studied in my DIP. Because of this I have been able to incorporate lessons learned from the DIP in action into my classroom. One such way has been in communicating my expectations to students. While of particular interest for FGS, I have found providing detailed descriptions of assignments, tests, and the value of class participation reduces the anxiety students feel in class (Collier \& Morgan, 2008). It also allows students to better understand my expectations.

Students spend a significant amount of time in the classroom (Fowler \& Boylan, 2010; Morales, 2014) which gives educators the ability to impact their lives in meaningful ways. I try to serve as a source of encouragement. I also regularly communicate my willingness to assist students with issues beyond those in my own course. Further, in my research for the DIP, I found it's very helpful for students to 
communicate the importance and availability of office hours and my expectations verbally and in my syllabi (McCarron \& Inkleas, 2006).

Cultural relevancy suggests, as a faculty member, I can also enhance student's success. This means I should consider things like cost, content, and timing to reduce barriers to student participation (Kezar et al., 2014). Adopting these strategies can be as simple as being available before and after class to answer student questions (Kezar et al., 2014). Being as explicit as possible can also be critical for students (Collier \& Morgan, 2008; McCarron \& Inkleas, 2006). I make sure to include detailed information on assignment expectations, grading criteria, exceptions to policies, etc. as a result.

\section{Scholarship}

In addition to impacting my development as a leader, the DIP has impacted my development as a scholar in numerous ways. When I first started the DIP, I felt like an imposter. Research was regulated to individuals far more intelligent and capable than myself. As my studies continued, I began to gain more confidence in my work and abilities. I found myself beginning to hold conversations on research and, much to my surprise, not only was I well equipped to engage in these discussions, I thoroughly enjoyed them. I no longer feel like an imposter but a scholar capable of doing quality, valuable work.

Reflecting on my master's degree, I can see how my ability to synthesize information and complex thoughts has developed. I am a more critical consumer of scholarly information. I find myself able to critically evaluate the merit, methods, and conclusions of other scholars and their work leading to higher quality in my own work. Additionally, my scholarly writing has improved as well. I will freely admit I found this 
final chapter the most difficult to write since the content relies on personal reflection rather than information of a more scholarly nature.

Finally, rather than relying on anecdotal evidence to make sweeping claims, I ensure my decisions are now backed by quality data. My position at the university has always involved a level of recruiting students. In this capacity, I have found great autonomy to experiment with a variety of strategies. In the past, development and trying new strategies was a haphazard process. In recent years, I have begun to take a more strategic approach which includes visiting with stakeholders, examining yield data, and soliciting feedback as a means to evaluate the effectiveness of particular strategies.

Further, this process has allowed me to become more comfortable with a number of data analysis tools including Qualtrics, Excel, and SPSS. The more I have worked with each program, the more my confidence grows. In addition to exposure through coursework, my committee has been instrumental in aiding my development in the area. I am thankful for their patience and willingness to teach me how to best utilize these tools not only for my current project, but for future research endeavors as well. Moreover, I am now able to impart this knowledge on the burgeoning scholars I now get to work with.

In addition to discovering data analysis tools, the tools I have available for conducting research have expanded. Prior to beginning the program, I had little knowledge of qualitative research methods. In truth, in many of my academic experiences, qualitative research was treated with general disdain. Through the program, not only did I develop qualitative research skills, I have also developed a sincere appreciation of the richness of qualitative research. I have further spread this 
appreciation through conversations with my colleagues, so much so that I have been tasked to design research protocols, moderate focus groups, and direct graduate student analysis of two separate qualitative research projects. One of those projects resulted in a second place win in the three-minute thesis competition held on campus.

The DIP process has allowed me to develop my evaluation skills as well. Since beginning the program, I have been asked to serve as the official evaluator for two grant projects within my college. As part of my duties, I have been responsible for developing measurable goals to aid in the evaluation process as well as collecting and analyzing data. The coursework in program evaluation has been invaluable in this venture. There are a number of books used throughout the DIP I reference often to ensure I follow sound evaluation procedures to ensure quality work.

Evaluation development has also been beneficial in the classroom, as I reconfigured my course learning objectives. My learning objectives now include measureable outcomes. These measurable outcomes allow me to not only ensure the learning goals of the course are being met, but also redesign class material, assignments, and exams to aid in the learning of those objectives.

Finally, the DIP has aided my ability to perform quality research. I can now form quality, measurable research questions, and design a study and data collection tools to answer those questions. I feel confident I can then choose and execute proper data analysis to answer the questions and present the results of the research in relevant ways. Moreover, I believe in my ability to guide master of science students to do the same. 


\section{Conclusion}

The DIP has had a significant impact on my development as a leader and scholar over the course of four years. As a leader I have come to have a deeper appreciation and understanding of the role of leadership in academia. I had the opportunity to work with excellent examples of mentorship who have shaped my outlook on my own approach to mentoring students. The DIP has also expanded my abilities in teamwork. I now understand the importance of healthy conflict for decision making. I have been able to share the many lessons I have learned with students. Further, my research has enhanced my teaching in the classroom. I have a better understanding of simple strategies that assist student success.

Moreover, the DIP has broadened my skills as a scholar. I am a more critical consumer of information. Further, my ability to conduct sound research, make data driven decisions, and utilize common statistical software have all greatly improved. These abilities have already paid dividends from conducing evaluations to research projects. 


\section{References}

Barton, A., \& Donahue, C. (2009). Multiple assessments of a first-year seminar pilot. The Journal of General Education, 58(4), 259-278.

Beattie, I. R., \& Thiele, M. (2016). Connecting in class? College class size and inequality in academic social capital. The Journal of Higher Education 87(3), $332-362$

Billson, J. M., \& Terry, M. B. (1982). In search of the silken purse: Factors in attrition among first-generation students. College \& University, 58, 57-75.

Blackwell, E., \& Pinder, P. J. (2014). What are the motivational factors of firstgeneration minority college students who overcome their family histories to pursue higher educations? College Student Journal, 48(1), 45-56.

Brouwer, J., Jansen, E., Flache, A., \& Hofman, A. (2016). The impact of social capital on self-efficacy and study success among first-year university students. Learning and Individual Differences 52, 109-118

Bui, V. T. (2002). First-generation college students at a four-year university: Background characteristics, reasons for pursuing higher education, and first-year experiences. College Student Journal, 36(1), 3-11.

Byrd, K. L., \& MacDonald, G. (2005). Defining college readiness from the inside out: First-generation college student perspectives. Community College Review 33(1), 22-37.

Cabrera, N., Miner, D., \& Milem, J. (2013). Can a summer bridge program impact firstyear persistence and performance?: A case study of the new start summer 
program. Research in Higher Education, 54(5), 481-498. doi:10.1007/s11162013-9286-7

Cambridge-Williams, T., Winsler, A., Kitsantas, A., \& Bernard, E. (2013). University 100 orientation courses and living-learning communities boost academic retention and graduation via enhanced self-efficacy and self-regulated learning. The Journal of College Student Retention 15(2), 243-268. doi:10.2190/CS.15.2.f

Choy, S. P., Horn, L. J., Nunez, A., \& Chen, X. (2000). Transition to college: What helps at-risk students and students whose parents did not attend college. New Directions for Institutional Research, 2000(107), 45-63.

Christopher, J. C., Wendt, D. C., Marecek, J., \& Goodman, D. M. (2014). Critical cultural awareness: Contributions to a globalizing psychology. American Psychologist, 69(7), 645-655. doi.org/10.1037/a0036851

Clemens, R. F. (2016). Transitioning from high school to college: Examining the sources and influences of social capital for a first-generation Latina student. The Qualitative Report, 21(11), 2044-2072.

Coffman, S. (2011). A social constructionist view of issues confronting first-generation college students. New Directions for Teaching \& Learning, 2011(127), 81-90. doi.org/10.1002/tl.459

Collier, P. J., \& Morgan, D. L. (2008). “Is that paper really due today?”: Differences in first-generation and traditional college students' understandings of faculty expectations. Higher Education, 55(4), 425-446. doi.org/10.1007/s10734-0079065-5

Connolly, S., Flynn, E. E., Jemmott, J., \& Oestreicher, E. (2017). First year experience 
for at-risk college students. College Student Journal, 51(1), 1-6.

Covarrubias, R., \& Fryberg, S. A. (2015). Movin' on up (to College): First-generation college students' experiences with family achievement guilt. Cultural Diversity \& Ethnic Minority Psychology, 21(3), 420-429. doi:10.1037/a0037844

Creswell, J. W. (2014). Research design: Qualitative, quantitative, and mixed methods approaches. Los Angeles, CA: Sage.

Daly, M. C., \& Bengali, L. (2014). FRBSF economic letter. Retrieved from http://www.frbsf.org/economic-research/publications/economicletter/2014/may/is-college-worth-it-education-tuition-wages/

Dumais, S. A. (2002). Cultural capital, gender, and school success: The role of habitus. Sociology of Education, 75(1), 44-68.

Field, A. (2013). Discovering statistics using IBM SPSS Statistics (4th ed.). Thousand Oaks, CA: Sage.

Fink, A. (2017). How to conduct surveys: A step-by-step guide (6th ed.). Thousand Oaks, CA: Sage.

Fowler, P. R., \& Boylan, H. R. (2010). Increasing student success and retention: A multidimensional approach. Journal of Developmental Education, 34(2), 2-10.

Escobedo, G. (2007). A retention/persistence intervention model: Improving success across cultures. Journal of Developmental Education 31(1), 12-17.

Evert., J. B. (2015). Public community colleges: Creating access and opportunities for first-generation college students. The Delta Kappa Gamma Bulletin 81(3), 52-58.

Gallup. (2015, May 22). Strengths insight report. Retrieved from https://gx.gallup.com/services/pdf?v=pdfGeneration.prince.7.0.binPath 
Garvin, \& Roberto (2013). What you don’t know about making decision (pp. 75-94), Boston, MA: Harvard Business Review Press. (Reprint R0108G, Originally published in August, 2001)

Girouard, J. E. (2018, November 8). How student loan debt is destroying the economy and how we can stop it in it's tracks. Forbes. Retrieved from https://www.forbes.com/sites/investor/2018/11/08/how-student-debt-isdestroying-the-economy-and-how-we-can-stop-it-in-its-tracks/\#6c3075c66197

Gochenauer, K. (2017). Minutes of the board of governors' finance and facilities committee. Retreived from https://www.missouristate.edu/bog/ffc-june-232017.htm

Grassi, E., Armun, J., \& Barker, H. B. (2006). Don't lose your working-class students. Academe, 92(5), 26-28. doi.org/10.2307/40253488

Hechinger Report. (2015, June 8). Heaviest debt burdens fall on 3 types of students. U.S. News \& World Report. Retrieved from http://www.usnews.com/news/articles/2015/06/08/heaviest-college-debt-burdensfall-on-3-types-of-students

Hottell, D. L., Martinez-Aleman, A. M., \& Rowan-Kenyon, H. T. (2014). Summer bridge program 2.0: Using social media to develop students' campus capital. Change: The Magazine of Higher Learning, 46(5), 34-38

Institute for College Access \& Success. (2015). State by State Data 2015. Retrieved from http://ticas.org/posd/state-state-data-2015

Ishitani, T. T. (2006). Studying attrition and degree completion behavior among firstgeneration college students in the United States. The Journal of Higher 
Education, 77(5), 861-885.

Kezar, A. J., Walpole, M., \& Perna, L. W. (2015). Engaging low-income students. In S. J. Quaye, \& S. R. Harper (Eds.), Student engagement in higher education: theoretical perspectives and practical approaches for diverse populations (pp. 237-255). New York, NY: Routledge.

Klein, D. (2016, October 25). The 2016 presidential candidates' plans for a $\$ 1.3$ trillion issue: What entrepreneurs need to know. Forbes. Retrieved from https://www.forbes.com/sites/davidklein1/2016/10/25/how-the-2016-presidentialcandidates-plan-to-address-the-1-3-trillion-issue-of-student-debt/

Kingston, P. W. (2001). The Unfulfilled Promise of Cultural Capital Theory. Sociology of Education, 74, 88-99.

Lencinoi, P. (2002). The five dysfunctions of a team. San Francisco, CA: Jossey-Bass.

Levi, D. (2014). Group dynamics for teams $\left(4^{\text {th }}\right.$ ed.). Los Angelas, CA: Sage.

Malecki, C. K., \& Demaray, M. K. (2006). Social support as a buffer in the relationship between socioeconomic status and academic performance. School Psychology Quarterly, 21(4), 375-395.

McCarron, G. P., \& Inkelas, K. K. (2006). The gap between educational aspirations and attainment for first-generation college students and the role of parental involvement. Journal of College Student Development, 47(5), 534-549.

McConnell, C. R., Brue, S. L., \& Flynn, S. M. (2012). Economics: Principles, problems, and policies (19th ed.). New York, NY: McGraw-Hill. 
Microsoft Office. (2019, March 29). Test your document's readability. Retrieved from https://support.office.com/en-ie/article/test-your-document-s-readability85b4969e-e80a-4777-8dd3-f7fc3c8b3fd2

Missouri Department of Higher Education. (2017). State of Missouri performance funding for higher education (4), 1-14.

Missouri State University, ARGOS (2019). ODSPROD-Student Enrollment [Data set] Retrieved from https://www.missouristate.edu/oir/Argos.htm

Missouri State University, ARGOS (2019a). ODSPROD-Retention Dashboard [Data set] Retrieved from https://www.missouristate.edu/oir/Argos.htm

Morales, E. E. (2014). Learning from success: How original research on academic resilience informs what college faculty can do to increase the retention of low socioeconomic status students. International Journal of Higher Education, 3(3), 92-102.

Moschetti, R., \& Hudley, C. (2008). Measuring social capital among first-generation and non-first-generation, working-class, white males. Journal of College Admission, 198, 25-30.

Office of the Registrar. (2018, March 23). Enrollment status/Reduced course load policy. Retrieved from https://www.missouristate.edu/registrar/catalog/enrstatus.html

Pallant, J. (2001). SPSS survival manual: A step by step guide to data analysis using SPSS for Windows (versions 10 and 11). Berkshire, UK: Open University Press.

Pascarella, E. T., Pierson, C. T., Wolniak, G. C., \& Terenzini, P. T. (2003). Experiences and outcomes of first-generation students in community colleges. Journal of 
College Student Development, 44(3), 420-429.

Pascarella, E. T., Pierson, C. T., Wolniak, G. C., \& Terenzini, P. T. (2004). Additional evidence on college experiences and outcomes. The Journal of Higher Education, 75(3), 249-284.

Pascarella, E. T., Terenzini, P. T., \& Wolfe. (1986). Orientation to college and freshman year persistence/withdrawal decisions. The Journal of Higher Education, 57(2), $155-174$.

Permzadian, V., \& Credé, M. (2016). Do first-year seminars improve college grades and retention? A quantitative review of their overall effectiveness and an examination of moderators of effectiveness, Review of Educational Research 86(1), 277-316. DOI: $10.3102 / 0034654315584955$

Petty, T. (2014). Motivating first-generation students to academic success and college completion. College Student Journal, 48(2), 257-264.

Pew Research Center. (2014, February 11). The rising cost of not going to college. Retrieved from http://www.pewsocialtrends.org/2014/02/11/the-rising-cost-ofnot-going-to-college/

Pew Research Center. (2019, January 17). Defining generations: Where Millennials end and Generation $Z$ begins. Retrieved from https://www.pewresearch.org/fact$\operatorname{tank} / 2019 / 01 / 17 /$ where-millennials-end-and-generation-z-begins/ft_19-0117_generations_2019/

Porter, S. R., \& Swing, R. L. (2006). Understanding how first-year seminars affect persistence. Research in Higher Education, 47(1), 89-109. doi: 10.1007/s11162005-8153-6 
Rahm, J., \& Moore, J. C. (2016). A case study of long-term engagement and identity-inpractice: Insights into the STEM pathways of four underrepresented youths. Journal of Research in Science Teaching, 53(5), 768-801. doi.org/10.1002/tea.21268

Redon, L. I. (2005). Realizing a transformed pedagogical dreamfield: Recasting agreements for teaching and learning. Spirituality in Higher Education, 2(1), 113.

Robinson, D. B, Barrett, J., \& Robinson, I. (2016). Culturally relevant physical education: Educative conversations with Mi'kmaw elders and community leaders. Education, 22(1), 2-21.

Schwartz, S. E., Kanchewa, S. S., Rhodes, J. E., Gowdy, G., Stark, A. M., Horn, J. P., Parnes, M., \& Spencer R. (2018). I'm having a little struggle with this, can you help me out? Examining impacts and processes of a social capital intervention for first-generation college students. American Journal of Community Psychology 61, 166-178. DOI 10.1002/ajep.12206

Shumaker, R., \& Wood, J. L. (2016). Understanding first- generation community college students: An analysis of covariance examining use of, access to, and efficacy regarding institutionally offered services. Community College Enterprise, 22(2), 9-17.

Soria, K. M., \& Stebleton, M. J. (2013). Social capital, academic engagement, and sense of belonging among working-class college students. College Student Affairs Journal, 31(2), 139-153. 
Strayhorn, T. L. (2012). Exploring the impact of facebook and myspace use on first-year students' sense of belonging and persistence decisions. Journal of College Student Development, 53(6), 783-796.

Terenzini, P. T. (1996). First-generation college students: Characteristics, experiences, and cognitive development. Research in Higher Education, 37(1), 1-22.

Thayer, P. B. (2000). Retention of students from first generation and low income backgrounds. The Journal of the Council for Opportunity in Education, 1, 3-9.

Tomasko, D. L., Ridgway, J. S., Waller, R. J., \& Olesik, S. V. (2016). Association of summer bridge program outcomes with STEM retention of targeted demographic groups. Journal of College Science Teaching, 45(4), 90-99.

U. S. Department of Education. (2014, October). Profile of undergraduate students: 2011-12. Retrieved from http://nces.ed.gov/pubs2015/2015167.pdf

Ward, L., Siegel, M. J., \& Davenport, Z. (2012). First generation college students: Understanding and improving the experience from recruitment to commencement. San Francisco, CA: John Wiley \& Sons.

Warnock, D. M., \& Hurst, A. L. (2016). “The poor kids' table”: Organizing around an invisible and stigmatized identity in flux. Journal of Diversity in Higher Education, 9(3), 261-276.

Williams, S. M., \& Ferrari, J. R. (2015). Identification among first-generation citizen students and first-generation college students: An exploration of school sense of community. Journal of Community Psychology, 43(3), 377-387.

Wohn, D., Ellison, N., Khan, M., Fewins-Bliss, R., \& Gray, R. (2013). The role of social media in shaping first-generation high school students' college aspirations: 
A social capital lens. Computers \& Education, 63, 424-436.

Woosley, S. A., \& Shepler, D. K. (2011). Understanding the early integration experiences of first-generation college students. College Student Journal 45(4), 700-714. 
Appendix A

INVITATION TO PARTICIPATE IN RESEARCH STUDY

Student Researcher's Name: Christine Sudbrock

Project Number: 2012349

Project Title: Defining First Generation: Examining the Appropriateness of First Generation Student Status Definitions and Social Support at a Public Four-Year University in the Midwest Based on Freshman-to-Sophomore Retention

\section{DESCRIPTION OF THE RESEARCH PROJECT}

This project is being done by a graduate student at Missouri State University in the Leadership and Education Policy doctoral program at the University of Missouri. I am looking at the parental education, community experiences of incoming freshmen, and their decision to return to the university the next fall.

Your participation is voluntary--you can choose to join the project or not. There are no negative consequences for you if you do not participate. If you join the research project and later do not want to continue to be in the study, you may withdraw at any time without penalty.

\section{WHY IS THIS STUDY BEING DONE?}

The purpose of this research is to understand your experiences during your first semester of college. The findings will be used to help inform first year programs to improve freshmen experiences and retention.

\section{HOW MANY PEOPLE WILL BE IN THE STUDY?}

Students in GEP sections across the university will be invited to participate.

\section{WHAT AM I BEING ASKED TO DO?}

You are being asked to complete an online survey. The survey will ask you questions regarding your experiences and feelings towards your first semester at college. It will also ask you questions about your family's education. The results may be shared with the university, but will not contain any information identifying you.

\section{HOW LONG WILL THE STUDY TAKE?}

The survey will take approximately 15-20 minutes to complete.

\section{WHAT ARE THE RISKS OF BEING IN THE STUDY?}

There are no foreseeable risks to you for participating in the study. The survey will ask you questions about your relationships with family, friends, professors, and advisor. You will be asked to give your $\mathrm{M}$ number and GEP section number. Your M number will be used to get information about you including your ACT score, high school GPA, 
and if you return to Missouri State Fall 2019. Your responses to this survey will not be tied to your $\mathrm{M}$ number. Instead you will be assigned a unique code. The code will then be used to identify answers. The key to the code will be stored on a secure laptop in a locked office. There are no risks to you if you choose not to participate. Your GEP section number will be used to identify the type of GEP section you are enrolled in.

\section{Continued on next page.}

\section{WHAT ARE THE BENEFITS OF BEING IN THE STUDY?}

There are no monetary benefits to participating in the study; however, you will have a chance to talk about your experiences and share your ideas. The information you provide may help to improve the experiences of future freshmen. A drawing will be held at the end of the semester for two $\$ 50$ gift cards to the bookstore. Winners will be notified through their university email account.

\section{CONFIDENTIALITY}

Information you share will be stored in the student researcher's secure computer. Information contained in the records may not be given to anyone unaffiliated with the study in a form that could identify you without your written consent, except as required by law.

\section{WHO DO I CONTACT IF I HAVE QUESTIONS, CONCERNS, OR COMPLAINTS?}

Please contact Ms. Christine Sudbrock [csudbrock@missouristate.edu] if you have questions about the research project. Additionally, you may ask questions, voice concerns or complaints.

\section{WHO DO I CALL IF I HAVE QUESTIONS OR PROBLEMS?}

If you have any questions regarding your rights as a participant in this research and/or concerns about the study, or if you feel under any pressure to enroll or to continue to participate in this study, you may contact the University of Missouri Campus Institutional Review Board (which is a group of people who review the research studies to protect participants' rights) at (573) 882-3181 or irb@missouri.edu.

If you do not want to participate in this study, there is nothing you need to do. If you do want to participate in the study, you will be asked to complete a short survey. 


\section{Appendix B}

Thank you for agreeing to take the freshman community survey. The survey will ask you questions about your relationships with family, friends, professors, and your advisor. The survey will take about 15 minutes to complete. As a reminder, all of your answers will be kept completely confidential. There are no penalties for choosing to not participate and you can withdraw from the study at any time.

Below are a number of statements related to your relationships. Please read each one and indicated how much you agree or disagree with each statement.

\begin{tabular}{|c|c|c|c|c|c|c|c|c|}
\hline & & $\begin{array}{l}\text { Strongly } \\
\text { Disagree }\end{array}$ & Disagree & $\begin{array}{l}\text { Slightly } \\
\text { Disagree }\end{array}$ & $\begin{array}{l}\text { Neither } \\
\text { Agree or } \\
\text { Disagree }\end{array}$ & $\begin{array}{l}\text { Slightly } \\
\text { Agree }\end{array}$ & Agree & $\begin{array}{l}\text { Strongly } \\
\text { Agree }\end{array}$ \\
\hline 1) & $\begin{array}{l}\text { My parents are supportive of my } \\
\text { coming to college. }\end{array}$ & $\square$ & $\square$ & $\square$ & $\square$ & $\square$ & $\square$ & $\square$ \\
\hline 2) & I feel listened to by my family. & 口 & $\square$ & $\square$ & $\square$ & $\square$ & $\square$ & $\square$ \\
\hline 3) & $\begin{array}{l}\text { My parents give me ideas when I } \\
\text { don't know what to do. }\end{array}$ & $\square$ & $\square$ & $\square$ & $\square$ & $\square$ & $\square$ & $\square$ \\
\hline 4) & $\begin{array}{l}\text { My parents show they are proud of } \\
\text { me. }\end{array}$ & $\square$ & $\square$ & $\square$ & $\square$ & $\square$ & $\square$ & $\square$ \\
\hline 5) & $\begin{array}{l}\text { I feel comfortable talking to my } \\
\text { classmates outside of class. }\end{array}$ & 口 & $\square$ & $\square$ & $\square$ & $\square$ & $\square$ & $\square$ \\
\hline 6) & $\begin{array}{l}\text { If I have difficulty with homework, a } \\
\text { classmate will help. }\end{array}$ & $\square$ & $\square$ & $\square$ & $\square$ & $\square$ & $\square$ & $\square$ \\
\hline 7) & $\begin{array}{l}\text { I have made a close friend I did not } \\
\text { have before I started college. }\end{array}$ & $\square$ & $\square$ & $\square$ & $\square$ & $\square$ & $\square$ & $\square$ \\
\hline 8) & I feel listened to by my friends. & $\square$ & $\square$ & $\square$ & $\square$ & $\square$ & $\square$ & $\square$ \\
\hline 9) & $\begin{array}{l}\text { My friends give me ideas when I } \\
\text { don't know what to do. }\end{array}$ & $\square$ & $\square$ & $\square$ & $\square$ & $\square$ & $\square$ & $\square$ \\
\hline 10) & $\begin{array}{l}\text { When I encounter a difficult } \\
\text { situation I have someone who can } \\
\text { help. }\end{array}$ & 口 & $\square$ & $\square$ & $\square$ & $\square$ & $\square$ & $\square$ \\
\hline 11) & $\begin{array}{l}\text { I plan to participate in one or more } \\
\text { clubs on campus. }\end{array}$ & $\square$ & $\square$ & $\square$ & $\square$ & $\square$ & $\square$ & $\square$ \\
\hline 12) & I scheduled work around class. & $\square$ & $\square$ & $\square$ & $\square$ & $\square$ & $\square$ & $\square$ \\
\hline 13) & I scheduled class around work. & $\square$ & $\square$ & $\square$ & $\square$ & $\square$ & $\square$ & $\square$ \\
\hline 14) & $\begin{array}{l}\text { I know about services on campus to } \\
\text { help when I have a problem in class }\end{array}$ & $\square$ & $\square$ & $\square$ & $\square$ & $\square$ & $\square$ & $\square$ \\
\hline 15) & $\begin{array}{l}\text { I feel confident I can use services on } \\
\text { campus to solve problems in class. }\end{array}$ & $\square$ & $\square$ & $\square$ & $\square$ & $\square$ & $\square$ & $\square$ \\
\hline 16) & $\begin{array}{l}1 \text { know about services on campus to } \\
\text { help solve financial problems. }\end{array}$ & $\square$ & $\square$ & $\square$ & $\square$ & $\square$ & $\square$ & $\square$ \\
\hline 17) & $\begin{array}{l}\text { I feel confident I can use services on } \\
\text { campus to solve financial problems. }\end{array}$ & $\square$ & $\square$ & $\square$ & $\square$ & $\square$ & $\square$ & $\square$ \\
\hline 18) & $\begin{array}{l}\text { I feel comfortable talking to a } \\
\text { faculty member outside of class. }\end{array}$ & $\square$ & $\square$ & $\square$ & $\square$ & $\square$ & $\square$ & $\square$ \\
\hline 19) & $\begin{array}{l}\text { If I have difficulty with homework, } \\
\text { the professor will help. }\end{array}$ & $\square$ & $\square$ & $\square$ & $\square$ & $\square$ & $\square$ & $\square$ \\
\hline
\end{tabular}




\begin{tabular}{|c|c|c|c|c|c|c|c|c|}
\hline 20) & I feel important to my professors. & $\square$ & $\square$ & $\square$ & $\square$ & $\square$ & $\square$ & $\square$ \\
\hline 21) & $\begin{array}{l}\text { I feel important to my GEP } \\
\text { instructor. }\end{array}$ & $\square$ & $\square$ & $\square$ & $\square$ & $\square$ & $\square$ & $\square$ \\
\hline 22) & I feel listened to by my professors. & $\square$ & $\square$ & $\square$ & $\square$ & $\square$ & $\square$ & $\square$ \\
\hline 23) & I feel like I matter to my professor. & $\square$ & $\square$ & $\square$ & $\square$ & $\square$ & $\square$ & $\square$ \\
\hline 24) & $\begin{array}{l}\text { My professor explains things I don't } \\
\text { understand. }\end{array}$ & $\square$ & $\square$ & $\square$ & $\square$ & $\square$ & $\square$ & $\square$ \\
\hline 25) & $\begin{array}{l}\text { I feel comfortable talking to my } \\
\text { advisor. }\end{array}$ & $\square$ & $\square$ & $\square$ & $\square$ & $\square$ & $\square$ & $\square$ \\
\hline 26) & I feel important to my advisor. & $\square$ & $\square$ & $\square$ & $\square$ & $\square$ & $\square$ & $\square$ \\
\hline 27) & I feel listened to by my advisor. & $\square$ & $\square$ & $\square$ & $\square$ & $\square$ & $\square$ & $\square$ \\
\hline 28) & I feel like I matter to my advisor. & $\square$ & $\square$ & $\square$ & $\square$ & $\square$ & $\square$ & $\square$ \\
\hline 29) & $\begin{array}{l}\text { My advisor gives me ideas when I } \\
\text { don't know what to do. }\end{array}$ & $\square$ & $\square$ & $\square$ & $\square$ & $\square$ & $\square$ & $\square$ \\
\hline 30) & $\begin{array}{l}\text { My advisor explains things I don't } \\
\text { understand. }\end{array}$ & $\square$ & $\square$ & $\square$ & $\square$ & $\square$ & $\square$ & $\square$ \\
\hline
\end{tabular}

31) Do you live on campus? $\square$ yes $\square$ no

32) How long is your commute in minutes?

33) How many credit hours are you taking $\quad \square<8 \quad \square 9-12 \quad \square$ 13-15 $\square$ 16-18 this semester?

$\begin{array}{llll}\begin{array}{l}\text { 34) Do you work on campus or off } \\ \text { campus? }\end{array} & \begin{array}{l}\square \text { on } \\ \text { campus }\end{array} & \begin{array}{l}\square \text { off } \\ \text { campus }\end{array} & \square \text { both } \\ \begin{array}{l}\text { 35) How many hours do you work per work } \\ \text { week? }\end{array} & \square 0-5 & \square \text { 6-10 } & \square \text { 11-15 } \square \text { 16-20 } \\ & \square 21-25 & \square \text { 26-30 } & \square>30\end{array}$

When answering the following questions, use the highest level of education either parent, gaurdian, or sibling has completed. Mark n/a if you don't have any siblings or they are younger than you.

\begin{tabular}{|c|c|c|c|c|}
\hline Leas than & $\begin{array}{l}\text { High School } \\
\text { Degree or }\end{array}$ & Some college Associate's & Bachelor's & $\begin{array}{l}\text { Graduate } \\
\text { Degree }\end{array}$ \\
\hline High School & $\begin{array}{l}\text { Equivilant (e.g. } \\
\text { GED) }\end{array}$ & but no degree Degree & Degree & $\begin{array}{l}\text { (Master's or } \\
\text { Doctorate) }\end{array}$ \\
\hline
\end{tabular}

36) Please mark the highest level of education your parent or gaurdian has completed.

37) Please mark the highest level of education your sibling has completed.
38) Sex
$\square$ Male
$\square$ Female

39) Ethnicity (please mark one) $\square$ Hispanic or Latino

$\square$ Not Hispanic or Latino

40) Race (you may choose 1 or $\square$ American Native or more) Alaska Native

$\square$ Native Hawaiian or other $\square$ White or Caucasian Pacific Islander
41) Age
$\square<18$
$\square 18$
$\square 19$
$\square 20$
$\square>20$ 


\section{Appendix C}

\section{Results}

The present study aimed to further explore the definition of FGS status through data analysis and the potential for social capital generation through different types of FYS. This section will present the results of the four research questions in detail as well as the factorial analysis and analysis of different types of social capital measured in the survey instrument. Discussion of the results and limitations will be presented in detail.

\section{Social Capital and Parental Education}

A one-way ANOVA was conducted using the unweighted version of social capital comparing the means of FGS-none, FGS-some, and continuing-generation students in order to answer the first research question, "Is initial social capital significantly different for full-time, first-time, new-in-college FGS-none, FGS-some, and continuing-generation students?" Levene's test for homogeneity was not violated. No statistically significant differences were found between initial social capital and FGS status.

As constructed, the scale loses sensitivity that would otherwise be present in a seven-point Likert scale. Therefore, a second social capital score was created assigning weights to how strongly students agreed or disagreed with each statement. Levene's test for homogeneity was not violated. There was not a statistically significant difference in initial social capital between FGS-none, FGS-some, and continuing-generation students $[F(2,336)=2.569 p=.078]$. The mean scores and standard deviations for initial and end of the semester social capital are presented in Table 4. The results were significant at the $7 \%$ level, but do not meet the standard significance level of 5\%. The effect size 
calculated by using eta squared was .015 and is considered small (Pallant, 2001). There was no statistically significant difference in initial social capital between FGS-none, FGS-some, and continuing-generation students using either social capital scale. This indicates that initial social capital is essentially equal regardless of parental education. Table 4

Computed Means and Standard Deviations for Initial and End of the Semester Weighted Social Capital

\begin{tabular}{|c|c|c|c|c|c|c|}
\hline & \multicolumn{2}{|c|}{ FGS-None } & \multicolumn{2}{|c|}{ FGS-Some } & \multicolumn{2}{|c|}{ Continuing-Generation } \\
\hline & $n$ & $M(S D)$ & $n$ & $M(S D)$ & $n$ & $M(S D)$ \\
\hline $\begin{array}{l}\text { Initial } \\
\text { Social }\end{array}$ & 67 & 38.925 & 72 & 41.667 & 200 & 46.023 \\
\hline Capital & & (26.499) & & (22.587) & & $(23.239)$ \\
\hline $\begin{array}{l}\text { Social } \\
\text { Capital } \\
\text { at the } \\
\text { end of } \\
\text { the } \\
\text { semester }\end{array}$ & 25 & $\begin{array}{c}43.28 \\
(21.343)\end{array}$ & 32 & $\begin{array}{c}49.781 \\
(17.973)\end{array}$ & 91 & $\begin{array}{c}55.231 \\
(20.233)\end{array}$ \\
\hline
\end{tabular}

Next, a one-way ANOVA was conducted using the weighted social capital variable to test for differences by FGS status and social capital at the end of the semester. Levene's test for homogeneity was not violated at .343 . There was a statistically significant difference in ending social capital between FGS-none, FGS-some, and continuing-generation students at a $2 \%$ level $[\mathrm{F}(2,145)=3.774, p=.025]$. The effect size calculated by using eta squared was .0494, bordering on a small to medium effect (Field, 2013; Pallant, 2001). Post hoc comparisons using the Tukey HSD test indicated the mean score for FGS-none ( $M=43.28, S D=21.343)$ was significantly lower than continuinggeneration students $(M=55.23, S D=20.23)$. The mean score for social capital at the end 
of the semester for FGS-some $(M=49.78, S D=17.97)$ was not statistically significantly different from FGS-none or continuing-generation students. The results indicate that FGS-none have less social capital at the end of the semester compared to continuinggeneration students.

\section{Social Capital and FYS Type}

A two-way ANOVA was conducted by FGS status and Intro section type in order to answer the second research question, "Is social capital significantly different for fulltime, first-time, new-in-college FGS-none, FGS-some, and continuing-generation students when comparing FYS focus at the end of the student's first semester?" Levene's test of equality of error variances was insignificant. There were no statistically significant effects found for any of the Intro or FGS status groups: FGS-status [F(2, $130)=1.67, p=.192]$; Intro type $[\mathrm{F}(3,130)=1.13, p=.339]$; or interaction $[\mathrm{F}(5,130)=1.069$, $p=.38]$. Repeating the analysis combining FGS-none and FGS-some into a single group did not produce significant results. Further, combining college and FGS college Intro sections compared to general content Intro sections did not yield significant results. The results indicate social capital at the end of the semester does not vary by the type of FYS students participate in.

\section{Change in Social Capital and Parental Education}

A paired samples $t$-test was conducted to answer the third research question, "Is the change in social capital significantly different for full-time, first-time, new-in-college FGS-none, FGS-some, and continuing-generation students?” There was statistically significant increases in social capital for FGS-none from initial social capital $(M=32.72$, $S D=29.91)$ to social capital at the end of the semester $(M=43.28, S D=21.34), t(24)=-$ 
2.881, $p<.008$. The eta squared statistic (-.565) indicates a large effect size (Field, 2013; Pallant, 2001). There was no statistically significant difference in social capital for FGSsome from initial social capital $(M=45.03, S D=22.65)$ to social capital at the end of the semester $(M=49.78, S D=17.97), t(31)=-1.77, p<.087$. There was a statistically significant difference in social capital for continuing-generation students from initial social capital $(M=46.78, S D=21.90)$ to social capital at the end of the semester $(M$ $=55.23, S D=20.23), t(90)=-4.229, p<.000$. The eta squared statistic $(.167)$ indicates a small effect (Pallant, 2001). The results indicate FGS-none were able to increase social capital by the end of the semester by a larger amount than continuing-generation students. FGS-some, on the other hand, were unable to increase their social capital in a meaningful way.

\section{Factor Analysis}

In order to answer the fourth and final research question, "Is the change in social capital significantly different for full-time, first-time, new-in-college FGS-none, FGSsome, and continuing-generation students by social capital type: peer, advisor, faculty, institutional, and faculty?", the 28 items of the social capital scale were subjected to PCA using SPSS. First, the suitability of the data was examined. Many of the coefficients on the correlation matrix were .3 or above. The Kaiser-Meyer-Oklin (KMO) value was .915 for initial social capital and .847 for social capital at the end of the semester exceeding the recommended value of .6 (Field, 2013; Pallant, 2001). Barlett's test of sphericity for both measures was significant at $p<.000$ indicating the data is well suited for factor analysis (Field, 2013; Pallant, 2001). 
The PCA using the initial weighted social capital scale found five components with Eignvalues greater than one explaining $39.96 \%, 12.51 \%, 7.94 \%, 5.55 \%$, and $4.91 \%$ of the variance, respectively. Inspection of the screeplot showed a clear break after the fifth component. The screeplot can be found in Appendix D as Figure 6. Therefore, all five components were kept for further analysis. Next, a Varimax rotation was performed. The rotated solution is presented in Table 5. All five components showed strong loadings. The five-factor solution explained a total of $70.86 \%$ of the variance with each component contributing $19.06 \%, 16.23 \%, 14.283 \%, 10.92 \%$ and $10.36 \%$ of the variance, respectively.

This process was repeated with the weighted social capital scale at the end of the semester. In this iteration seven components were found with Eigenvalues of one or greater explaining $35.48 \%, 11.41 \%, 9.63 \%, 6.35 \%, 5.12 \%, 3.94 \%$, and $3.71 \%$ of the variance, respectively. Inspection of the screeplot showed a clear break after the fifth component. The screeplot can be found in Appendix C as Figure 7. Five components were kept for further analysis with Varimax rotation. The rotated solution is presented in Table 6. All five components showed strong loadings. The five-factor solution explained a total of $67.99 \%$ of the variance with each component contributing $16.89 \%$, $16.15 \%, 12.328 \%, 11.35 \%$, and $11.27 \%$ of the variance, respectively. 
Table 5

Varimax Rotated Component Matrix for Initial Social Capital Scale

\begin{tabular}{|c|c|c|c|c|c|}
\hline \multicolumn{6}{|c|}{ Varimax Rotated Component Matrix Initial Social Capital } \\
\hline & 1 & 2 & 3 & 4 & 5 \\
\hline Advisor listens & 0.912 & - & - & - & - \\
\hline Important to advisor & 0.892 & - & - & - & - \\
\hline Matter to advisor & 0.89 & - & - & - & - \\
\hline Advisor helps explain & 0.886 & - & - & - & - \\
\hline Advisor gives ideas & 0.876 & - & - & - & - \\
\hline Comfortable with advisor & 0.863 & - & - & - & - \\
\hline Matter to faculty & - & 0.861 & - & - & - \\
\hline Faculty listen & - & 0.845 & - & - & - \\
\hline Important to faculty & - & 0.827 & - & - & - \\
\hline Faculty help with homework & - & 0.75 & - & - & - \\
\hline Faculty helps explain & - & 0.633 & - & - & - \\
\hline Comfortable with faculty & - & 0.573 & - & 0.398 & - \\
\hline Important to GEP instructor & - & 0.527 & - & - & - \\
\hline Friends listen & - & - & 0.777 & - & - \\
\hline Made new friend & - & - & 0.758 & - & - \\
\hline Friends give ideas & - & - & 0.722 & - & - \\
\hline Comfortable talking with classmates & - & - & 0.709 & - & - \\
\hline Classmates will help with class & - & - & 0.623 & - & - \\
\hline Classmates will help with homework & - & - & 0.591 & - & 0.338 \\
\hline Joined new club & - & - & 0.547 & - & - \\
\hline Know about financial services & - & - & - & 0.826 & - \\
\hline Know about university services & - & - & - & 0.733 & - \\
\hline Can use financial services & - & 0.346 & - & 0.733 & - \\
\hline Can use university services & - & - & 0.303 & 0.733 & - \\
\hline Parents proud & - & - & - & - & 0.836 \\
\hline Parents give ideas & - & - & - & - & 0.799 \\
\hline Family listens & - & - & 0.315 & - & 0.779 \\
\hline Parents support college & - & - & - & - & 0.713 \\
\hline
\end{tabular}

Note. Factor loadings less than .30 are not reported 
Table 6

Varimax Rotated Component Matrix for End of the Semester Social Capital Scale

\begin{tabular}{|c|c|c|c|c|c|}
\hline \multicolumn{6}{|c|}{ Varimax Rotated Component Matrix End of Semester Social Capital } \\
\hline & 1 & 2 & 3 & 4 & 5 \\
\hline Advisor listens & 0.855 & - & - & - & - \\
\hline Important to advisor & 0.857 & - & - & - & - \\
\hline Matter to advisor & 0.883 & - & - & - & - \\
\hline Advisor helps explain & 0.841 & - & - & - & - \\
\hline Advisor gives ideas & 0.848 & - & - & - & - \\
\hline Comfortable with advisor & 0.778 & - & - & - & - \\
\hline Matter to faculty & - & 0.845 & - & - & - \\
\hline Faculty listen & - & 0.833 & - & - & - \\
\hline Important to faculty & - & 0.796 & - & - & - \\
\hline Faculty help with homework & -- & 0.736 & - & - & - \\
\hline Faculty helps explain & - & 0.792 & - & - & - \\
\hline Comfortable with faculty & - & 0.628 & 0.369 & - & - \\
\hline Important to GEP instructor & - & - & - & - & 0.389 \\
\hline Friends listen & - & - & - & - & 0.66 \\
\hline Made new friend & - & - & - & - & 0.772 \\
\hline Friends give ideas & - & - & - & - & 0.591 \\
\hline Comfortable talking with classmates & - & - & - & - & 0.733 \\
\hline Classmates will help with class & - & - & - & - & 0.689 \\
\hline Classmates will help with homework & - & - & 0.514 & 0.39 & 0.35 \\
\hline Joined new club & - & - & - & - & - \\
\hline Know about financial services & - & 0.354 & 0.769 & - & - \\
\hline Know about university services & - & 0.416 & 0.763 & - & - \\
\hline Can use financial services & - & - & 0.782 & - & - \\
\hline Can use university services & - & - & 0.712 & - & - \\
\hline Parents proud & - & - & - & 0.831 & - \\
\hline Parents give ideas & - & - & - & 0.741 & - \\
\hline Family listens & - & - & - & 0.821 & - \\
\hline Parents support college & - & - & - & 0.802 & - \\
\hline
\end{tabular}

Note. Factor loadings less than .30 are not reported

The survey instrument designed for the study aimed at developing a measure of college social capital. Survey items were developed based on the literature and focused on students' interactions and comfort with family, peers, faculty, advisors, and 
institutional services. Questions focused on whether or not students felt they were important and listened to by sources of social capital (parents, friends, advisor, etc.), and how likely someone (friend, professor, advisor, etc.) would be to help with homework, explain things they did not understand, or offer the students ideas for problem solving. Survey items were clustered together depending on the source of the social capital starting with items related to family and ending with questions regarding advisors.

The preliminary factor analysis supports the grouping of certain types of social capital together. In each iteration the components grouped into roughly five categories: (a) advisor social capital, (b) faculty social capital, (c) institutional social capital, (d) family social capital, and (e) peer social capital. For both initial social capital and social capital at the end of the semester the components of advising and faculty social capital explained the most variance $(19.06 \%$ and $16.89 \%$ in initial social capital, and $16.23 \%$ and $16.15 \%$ in social capital at the end of the semester). It appears students' interactions and comfort with advisors and faculty may provide significant sources of social capital. In the PCA for the initial social capital scale the next three components were peers social capital (14.28\%), institutional social capital (10.92\%), and family social capital (10.36\%). For social capital at the end of the semester the order of components was institutional social capital (12.33\%), family social capital (11.35\%), and peer social capital $(11.27 \%)$.

\section{Differences in Types of Social Capital}

One-way ANOVAs were conducted for each proposed type of social capital to examine potential significant differences by FGS status beginning with types of initial social capital. Initial institutional, advisor and faculty social capital were not significantly different for any of the FGS status groups. Initial peer social capital was 
significantly different for FGS-none $[\mathrm{F}(2,334)=9.607, p=.011],(M=10.40, S D=8.17)$ and continuing-generation students $(M=13.12, S D=6.28), p<.01$, with a calculated effect size of .027, indicating a small effect size (Pallant, 2001). Initial family social capital was significantly different as well $[\mathrm{F}(2,334)=9.607, p=.000]$, but Levene's test of homogeneity was violated. Therefore, a Kruskal-Wallis test was conducted to test for significant differences. FGS-none and FGS-some were not significantly different in initial family social capital but both were significantly different from continuinggeneration students at $p<.006$ and $p<.015$, respectively. The results indicate FGS-none and FGS-some have lower family social capital than continuing-generation students.

Advisor $[\mathrm{F}(2,150)=.937, p=.394]$ and faculty social capital $[\mathrm{F}(2,153)=.45$, $p=.693]$ at the end of the semester were not significantly different for any of the FGS status groups. Family capital at the end of the semester was significantly different but Levene's test for homogeneity was violated. A Kruskal-Wallis test was conducted and found significant differences between FGS-none and continuing-generation students, $p<.05$, but no significant differences between FGS-some and either of the other parental education groups. This indicates FGS-none had lower family social capital at the end of the semester than continuing-generation students. Table 7 shows the calculated means and standard deviations for the types of social capital by FGS-status for initial social capital. 
Table 7

Calculated Means and Standard Deviations for Initial Social Capital Types by FGS-

Status

\begin{tabular}{|c|c|c|c|c|c|c|}
\hline \multirow{2}{*}{$\begin{array}{l}\text { Type of } \\
\text { Social } \\
\text { Capital }\end{array}$} & \multicolumn{2}{|c|}{ FGS-None } & \multicolumn{2}{|c|}{ FGS-Some } & \multicolumn{2}{|c|}{$\begin{array}{l}\text { Continuing- } \\
\text { Generation }\end{array}$} \\
\hline & $n$ & $M(S D)$ & $n$ & $M(S D)$ & $n$ & $M(S D)$ \\
\hline Advisor & 67 & $\begin{array}{l}7.238 \\
(7.62)\end{array}$ & 71 & $\begin{array}{l}7.7746 \\
(8.126)\end{array}$ & 193 & $\begin{array}{l}8.497 \\
(8.376\end{array}$ \\
\hline Faculty & 67 & $\begin{array}{c}8.149 \\
(9.083)\end{array}$ & 71 & $\begin{array}{c}8.254 \\
(7.173)\end{array}$ & 196 & $\begin{array}{c}8.48 \\
(8.162)\end{array}$ \\
\hline Institutional & 67 & $\begin{array}{c}5.299 \\
(4.991)\end{array}$ & 72 & $\begin{array}{c}5.222 \\
(4.706)\end{array}$ & 200 & $\begin{array}{c}6.06 \\
(4.888)\end{array}$ \\
\hline Family & 67 & $\begin{array}{c}7.836 * * \\
(4.968)\end{array}$ & 71 & $\begin{array}{l}8.944 * \\
(3.46)\end{array}$ & 199 & $\begin{array}{l}9.92 * * \\
(2.766)\end{array}$ \\
\hline Peer & 67 & $\begin{array}{c}10.403 * * \\
(8.174)\end{array}$ & 71 & $\begin{array}{c}11.592 \\
(6.31)\end{array}$ & 199 & $\begin{array}{c}13.121 * * \\
(6.288)\end{array}$ \\
\hline
\end{tabular}

Note: The means are significantly different at the **.05 level or *.10 level.

Peer social capital at the end of the semester was also significantly different $[\mathrm{F}(2$, $145)=3.774 p=.054]$ for FGS-none $(M=11.2, S D=5.58)$, and continuing-generation students $(M=14.18, S D=5.68), p<.04$. The effect size that was calculated was .0378 , a small effect (Pallant, 2001). Institutional social capital at the end of the semester was significantly different, but Levene's test for homogeneity was violated. When the Kruskal-Wallis test was conducted, there were no significant differences between the FGS status groups. The results indicate FGS-none had lower amounts of peer social capital at the end of the semester compared to continuing-generation students, but their levels of institutional social capital were similar. Table 8 shows the calculated means and 
standard deviations for the types of social capital by FGS-status for social capital at the end of the semester.

Table 8

Calculated Means and Standard Deviations for End of the Semester Social Capital Types by FGS-Status

\begin{tabular}{|c|c|c|c|c|c|c|}
\hline \multirow{3}{*}{$\begin{array}{l}\text { Type of } \\
\text { Social Capital }\end{array}$} & \multicolumn{2}{|c|}{ FGS-None } & \multicolumn{2}{|c|}{ FGS-Some } & \multicolumn{2}{|c|}{$\begin{array}{l}\text { Continuing- } \\
\text { Generation }\end{array}$} \\
\hline & \multirow[b]{2}{*}{$n$} & $M(S D$ & \multicolumn{2}{|c|}{$M(S D$} & \multirow[b]{2}{*}{$n$} & \multirow[b]{2}{*}{$M(S D)$} \\
\hline & & ) & $n$ & ) & & \\
\hline \multirow[t]{2}{*}{ Advisor } & \multirow[t]{2}{*}{25} & 10.76 & \multirow[t]{2}{*}{32} & 10.813 & \multirow[t]{2}{*}{96} & 12.302 \\
\hline & & $(6.273)$ & & (8.487) & & (5.963) \\
\hline \multirow[t]{2}{*}{ Faculty } & \multirow[t]{2}{*}{25} & 10.04 & \multirow[t]{2}{*}{32} & 10.781 & \multirow[t]{2}{*}{99} & 11.475 \\
\hline & & $(6.024)$ & & $(5.852)$ & & (7.671) \\
\hline \multirow[t]{2}{*}{ Institutional } & \multirow[t]{2}{*}{25} & $4.04 * *$ & \multirow[t]{2}{*}{32} & 6.281 & \multirow[t]{2}{*}{97} & $7.464 * *$ \\
\hline & & (5.549) & & (3.513) & & (4.388) \\
\hline \multirow[t]{3}{*}{ Family } & \multirow[t]{3}{*}{25} & $7.24 * *$ & \multirow[t]{3}{*}{32} & 8.781 & \multirow[t]{3}{*}{97} & $10 * *$ \\
\hline & & $(5.71)$ & & (4.172) & & $(2.3)$ \\
\hline & & & & & & $14.184 *$ \\
\hline \multirow[t]{2}{*}{ Peer } & \multirow[t]{2}{*}{25} & $11.2 * *$ & \multirow[t]{2}{*}{32} & 13.125 & \multirow[t]{2}{*}{98} & $*$ \\
\hline & & (5.583) & & $(4.982)$ & & $(5.685)$ \\
\hline
\end{tabular}

\section{Changes in Types of Social Capital}

Using a paired $t$-test, changes in the type of social capital were examined for significant differences. The results are presented in Table 9 with calculated effect sizes for significant results. Changes in advisor social capital were significantly different for FGS-none and continuing-generation students. The change in faculty social capital was not significantly different for FGS-none but was significant for FGS-some and continuing-generation students with large calculated effect sizes. Changes in peer social capital were insignificant for FGS-none and continuing-generation students, but significant for FGS-some. Changes in institutional social capital were insignificant for 
FGS-none and FGS-some. The change in institutional social capital was significant for continuing-generation students with a large calculated effect size. Changes in family social capital were insignificant for all groups.

The results indicate FGS-none were able to increase advisor social capital but were not able to increase faculty social capital, peer social capital, institutional social capital, or family social capital. FGS-some were able to increase faculty social capital and peer social capital. They were unable to change institutional social capital, advising social capital, family social capital, or peer social capital. Continuing-generation students were able to increase advisor social capital, faculty social capital, and institutional social capital. Continuing-generation students did not change their family social capital or peer social capital.

Table 9

Changes in Type of Social Capital

Continuing-

FGS-None FGS-Some Generation

\begin{tabular}{|c|c|c|c|c|c|c|c|c|c|}
\hline \multirow[b]{2}{*}{ FGS Status } & & & \\
\hline & $n$ & $M(S D)$ & eta & $n$ & $M(S D)$ & eta & $n$ & $M(S D)$ & eta \\
\hline & & & - & & & & & & \\
\hline Advisor & 25 & $\begin{array}{c}4.44 * * \\
(6.88)\end{array}$ & .256 & 31 & $\begin{array}{c}.453 \\
(8.37)\end{array}$ & & 92 & $\begin{array}{c}3.185 * * \\
(7.619)\end{array}$ & -.0543 \\
\hline Faculty & 25 & $\begin{array}{c}2.84 \\
(7.684)\end{array}$ & & 32 & $\begin{array}{c}2.563 * * \\
(5.593)\end{array}$ & -.111 & 97 & $\begin{array}{l}2.68 * * \\
(7.338)\end{array}$ & -.0439 \\
\hline Institutional & 25 & $\begin{array}{c}.16 \\
(5.21)\end{array}$ & & 32 & $\begin{array}{c}.0938 \\
(4.075)\end{array}$ & & 97 & $\begin{array}{c}1.773 * * \\
(4.492)\end{array}$ & -.0481 \\
\hline Family & 25 & .4 & & 31 & .226 & & 98 & .196 & \\
\hline Peer & 25 & $\begin{array}{c}(2.693) \\
2.72 \\
(8.08) \\
\end{array}$ & & 31 & $\begin{array}{c}(2.291) \\
1.742 * \\
(4.633)\end{array}$ & .0817 & 98 & $\begin{array}{c}(1.869) \\
.735 \\
(4.663) \\
\end{array}$ & \\
\hline
\end{tabular}

Note. ${ }^{* *} p<.01,{ }^{*} p<.05$. 


\section{Discussion}

In this section the results will be further explored. In addition to exploring potential explanations for the results based on past research, the implications of the results for literature and practice will be discussed. Moreover, limitations for the study will be presented and areas for future research will also be discussed.

\section{Defining FGS}

One of the goals of this research project was to explore the suitability of the current operational definition of FGS status. Upon first inspection, there were no significant differences between FGS status and initial scores of social capital using either calculation of the social capital variable. Looking at the five types of social capital as identified by factor analysis tells a different story. There were no statistically significant differences between FGS-none and FGS-some in initial family social capital, but both were significantly lower than continuing-generation students' initial family social capital.

A lack of difference in family social capital between FGS-none and FGS-some is seemingly at odds with the suggestion that FGS-some have greater levels of family social capital than FGS-none (Ward et al., 2012). The proposed difference in family social capital is the cornerstone of the argument for using a more restrictive definition of FGS status.

Ward et al. (2012) assert social capital is accrued throughout a parent's education and is not granted magical relevancy upon earning a degree. One potential mitigating factor may be how long a parent persisted in their education (one semester, 11 semesters, etc.). Moreover, potentially as important as completing a four-year degree is the reason a parent discontinued their education. They may have stopped for any number of reasons 
including achieving the necessary educational credentials for their desired career field, lack of financing, poor academic performance, etc. The exact reasoning could have serious implications for social capital.

Parents who complete an associate's degree, made a conscientious decision to discontinue their education, or who persisted for multiple years, may likely have a more solid understanding of the college process and may be better able to provide relevant social capital compared to parents who involuntarily discontinued their education and/or spent less time in higher education. Parents who were forced to quit may have done so in part because of their own lack of social capital. If this is the case, they are not able to pass as much social capital to their children. In this sample of FGS-none and FGS-some, this does not appear to be the case. Rather, both groups appear to have similarly lower levels of family social capital compared to continuing-generation students.

In two separate studies examining potential differences between FGS-none, FGSsome, and continuing-generation students, FGS-some were found to share characteristics with both groups. Choy et al. (2000) found FGS-none averaged two risk factors for dropping out of high school (and therefore never making it to college) while FGS-some averaged 1.6 risk factors and continuing-generation students averaged 1.3 risk factors. These differences were not tested for significance. Similarly, FGS-none had the lowest percentage of students graduating in 1992 in each step of the college enrollment process, followed by FGS-some and the highest percentage being continuing-generation students (Choy et al., 2000). These differences were untested for significance.

Ishitani (2006) found FGS-none were most likely to discontinue their education followed by FGS-some. FGS-none were 8.5 times more likely to drop out during the 
second year, while FGS-some were 4.4 times more likely to drop out during the second year compared to continuing-generation students (Ishitani, 2006). While FGS-some had lower risk for dropping out compared to FGS-none, both groups were significantly more likely to discontinue their education compared to continuing-generation students.

While statistically significant differences were found between FGS-none and continuing-generation students for some types of social capital, there were no statistically significant differences found between FGS-none and FGS-some. Further, there were no statistically significant differences between FGS-none and FGS-some students in terms of initial social capital or social capital at the end of the semester. FGS-some were able to significantly increase faculty and peer social capital whereas FGS-none were not.

Moreover, analysis on each of the three research questions combining FGS-none and FGS-some did not change the significance or direction of the results. The literature has used a variety of definitions to examine a multitude of outcomes for FGS. The overwhelming consensus is that FGS are less likely to persist to graduation (CambridgeWilliams et al., 2013; Ishitani, 2006). Therefore, a less restrictive definition of FGS status should be used to catch all at-risk students. Using a broader definition means resources will need to be sufficient for a larger number of students. Further, it also indicates the current information collected by college admissions is appropriate for the time being.

\section{Social Capital and FYS}

No statistically significant results were found for social capital by FYS and FGS status. This may indicate students are able to effectively generate social capital regardless of the type of FYS. If this is the case, the university might be better served by 
focusing resources on general content Intro sections rather than devoting more resources on recruiting instructors for additional FGS college sections.

The strategies utilized in FGS college sections are likely to benefit all students (Thayer, 2000). FGS in particular want more detailed information on notetaking, descriptions of assignments, specifics of faculty expectations, and the value of class participation (Collier \& Morgan, 2008). FYS cover a number of these topics for all students (Permzadian \& Credé, 2016). Additionally, in order to accommodate all FGS students in FGS college Intros, over 34 sections would be required based on fall 2018 enrollment numbers, representing roughly one-third of the sections offered the same semester.

Further, because FGS sections are also college focused, some sections would only be partially filled, while the lowest enrollment in fall 2018 was 24 students out of an available 32 seats with the majority of sections being within one to two students of capacity. Creating enough sections to accommodate all incoming FGS would require recruiting additional instructors and a significant investment since instructors are compensated for teaching. As it stands, the study does not provide concrete evidence to expand or contract FGS college sections. Fiscal considerations for creating additional sections which would be below capacity must be taken into account.

Another consideration is the sample size may have been too small to detect significant effects by Intro type. In the final sample, there were eight FGS-none in general content Intro sections, six in college-specific sections, and 11 in FGS college sections. There were 11 FGS-some in general content Intro sections, two in college Intro sections, 18 in FGS college sections and two in specialized Intro sections. Combining the 
two FGS groups into a single FGS sample did not yield significant results. Moreover, combining the college and FGS college sections did not produce significant results by FGS status. It is also important to note three continuing-generation students were enrolled in FGS college sections. It is unclear if students were erroneously enrolled in a FGS college Intro section, misclassified as FGS by the university, or misclassified themselves on the survey used for this study.

\section{Types of Social Capital}

Family social capital was significantly lower for FGS-none at the beginning and end of the semester compared to continuing-generation students, while family social capital for FGS-some was significantly different from continuing-generation students at the beginning of the semester only. An important aspect of family social capital is the ability for a parent to act as a mentor, providing advice about college culture and sharing their own academic experiences (Evert, 2015). Unfortunately, the parents of FGS, especially FGS-none, are unable to share their experiences acculturating students to college culture if those experiences do not exist (Shumaker \& Wood, 2016).

Parents also aid students as they apply for college. Choy et al. (2000) found the parents of FGS-none and FGS-some were less likely to discuss post-secondary plans or attend programs on educational opportunities with their students than the parents of continuing-generation students. In addition to orienting students to college culture, parents provide valuable support once students are at college, helping with problem solving and coaching their students on appropriate ways to handle situations (Collier \& Morgan, 2008). For example, Beattie and Thiele (2016) found pre-college family social 
capital was a valuable mitigating factor for students' interactions with faculty in large classes.

Unfortnately, FGS may not believe their parents value their pursuits of higher education. Billson and Terry (1982) found FGS were less likely to believe their parents valued education, which may, in turn, influence family social capital as it was measured in the survey. Specifically, the survey included the item "my parents are supportive of my coming to college." Terenzini (1996) found FGS were less likely to receive encouragement from family to attend college while Billson and Terry (1982) found only $61 \%$ of FGS compared to $73 \%$ of continuing-generation students reported parents being emotionally supportive.

Brouwer et al., (2016) contended the importance of family social capital diminishes as students transition to college and instead other sources of social capital, including peers and faculty, become more important. For instance, Wohn et al. (2013) found peer norms were the best predictor of college application efficacy. Unfortunately, in addition to having lower family social capital, FGS-none also had significantly lower peer capital. There are two potential theories to explain lower peer social capital. The first theory is that, as a hidden population (Ward et al., 2012), FGS-none have a harder time finding peers with similar life experiences and therefore may feel more isolated, much like the low SES students in Warnock and Hurst's (2016) study. Similarly, Soria and Stebleton (2013) found working-class students reported having a harder time finding peers.

The second theory, is because FGS are more likely to be low SES (Bui, 2002; Coffman, 2011; Covarrubias \& Fryberg, 2015; Kezar et al., 2015; McCarron \& Inkelas, 
2006; Thayer, 2000) and have more commitments vying for their time such as work (Bui, 2002; Kezar et al., 2015; McCarron \& Inkelas, 2006; Thayer; 2000), family (Collier \& Morgan, 2008; Hottell et al., 2014), and studying (Bui, 2002; Hottell et al., 2014), the students have less time to interact with friends. In fact, Billson and Terry (1982) found FGS were more likely to cite having their best friend at work compared to continuinggeneration students who were more likely to claim their best friend was at college.

During the transition to college, students must manage not only the academic transition but build new social networks as well (Brouwer et al., 2016; Permzadian \& Credé, 2016). FGS are more likely to commute than continuing-generation students (Billson \& Terry, 1982; Terenzini, 1996). At the university under study, all incoming freshmen are required to live on campus in a residence hall unless they are married or live within 60 miles of the university. Unfortunately, living off campus presents a number of complications for students, namely that commuting students are less likely to participate in engagement activities. Strayhorn (2012) found FGS who spent more time on social networking sites had lower levels of sense of belonging and theorized students used social networking sites to cope with feeling disconnected to the university. In the same way, commuting students, such as FGS, may turn to their existing social ties instead of creating new ones at college. If these friends are not also at the university, it may further exacerbate lack of integrating on campus and developing peer social capital.

A further complication of commuting is the amount of time spent driving. Time may be one of the largest factors facing FGS and social capital generation. First, because FGS are generally less academically prepared than continuing-generation students, they spend more time studying to compensate (Bui, 2002; Hottell et al., 2014). Secondly, 
because FGS are more likely to be low SES, they tend to work more hours (Bui, 2002;

Kezar et al., 2015; McCarron \& Inkelas, 2006; Thayer; 2000). Pascarella et al. (2004) found FGS who worked more had less cognitive growth. Terenzini (1996) found FGS spent less time studying per week because of work. Moreover, Billson and Terry (1982) found FGS were more likely to give priority to work and prioritize working overtime hours above studying the more hours they worked. Similarly, Soria and Stebleton (2013) found working class students had lower levels of social capital and reported going out less with friends.

All of this points to FGS having lower peer social capital due to having less time. Encouragingly, the overall effect size was small. Intro may, in fact, be responsible for the small effect size. Cambridge-Williams et al. (2013) found not only did students report higher satisfaction with the university and college experience after participating in a FYS, but they also reported greater ease of making friends. It is plausible that, without Intro, the effect size of lower peer social capital for FGS-none would be larger.

FYS aim to help integrate students academically and socially as they transition to college (Pascarella et al., 2003; Petty, 2014; Thayer, 2000; Ward et al., 2012). It remains unclear if the strategies employed by Intro help FGS-none better connect with peers than they would without the aid of Intro. For example, Intro requires students to complete a four-hour service project. The service project would ideally be completed with classmates as a way to increase peer social capital. Unfortunately, FGS may not be available to participate at the same times as other students if activites take place on weekends or evenings (Collier \& Morgan, 2008; Hottell et al., 2014; Ward et al., 2012). 
At the least this presents a missed opportunity for connecting with peers, and at worst, may make a FGS feel more isolated.

One potential solution is to have opportunities to meet the requirement as a class during the regularly scheduled meeting time. Using class time allows all students to fully participate. Unfortunately, completing the service project as currently designed would use a minimum of four class periods. It would also take away autonomy from students to pick a project they are passionate about.

One potential advantage of the FGS college Intro sections is the potential for Intro sections to act as a cohort with more opportunities to develop meaningful relationships as students may find themselves enrolled in one or two additional classes together (Beattie and Thiele, 2016). Similarly, the college and FGS college sections of Intro have the potential to mimic a learning community which has been shown to increase the ease of making friends (Cambridge-Williams et al., 2013; Thayer, 2000). Regardless of the Intro focus, time should be spent helping FGS connect with peers.

\section{Changing Social Capital}

Significant results were found for ending social capital scores and change in social capital scores. FGS-none had statistically significantly lower social capital at the end of the semester than continuing-generation students whereas at the beginning of the semester there were no statistically significant differences. Part of this effect may be attributed to attrition of students from the sample. FGS-some did not have statistically significant ending social capital compared to FGS-none or continuing-generation students. Further, the change in social capital for FGS-some was insignificant. 
Schwartz et al. (2018) found social capital could be changed by a brief intervention strategy. In their mixed methods study, they discovered students were resilient even when faced with what they perceived as unhelpful or harmful interactions with faculty (Schwartz et al., 2018). Students described interactions with faculty who appeared to be too busy or seemed judgmental. Instead of being discouraged, students persisted in reaching out to a variety of sources for help (Schwartz et al., 2018).

As theorized, FGS-none were able to increase their social capital the most by the end of the semester and had the largest effect size. This is potentially because of the marginal effect; they have the most room to grow (McConnell et al., 2012). The range for initial social capital was -38 to 84 , a range of 122 with a standard deviation of 26.499 . The range for social capital at the end of the semester was -8 to 72 , a range of only 80 with a standard deviation of 21.343. These scores may more accurately reflect social capital, as students may have had more experience using their social networks over the course of the semester in addition to gaining overall levels of social capital. On the other hand, the range of continuing-generation students' initial social capital was -34 to 84 , a range of only 118 and standard deviation of 23.239 , and ending social capital of 0 to 84 , a range of 84 and standard deviation of 20.23 .

Furthermore, continuing-generation students are already partially oriented to academic culture, meaning, they have less room to grow in terms of social capital. First, their parents are able to share key pieces of information with them like academic jargon. Secondly, continuing-generation students may know how to act in an academic setting thanks to their parents' coaching (Collier \& Morgan, 2008). This may lead to individuals at the university viewing them more favorably and giving continuing-generation students 
an easier time transitioning to college compared to FGS-none (Kingston, 2001). Further, continuing-generation students may have more confidence in their ability to do good work and are therefore more comfortable talking to faculty members. This theory is further supported by the increase in faculty social capital for continuing-generation students compared to FGS-none.

Another important consideration for social capital generation is that FGS-none may also require more time to generate social capital than the first 16 weeks of college. The additional time commitments of many FGS for work and family commitments (Collier \& Morgan, 2008; Hottell et al., 2014) combined with increased time spent studying (Bui, 2002; Hottell et al., 2014) may mean it takes FGS longer to fully integrate into college and therefore build social capital (Ward et al., 2012). This may be more apparent for students working in excess of 20 hours per week who may even be advised to attend college part-time (Fowler \& Boylan, 2010).

Delving further into the change in types of social capital by FGS status provides additional insight. Unsurprisingly, family social capital did not significantly change for any of the groups by the end of the semester. The change in peer social capital was not significantly different for FGS-none or continuing-generation students. As discussed previously, there are a number of reasons FGS-none have lower peer social capital, the chief reason being the amount of time they have available. In addition to a higher likelihood FGS are commuting, FGS may also stay more connected to previously created social networks and put less emphasis on creating new friends in college. Continuinggeneration students, on the other hand, are more likely to live on campus. Living on campus means their family more than likely lives farther than 60 miles from campus, 
which may encourage these students to form new social connections earlier in the semester, which would account for the change in peer social capital being insignificant. Interestingly, the change in peer social capital for FGS-some was significant. It is unclear if FGS-some face the same time constraints as FGS-none. Moreover, it is unclear if FGS-some are more likely to commute or live on campus. It is possible FGS-some may be a combination of both. For example, if FGS-some are more likely to live on campus but also have higher demands on their time, it may take them longer than continuing-generation students to make social connections. Another explanation is that FGS-some may see the benefit of expanding their college social network rather than keeping strong ties to friends from high school living in the area. Both of these possibilities warrant future investigation.

Continuing-generation students were the only group to increase institutional social capital. There were four survey items related to institutional social capital. These items asked how familiar students were to services on campus related to helping with coursework and financial aid. The items also assessed how confident students were in their ability to use the services to solve problems. Again, time may partially explain why FGS-none and FGS-some were not able to significantly increase institutional social capital.

In their study, Shumaker and Wood (2016) found no significant difference between FGS and continuing-generation students' use of services at a university while FGS reported higher perceived service access, but lower perceived service efficacy (Shumaker \& Wood, 2016). The authors concluded, while FGS utilized services at the 
same rate, the use did not produce similar results (Shumaker \& Wood, 2016). It appears FGS-none and FGS-some need additional help connecting with institutional resources.

Both FGS-some and continuing-generation students were able to significantly increase faculty social capital while FGS-none were not able to significantly increase faculty social capital. FGS-none may have difficulty building faculty social capital because of larger class sizes. At many universities, incoming students enroll in entrylevel and general education courses, both of which tend to have higher enrollment and class sizes. Beattie and Thiele (2016) theorized large class sizes make it more difficult to generate social capital. The larger number of students may mean faculty are less able to develop interpersonal relationships.

It was found that large class sizes significantly negatively affected all six of the study's academic social capital measures either directly or indirectly (Beattie \& Thiele, 2016). In classes greater than 60 students, all students were less likely to talk about course materials with professors. Moreover, FGS were less likely to talk about ideas from the course, and African American students were less likely to discuss careers with faculty (Beattie \& Thiele, 2016). Also noteworthy from the study is pre-college family social capital aided students in interacting in large classes. These findings do not bode well for FGS who are more likely to have lower levels of family social capital. Moreover, talking with professors may also be critical for understanding their expectations and therefore fully reaping academic rewards (Collier \& Morgan, 2008).

Another factor potentially affecting faculty social capital generation is student and faculty expectations of communication. Through focus groups, Collier and Morgan (2008) found all students regard communication as a key factor for college success. 
Unfortunately, students had differing opinions on who is ultimately responsible for initiating communication. In the study both FGS and continuing-generation students viewed communication as a way to build relationships, while faculty felt students should use communication to problem solve (Collier \& Morgan, 2008). Further, students did not know the purpose of office hours which could be addressed in Intro.

The orientation toward communication and relationship building may also be why all students were able to increase advisor social capital with FGS-none having the largest effect size. FGS might find it easier to connect with their advisor while they struggle to connect with faculty. Intrusive advising has been shown to have positive impacts on FGS (Fowler \& Boylan, 2010; Kezar et al., 2015; Thayer, 2000). Advisors may also play an important role in connecting students with additional resources. Escobedo (2007) for instance, found college staff members were instrumental for encouraging students to communicate with their instructors.

An additional consideration explaining the change in advisor social capital is the university's policy for registration. At the university, first-year students are not permitted to enroll in the following semester's classes until their academic advisor provides a registration release. It is likely students had not yet met with their advisor prior to completing the initial social capital survey. Likewise, it is unlikely students had not yet met with their advisor prior to completing the follow up survey. The large effect size connected to the change in advisor social capital for FGS-none may also indicate that FGS-none were the most apprehensive about advising prior to meeting with their advisor. 


\section{Recommendations}

The following are recommendations based on this research for defining FGS status and generating social capital.

(1) The current operational definition of FGS status should remain unchanged. Evidence was not found to support considering FGS-none and FGS-some as distinct populations.

(2) FGS college focused FYS should not be expanded without additional indicators of success such as cumulative first-year GPA and/or freshmen-to-sophomore retention. Instead, students might be best served by expanding the FGS Intro training to all Intro instructors. These strategies are likely to translate and be useful to all FGSstatus groups (Thayer, 2000).

(3) FGS training should also be expanded to include advisors. FGS-none were able to significantly increase advising social capital with the largest effect size. The oneon-one setting may also be more appropriate for FGS to build meaningful social capital (Grassi et al., 2006). Further, advisors can be an asset in helping connect FGS with other sources of social capital at the university (Escobara, 2007).

(4) Finally, instructors teaching freshmen-level courses should also participate in FGS centered training. This would not only likely help build faculty social capital, but also has the potential to increase other types of social capital. Students spend a majority of their time in classes (Fowler \& Boylan, 2010; Morales, 2014). Adopting policies and strategies sensitive to FGS could have profound effects. Such strategies should include explicitly stating expectations for coursework, class participation, and office hours (Collier \& Morgan, 2008). Another strategy to aid FGS could be faculty being available 
before and after class to answer questions (Kezar et al., 2015) or even occasionally ending class earlier to allow for faculty/student interactions. Faculty can also incorporate assignments to connect students with peers and institutional resources. To help further facilitate faculty/student interactions, freshmen level class sizes could also be decreased. The financial implications (including hiring more faculty and paying for overload teaching) must also be considered.

\section{Limitations and Future Research}

There are a number of limitations relevant to the study at hand that bear reflection. First, there was a low response rate to the initial and follow-up surveys. There is a risk that non-response bias might exist. Further, the research methods used are unable to control for confounding factors. Conducting a regression analysis can also aid in the discussion of social capital generation and defining FGS status by controlling for other potentially confounding factors such as race, ethnicity, gender, SES, siblings' education, living arrangement (specifically on-campus vs. off-campus), and the number of hours worked in addition to FYS focus.

A potentially significant confounding variable in the generation of social capital through different types of FYS is the amount of time students have available. There are a multitude of reasons why FGS have less time than continuing-generation students. In the future, information should not only be gathered on the number of hours worked per week, but also include estimates of time spent studying, socializing, and with family. By collecting more detailed information on the amount of time devoted to various pursuits, it will be easier to isolate the effects of FYS on social capital generation. Additionally, the 
research focus should be expanded to include part-time students where the issue of time may be most pronounced.

Future studies should examine additional outcomes related to FGS-none and FGSsome to see if significant differences exist to further explore potential differences in these populations and the implications of defining FGS status. Studies could examine potential differences in retention and first-year cumulative GPA, for instance. Moreover, additional research should be done to further explore the effectiveness of different types of FYS. In addition to a larger, local sample, to examine social capital generation, other outcomes can be studied such as first-year cumulative GPA and freshmen-to-sophomore retention which are of particular interest to university administration. Finally, future research should examine what, if any, relationship exists between social capital and other desirable outcomes such as first-year cumulative GPA and retention.

\section{Conclusion}

Graduating college is an important milestone for an increasing number of students. The investment in higher education is one that continues to pay off (Pew Research Center, 2014). For FGS, graduating college can be more of a challenge than for continuing-generation students (Billson \& Terry, 1982; McCarron \& Inkelas, 2006; Thayer, 2000). Numerous studies have examined factors that affect FGS students in higher education (Billson \& Terry, 1982; Blackwell \& Pinder, 2014; Bui, 2002; Byrd \& MacDonald, 2005; Cabrera et al., 2013; Choy, et al., 2000; Coffman, 2011; Kezar et al., 2015; Ishitani, 2006; McCarron \& Inkelas, 2006; Terenzini, 1996; Thayer, 2000;

Tomasko et al., 2016; Wohn et al., 2013). 
To date, the literature has not measured how social capital may differ based on parental education as well as the role of social capital in FGS experiences in FYS. This study did not find any evidence for considering FGS-none and FGS-some as distinct populations. Evidence was found that social capital at the end of the semester for FGSnone was significantly smaller than social capital at the end of the semester for continuing-generation students. Moreover, the increase in social capital was significant for FGS-none and continuing-generation students while it was insignificant for FGSsome. Factor analysis revealed support for five dimensions of social capital as captured by the survey instrument: (a) advisor social capital, (b) faculty social capital, (c) institutional social capital, (d) family social capital, and (e) peer social capital.

FGS-none and continuing-generation students increased advisor social capital by the end of the semester while FGS-some and continuing-generation students increased faculty social capital. FGS-some increased peer social capital and continuing-generation students increased institutional social capital. One of the factors potentially impacting social capital generation for FGS is time. More can be done in classrooms to help FGS develop social capital while respecting their time constraints (Fowler \& Boylan, 2010; Kezar et al., 2015; Morales, 2014). 
Appendix D

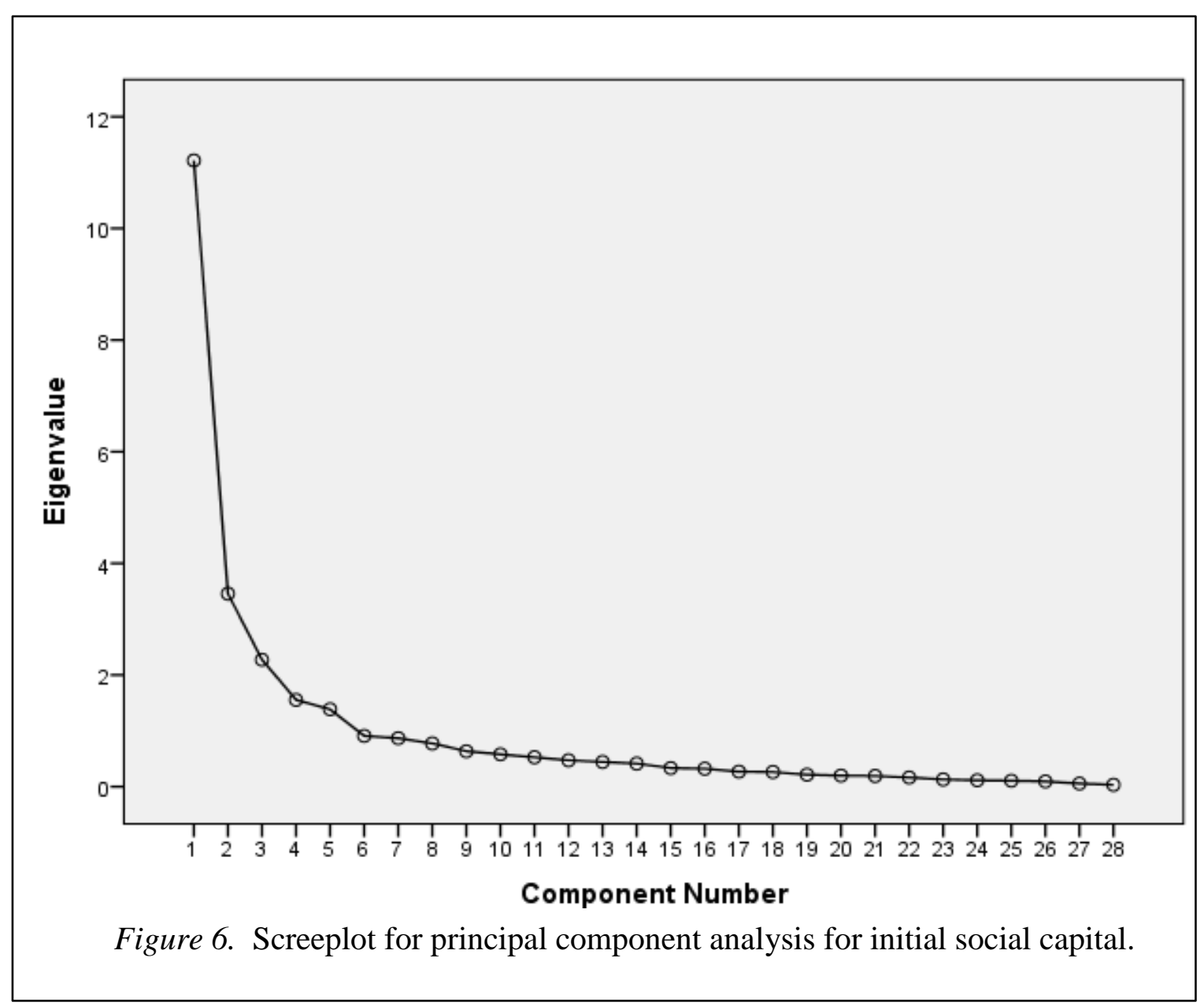




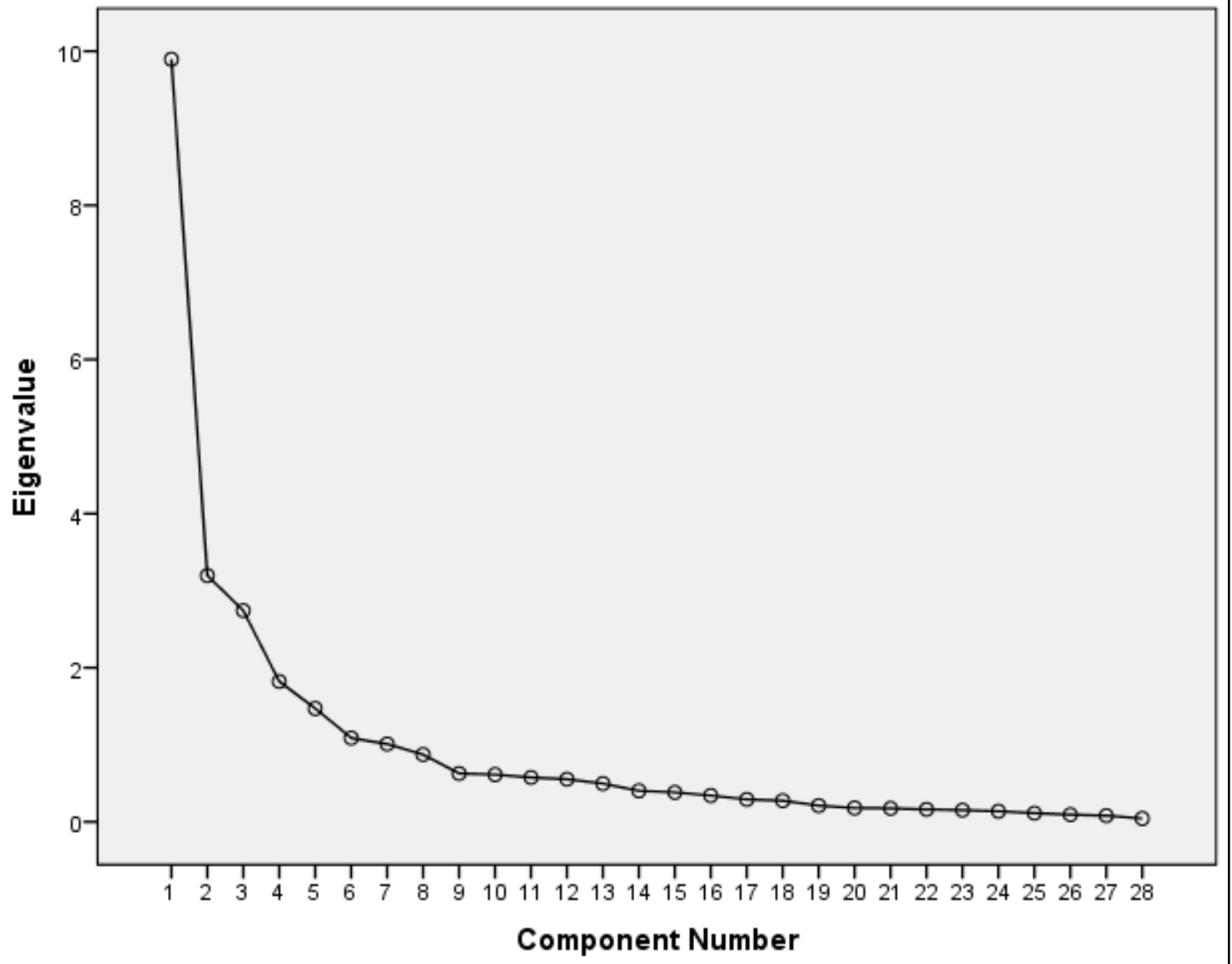

Figure 7. Screeplot for principal component analysis for social capital at the end of the semester 


\section{VITA}

Christine E. Sudbrock has been a lifelong learner. She graduated from Lexington High School in 2005 before earning her Bachelor of Science from Missouri State University in Agriculural Business Marketing and Sales and General Agriculture with an emphasis in Communication. Afterward, Christi earned a Master of Science from the University of Illinois in Agriculture and Consumer Economics in 2011. It was during her time here that her passion for teaching was ignited.

After completing graduate school, she returned to teach at Missouri State University in August of 2011 where she has worked since. During her time at Missouri State, Christi has had the opportunity to share her love of agricultural economics with students, develop study abroad trips, and further her development as an educator.

After teaching for a few years, Christi decided to continue her education by pursuing a Doctor of Education in Educational Leadership and Policy Analysis at the University of Missouri-Columbia by participating in the cooperative program, allowing her to work on her advanced degree while continuing in her career field. While working to complete the doctorate degree, Christi has welcomed two beautiful children into the world, Riley Grace and Keith Marzell (Marz). Upon completing her degree she looks forward to continuing her passion for teaching and enjoying her family. 